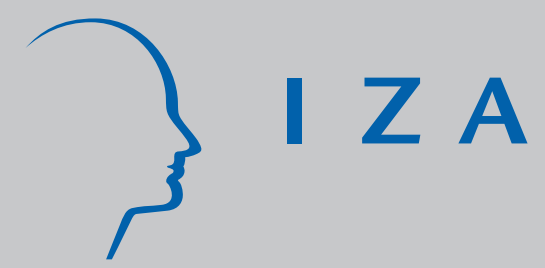

IZA DP No. 10224

The Skill Content of Occupations across

Low and Middle Income Countries:

Evidence from Harmonized Data

Emanuele Dicarlo

Salvatore Lo Bello

Sebastian Monroy-Taborda

Ana Maria Oviedo

Maria Laura Sanchez-Puerta

Indhira Santos

September 2016 


\title{
The Skill Content of Occupations across Low and Middle Income Countries: Evidence from Harmonized Data
}

\author{
Emanuele Dicarlo \\ University of Zurich
}

Salvatore Lo Bello

Universidad Carlos III de Madrid

Sebastian Monroy-Taborda
Ana Maria Oviedo

The World Bank

Maria Laura Sanchez-Puerta

The World Bank and IZA

Indhira Santos

The World Bank

\section{Discussion Paper No. 10224 \\ September 2016}

\author{
IZA \\ P.O. Box 7240 \\ 53072 Bonn \\ Germany \\ Phone: +49-228-3894-0 \\ Fax: +49-228-3894-180 \\ E-mail: iza@iza.org
}

\begin{abstract}
Any opinions expressed here are those of the author(s) and not those of IZA. Research published in this series may include views on policy, but the institute itself takes no institutional policy positions. The IZA research network is committed to the IZA Guiding Principles of Research Integrity.

The Institute for the Study of Labor (IZA) in Bonn is a local and virtual international research center and a place of communication between science, politics and business. IZA is an independent nonprofit organization supported by Deutsche Post Foundation. The center is associated with the University of Bonn and offers a stimulating research environment through its international network, workshops and conferences, data service, project support, research visits and doctoral program. IZA engages in (i) original and internationally competitive research in all fields of labor economics, (ii) development of policy concepts, and (iii) dissemination of research results and concepts to the interested public.
\end{abstract}

IZA Discussion Papers often represent preliminary work and are circulated to encourage discussion. Citation of such a paper should account for its provisional character. A revised version may be available directly from the author. 


\section{ABSTRACT \\ The Skill Content of Occupations across Low and Middle Income Countries: Evidence from Harmonized Data ${ }^{1}$}

Using new and harmonized worker-level survey data on tasks at work in the developing world, this paper constructs, for the first time, a measure of the skill content of occupations for 10 low and middle-income countries. Following Autor, Levy and Murnane (2003), Acemoglu and Autor (2011), and Autor and Handel (2013), we map tasks into non-routine analytical, non-routine interpersonal, and routine \& manual skill groups. We find significant differences in the skill mix used by workers across different occupations, with selected whitecollar occupations being intensive in Analytical and Interpersonal skills, while others- mostly blue collar, but not only - being more intensive in Routine and Manual skills. We also find that the rankings of occupations along the skill dimensions are quite stable across countries, and they correlate significantly higher between middle- and low-income countries than between them and the United States. Hence, the common practice of assuming the same skill structure for occupations in the United States and other countries can be misleading. Finally, we find that the heterogeneity of skill content between occupations (within countries) tends to decrease with the level of income, while the heterogeneity within occupations decreases only weakly (or not at all) for higher income levels. Taken together, these results suggest that as countries develop, they tend to adopt and use certain skills more widely, especially across occupations. This may suggest some degree of specialization in skills content of tasks as countries develop, especially moving towards less occupation-specific Analytical or Interpersonal skills that are becoming increasingly relevant across the board.

JEL Classification: J240

Keywords: skills, occupational classification, skill biased, skill building, specific human capital

Corresponding author:

Maria Laura Sanchez-Puerta

The World Bank

1767 22nd St N

Arlington, VA 22209

USA

E-mail: msanchezpuerta@worldbank.org

\footnotetext{
1 The authors are grateful to Julian Messina, Giovanni Pica, Omar Arias and David Robalino for valuable comments and suggestions. The views expressed here are those of the authors and do not represent the official views of the WBG or its Board of Directors. All errors are our own.
} 


\section{Introduction}

Do the job tasks performed by an office clerk in Bolivia require the same skills as those performed by a clerk in Ghana, Vietnam, or the United States? Is there convergence in the production processes of similar jobs across countries ? Or conversely, do countries display heterogeneous skill content for similar occupations? ${ }^{2}$

In a scenario where technology diffusion across countries homogenizes the tasks performed in certain occupations, looking at the nature of an occupation in one particular country, for instance one where technology originates from (or where it is quickly adopted), would provide a fair representation of how the same occupation is performed in other countries. If, on the other hand, technology diffuses only imperfectly or slowly, or the skill content of occupations depends heavily on the input mix and a specific technology associated to it, then assuming the skill content of occupations is similar across countries can be misleading.

This paper seeks to answer this question by using new survey data to construct, for the first time, a measure of skill content (embedded in the tasks) of occupations in low and middle-income countries. The paper takes advantage of data collected at the worker level to understand the distribution of the skills used by workers within and across occupations (within countries). The interaction of capital, labor, and technology in the production function determines the type of skills that workers use in their jobs. As a result, as long as there is heterogeneity of capital (and labor) within occupations, there is also likely to be heterogeneity in the type of skills used.

The paper compares the distribution of skill intensity of occupations across countries and with that of the United States, the most often-used reference country to describe the evolution of the skill content in other countries. ${ }^{3}$ It then looks at whether richer countries display lower heterogeneity in work's skill mix, either between or within occupations, which would suggest that economic development and technological progress are related with a more equal skill content of occupations. Understanding this heterogeneity in skills at work is becoming increasingly important given the changing nature of work associated with globalization and technological change (Acemoglu and Autor, 2011; Aedo et al, 2013; Autor, Dorn, and Hanson, 2015). While global phenomena, these trends are likely to play out very differently across countries, calling for a country-specific mapping of jobs and skills.

This paper builds on the seminal work of Autor, Levy and Murnane (2003) -ALM henceforth—as well as Acemoglu and Autor (2011); and Autor and Handel (2013), who analyze the skill content of tasks within occupations in the United States. ALM and the literature that follows, show that the increased computerization of tasks in the U.S. is associated with changes in the skill requirements for workers in the past decades. In particular, they find that employment is shifting towards occupations that are more intensive in Non-routine Analytical and Interpersonal skills, which are hard for computers to emulate, and where workers complement technology well. Occupations such as management, elderly care or preschool teaching are some examples of occupations more intensive in Non-routine and Cognitive skills. In contrast,

\footnotetext{
2 This could depend on whether capital and labor inputs restrict the technologies and production processes that can be used (Basu and Weil, 1998; Acemoglu and Zilibotti, 2001).

${ }^{3}$ The assumption often made in the current literature is that the (relative) skill content of occupations is constant across countries and identical to that of the United States Thus, changes in employment across occupations, once we fix the mapping from occupations to skills- can be used to measure changes in the demand for skills in the economy.
} 
employment is moving away from occupations that are intensive in Routine skills-as they are easily codifiable, and therefore automatable—such as telemarketers or clerical workers.

More recently, papers such as Aedo et al. (2013) and Arias et al. (2014), have applied the ALM methodology to analyze the evolution of skills and occupations in other countries. However, in the absence of appropriate data, these papers assume that the (relative) skill content of occupations is both constant over time and across countries (and identical to the one of the U.S.), so that the analysis focuses on changes in employment patterns across occupations, rather than on skills used at work. These papers find a somewhat similar evolution of skills use to that ALM find in the US, that is, a general increase in occupations more intensive in Non-routine Cognitive skills, and a decline in Routine Manual skill-intensive occupations, although there is significant heterogeneity across countries.

This paper follows the methodology of Acemoglu and Autor (2011) and Autor and Handel (2013) to construct three indices of skill intensity (Analytical, Interpersonal, and Routine/Manual) at the worker level, which is then aggregated at the 3-digit occupation level. It uses worker level data collected by the World Bank’s Skills Toward Employment and Productivity (STEP) skill measurement surveys, a unique set of comparable individual and household surveys, representative of urban areas in 10 developing countries, that documents the nature of the tasks that workers carry out in their jobs. ${ }^{4}$ Thus, this paper captures the heterogeneity of skill content not only across occupations but also within occupations. The STEP survey is comparable to the US STAMP survey (Handel, 2010), which allows to compare results with those of the United States.

Our findings can be summarized as follows. First, the skill mix used is very different across occupations. That is, occupations such as managers and professionals tend to have higher Analytical and Interpersonal skill content, and lower Routine/Manual skill content, whereas plan operators and craft workers, for instance, tend to have a higher Routine/Manual skill content. Second, these patterns are very similar across countries. That is, the intensity of occupations in Analytical and Interpersonal skills and in Routine/Manual skills is highly correlated across countries, especially in the case of the former. Correlations are high for the entire sample, and not higher among countries of similar income per capita or belonging to the same region. Our third finding is that these correlations are significantly higher among middle- and low-income countries than between them and the United States. As a result, assuming countries have the same skill intensity levels as the United States, as is done in much of the literature to date, does not necessarily reflect the actual skill intensity of occupations in developing This calls for caution when assuming the same structure of skill content for occupations as in the US, as has been done so far in the literature.

Fourth, there is considerable heterogeneity in the skills used across occupations (within countries), but it tends to decrease with the level of income. Heterogeneity within occupations, on the other hand, decreases only weakly (or not at all) with the level of income, although this result also reflects limitations of the data at hand. Taken together, this seems to suggest either increased specialization in terms of skills used in tasks as countries develop, and/or a more widespread use of some skills across occupations as countries develop. As countries become richer, and ICT and non-ICT capital replaces labor in routine tasks across most occupations, the skills used by workers across occupations become more similar. That is, workers—across

\footnotetext{
${ }^{4}$ The surveys used in this paper correspond to the following countries: Armenia, Bolivia, Colombia, Georgia, Ghana, Kenya, Lao PDR, FYR Macedonia, Sri Lanka, and Vietnam
} 
occupations - start to use, for example, more nonroutine analytical and interpersonal skills, the skills that can not be substituted away by technology. This would mean, for example, that the skills mix required for a machine operator (an occupation usually intensive in routine skills) is further away from that required for a researcher (usually intensive in nonroutine analytical skills) in a poor country than in a richer country, as in the latter technology already substitutes for many of the routine tasks of the machine operator, leaving him/her with more tasks that require nonroutine skills (e.g. critical thinking and problem-solving skills to address machine failures, adapting the machine for more tailored products, etc). This finding is consistent with more recent literature showing that indeed the complementarity across skills has increased significantly in the United States between 2006 and 2014 (MacCrory et al 2014). This finding is also consistent with the observation that -as documented in this paper- the use of nonroutine analytical and interpersonal skills across occupations increases with countries' income level.

The rest of the paper is organized as follows. Section 2 provides a brief literature review describing the main methodological innovations and results from the papers of ALM and others. Section 3 describes the data from the STEP surveys and the methodology we use to construct the skill measures and aggregate them. Section 4 describes the results of the comparisons of the skill measures across countries and across occupations, and relative to the same measures in the US. Section 5 offers some concluding remarks.

\section{Literature review: Measuring the skill content of tasks}

Since the 1990s, there was been a significant growth in the economic literature related to skill-biased technological change. Starting in the 1980s, the U.S. and other high income economies experienced a pronounced rise in wage inequality, partly associated with an increase in the demand of college graduated labor. Among other hypotheses, one strand of the literature focused on understanding the role of technology in explaining these changes in labor demand. This phenomenon was labeled "Skill Biased Technological Change" (SBTC). ${ }^{5}$

During the 1990s, a new strand of the literature began to study patterns of the labor market that were not fully consistent with the traditional SBTC hypothesis (for instance, Levy and Murnane, 1996). In their seminal paper, Autor, Levy and Murnane (2003) use an alternative interpretation of technological changebased on the so called task approach - to study how computerization affects the employment structure. They implement and test a simple theory where the falling price of computer technology induces changes in tasks performed by workers. Their claim is that computer capital substitutes for workers performing a well-defined set of routine tasks, while it complements workers who use more abstract analytical skills in their work tasks. Then, as computer prices fall, firms begin substituting occupations intensive in routine tasks. As a consequence, the demand for non-routine task inputs increases, equally raising demand for more educated workers.

The idea behind the task approach is that a job is composed of different tasks that need a specific set of skills to be performed. ALM start from a very simple question: "what are the tasks that can be performed by a computer?" The authors argue that machines can perform tasks that follow explicitly programmed rules, that is, tasks that are "codifiable" or routine. Thus, machines can be used instead of workers in these tasks. The authors label the skills required in such tasks as "routine" skills. In contrast, a great number of manual and cognitive tasks require procedures that are not easily executable for machines. These are the

\footnotetext{
${ }^{5}$ See, for example, Tinbergen (1974); Katz and Murphy (1992); Berman et al. (1998); Acemoglu (2002).
} 
tasks that require a set of actions and evaluations that cannot be described in terms of programmable rules. These are "non-routine” skills, and can encompass both abstract (“cognitive”) and manual skills.

ALM, using data from the Current Population Survey (CPS) and the Dictionary of Occupational Titles (DOT), analyze changes in the employment structure considering tasks performed at work, both within and between industries, finding evidence that supports the implications of their model. They detect a decline in routine cognitive labor inputs in the US economy starting from the 1970s. Moreover, a shift toward nonroutine cognitive tasks was concentrated in rapidly computerizing industries.

Acemoglu and Autor (2011) develop a new model proposing a richer framework, where changes in earnings and employment are shaped by the interaction among worker skills, job tasks, technology and trading opportunities. The novelty of their model is that the assignment of skills to tasks is endogenous. Acemoglu and Autor (2011) further expand ALM's classification into five categories of skills embedded within the tasks:

- Non-routine cognitive analytical, referring to analyzing data, thinking creatively and interpreting information for others, common in occupations such as researchers and artists;

- Non-routine cognitive interpersonal, referring to establishing and maintaining personal relationships and managing people, common in occupations such as managers, teachers and sales;

- Routine cognitive, referring to abstract activities that require repeating the same tasks, being accurate or exact, and doing structured work, common in occupations such as record-keepers and cashiers;

- Routine manual, referring to manual tasks that are intensive in repetitive, exact, and structured movements, common in occupations such as machine operators and repetitive assembly;

- Non-routine manual physical, referring to manual tasks that are difficult for machines to perform because they require dexterity and spatial orientation, common in occupations such as truck drivers and janitorial services.

Much of the literature in this area has maintained this classification in the following years.Acemoglu and Autor find a positive correlation of education and cognitive non-routine tasks together with a negative one with manual tasks. Routine scores instead are found to be strongly non-monotone in education.

More recently, this task approach has been extended to other developed countries. Spitz-Oener (2006) analyzes the changes in job task requirements in West Germany between the late 1970s and the late 1990s. Using the Qualification and Career Survey, she was able to assess changes in skill requirements within jobs. Spitz-Oener (2006) builds directly on the ALM (2003) analysis and finds a significant change in job tasks requirements within occupations: a consistent drop in manual and cognitive tasks together with an increase in non-routine analytical tasks. Furthermore, neither women participation nor changes in educational structure were able to explain those changes. Indeed, the shift in tasks requirements was identified consistently across age, gender and educational categories. Moreover, the author finds evidence consistent with "Routine Biased Technological Change: - RBTC - (by shifting tasks within occupations toward more analytical skills) having a significant effect on the rise of educational attainment.

Goos, Manning and Salomons (2014) test the hypothesis that Routine Biased Technological Change is biased towards replacing labor in routine tasks by analyzing changes in the employment structure of 16 European countries from 1993 up to 2008. After finding supporting evidence in 14 out of the 16 countries of the sample, they develop a model that quantifies the importance of RBTC in explaining the observed job 
polarization, that is, the rise in the share of employment in occupations intensive in non-routine skillsmost common in low- and high-paying occupations - accompanied by a decline in middle-paying occupations intensive in routine skills. They underline a shift within-industry from routine occupations together with between-industries changes in the employment structure, leading to more computerized industries.

MacCrory et al. (2014) explore the changes in the relative importance of different types of skills within occupations in the United States. They were able not only to replicate the skill categories following Acemoglu and Autor (2011) but to construct new skill categories more relevant to the hypothesis on how recent changes in automation capabilities have affected the occupational skill composition. They find evidence that there is a significant reduction in the demand for skills that compete with machines ("substitutable" skills, such as basic perception), an increase in the demand for skills where machines are still limited in their capacity ("non-substitutable" skills, such as interpersonal skills), and an increase in the demand for skills that complement machines ("complementary” skills, such as deductive reasoning).

This literature is much less advanced in developing countries. So far it has been largely limited to combining the skills intensities for different occupations derived for the United States in the literature above with the employment structure of individual developing countries. Aedo et al. (2013) assess changes in the intensity of manual, routine, and analytical skills in several Latin American, Asian, and African countries. This research shows that national intensity in manual skills declines with GNP per capita while the abstract intensity increases. Moreover, analyzing trends, the authors find an increase in intensity of employment in abstract skills in all the countries of the sample, together with a decrease in the intensity of employment in manual skills. The evolution in the intensity of routine skills is more mixed across countries. Similarly, Arias et al. (2014) use the skill requirements, defined following Autor, Levy and Murnane (2003) and Acemoglu and Autor (2011), from different occupations in the U.S. and extrapolate these measures to the occupational structure of countries in Central and Eastern Europe and Central Asia. The authors also find evidence of a change in skills demand consistent with RBTC, with changes most marked in countries that have done the most market reforms since their economic transition in the 1990s.

In this paper, we contribute to the existing literature in two main ways. First, using newly available data from 10 developing countries, we provide the first estimates of skill content of occupations in developing countries. These new data allow us to overcome a key constraint in the literature so far, given the difficulties in building or obtaining the necessary data to perfom a task-based analysis of employment. Second, we extend the overall literature by analyzing how the skill content of employment (within and across occupations) varies with a country's level of development. In doing this, this paper opens up new potential avenues for research and for better understanding the evolution of skill demands in developing countries.

\section{Data}

This paper uses microeconomic data from the World Bank's Skills toward Employment and Productivity (STEP) surveys. In addition to socio-economic, demographic, employment, education and family background characteristics, the surveys have a series of harmonized questions on specific tasks that the respondent uses in his or her job. We use the STEP surveys for 10 developing countries (Armenia, Bolivia, Colombia, Georgia, Ghana, Kenya, Lao PDR, FYR Macedonia, Sri Lanka, and Vietnam), administered between 2012 and 2013. 
The STEP skills measurement surveys are representative of the working age population in urban areas. The survey collects information on all individuals in the household. It randomly selects an individual between 15 to 64 years old to answer the complete questionnaire, which includes detailed employment and skills questions.

A summary of descriptive statistics is presented in Table 1. The sample size of the surveys is between 1196 and 3896 households . The average age of the respondent is between 29 (Kenya) and 40 (FYR Macedonia) years old. In terms of labor market indicators, the labor force participation was between 53 percent (Georgia and Sri Lanka) and 84 percent (Lao PDR), while the employment rate was more spread out ranging from 30 percent (Georgia) to 83 percent in (Lao PDR). The unemployment rate is also widely spread across the countries ranging from as low as 1 percent in Lao PDR up to 43 percent in Georgia. The median hourly earnings in constant 2010 US dollars ranges between \$0.63 in Lao PDR and \$2.05 in FYR Macedonia. For most of the countries, more than half of all employment is divided into professionals, clerical support workers, and craft and related workers. The exception is Lao PDR where about a third is in skilled agricultural, forestry and fishery workers. In terms of industry, in most countries, employment is concentrated in wholesale, retail, transport and food services, however for Armenia and Georgia most of the employment is concentrated in the public administration, education, human health and social work sector.

The availability in STEP of detailed harmonized occupational employment information (at the 3-digit level) and of the tasks performed at work by each individual allows, for the first time, to measure the skill content of jobs in developing countries. Individuals are asked about many types of tasks, including frequency and type of documents read and written at work, contact with clients or customers, supervise other workers, or to operate heavy machinery (more details in section 4). 
Table 1. Descriptive Statistics of STEP surveys

\begin{tabular}{|c|c|c|c|c|c|c|c|c|c|c|}
\hline & \multicolumn{2}{|c|}{ Armenia } & \multicolumn{2}{|c|}{ Bolivia } & \multicolumn{2}{|c|}{ Colombia } & \multicolumn{2}{|c|}{ Georgia } & \multicolumn{2}{|c|}{ Ghana } \\
\hline Variable & Mean & SD & Mean & SD & Mean & SD & Mean & SD & Mean & SD \\
\hline Gender (proportion women) & 0.70 & $\begin{array}{c}0.01 \\
)\end{array}$ & 0.59 & $\begin{array}{c}(0.02 \\
)\end{array}$ & 0.59 & $\begin{array}{c}(0.02 \\
)\end{array}$ & 0.68 & $\begin{array}{c}0.01 \\
)\end{array}$ & 0.58 & $\begin{array}{c}(0.01 \\
)\end{array}$ \\
\hline Age (average years) & 38.31 & $\begin{array}{c}(0.29 \\
)\end{array}$ & 32.44 & $\begin{array}{c}(0.50 \\
)\end{array}$ & 34.90 & $\begin{array}{c}(0.46 \\
)\end{array}$ & 38.24 & $\begin{array}{c}(0.34 \\
)\end{array}$ & 33.00 & $\begin{array}{c}(0.39 \\
)\end{array}$ \\
\hline Labor force participation (\%) & 53.60 & $\begin{array}{c}(0.01 \\
)\end{array}$ & 78.31 & $\begin{array}{c}(0.01 \\
)\end{array}$ & 76,57 & $\begin{array}{c}(0.01 \\
)\end{array}$ & 52,55 & $\begin{array}{c}(0.01 \\
)\end{array}$ & 75,10 & $\begin{array}{c}(0.01 \\
\quad)\end{array}$ \\
\hline Employment rate (\%) & 34,50 & $\begin{array}{c}0.01 \\
)\end{array}$ & 71,88 & $\begin{array}{c}(0.01 \\
)\end{array}$ & 65,80 & $\begin{array}{c}(0.01 \\
)\end{array}$ & $\begin{array}{c}29,96 \\
0.30\end{array}$ & $\begin{array}{c}0.01 \\
)\end{array}$ & $\begin{array}{c}69,88 \\
0.70\end{array}$ & $\begin{array}{c}(0.01 \\
)\end{array}$ \\
\hline Unemployment rate (\%) & $\begin{array}{c}35,64 \\
0.36\end{array}$ & $\begin{array}{c}0.01 \\
)\end{array}$ & $\begin{array}{l}8,21 \\
0.08\end{array}$ & $\begin{array}{c}(0.01 \\
)\end{array}$ & $\begin{array}{c}14,07 \\
0.14\end{array}$ & $\begin{array}{c}(0.01 \\
)\end{array}$ & $\begin{array}{c}42,99 \\
0.43\end{array}$ & $\begin{array}{c}0.01 \\
)\end{array}$ & $\begin{array}{l}6,95 \\
0.07\end{array}$ & $\begin{array}{c}(0.00 \\
)\end{array}$ \\
\hline Median hourly earnings (USD 2010 constant) & 1.31 & $\begin{array}{c}(0.03 \\
\quad)\end{array}$ & 1.43 & $\begin{array}{c}(0.06 \\
)\end{array}$ & 1.88 & $\begin{array}{c}(0.06 \\
)\end{array}$ & 1.60 & $\begin{array}{c}(0.07 \\
)\end{array}$ & 0.80 & $\begin{array}{c}(0.04 \\
\quad) \\
\end{array}$ \\
\hline Occupations(\% of employment) & & & & & & & & & & \\
\hline Armed forces & 1,95 & $\begin{array}{c}(0.00 \\
)\end{array}$ & 0,33 & $\begin{array}{c}(0.00 \\
)\end{array}$ & 0,25 & $\begin{array}{c}(0.00 \\
)\end{array}$ & 1,16 & $\begin{array}{c}(0.00 \\
)\end{array}$ & - & - \\
\hline Managers & 5,90 & $\begin{array}{c}0.01 \\
)\end{array}$ & 6,05 & $\begin{array}{c}(0.01 \\
)\end{array}$ & 3,52 & $\begin{array}{c}(0.01 \\
)\end{array}$ & 10,50 & $\begin{array}{c}0.01 \\
)\end{array}$ & 2,57 & $\begin{array}{c}(0.00 \\
)\end{array}$ \\
\hline Professionals & 33,37 & $\begin{array}{c}(0.02 \\
)\end{array}$ & 10,77 & $\begin{array}{c}(0.01 \\
)\end{array}$ & 7,46 & $\begin{array}{c}(0.01 \\
)\end{array}$ & 33,49 & $\begin{array}{c}(0.02 \\
)\end{array}$ & 12,04 & $\begin{array}{c}(0.01 \\
)\end{array}$ \\
\hline Technicians and associate professionals & 11,28 & $\begin{array}{c}0.01 \\
)\end{array}$ & 8,67 & $\begin{array}{c}(0.01 \\
)\end{array}$ & 6,37 & $\begin{array}{c}(0.01 \\
)\end{array}$ & 8,19 & $\begin{array}{c}(0.01 \\
)\end{array}$ & 2,79 & $\begin{array}{c}(0.01 \\
)\end{array}$ \\
\hline Clerical support workers & 9,01 & $\begin{array}{c}(0.01 \\
)\end{array}$ & 4,68 & $\begin{array}{c}(0.01 \\
)\end{array}$ & 8,22 & $\begin{array}{c}(0.01 \\
)\end{array}$ & 5,58 & $\begin{array}{c}(0.01 \\
)\end{array}$ & 1,98 & $\begin{array}{c}(0.00 \\
\quad)\end{array}$ \\
\hline Service and sales workers & 16,98 & $\begin{array}{c}0.01 \\
)\end{array}$ & 31,84 & $\begin{array}{c}(0.02 \\
)\end{array}$ & 30,71 & $\begin{array}{c}(0.02 \\
)\end{array}$ & 19,94 & $\begin{array}{c}(0.02 \\
)\end{array}$ & 41,77 & $\begin{array}{c}(0.01 \\
)\end{array}$ \\
\hline Skilled agricultural, forestry and fishery workers & 0,48 & $\begin{array}{c}(0.00 \\
)\end{array}$ & 0,47 & $\begin{array}{c}(0.00 \\
)\end{array}$ & - & - & 0,53 & $\begin{array}{c}(0.00 \\
)\end{array}$ & 10,42 & $\begin{array}{c}(0.02 \\
)\end{array}$ \\
\hline Craft and related trades workers & 7,37 & $\begin{array}{c}(0.01 \\
)\end{array}$ & 18,73 & $\begin{array}{c}(0.01 \\
)\end{array}$ & 15,92 & $\begin{array}{c}(0.02 \\
)\end{array}$ & 7,03 & $\begin{array}{c}(0.01 \\
)\end{array}$ & 18,43 & $\begin{array}{c}(0.01 \\
)\end{array}$ \\
\hline
\end{tabular}




\begin{tabular}{|c|c|c|c|c|c|c|c|c|c|c|}
\hline Plant and machine operators, and assemblers & 5,93 & $\begin{array}{c}(0.01 \\
)\end{array}$ & 5,82 & $\begin{array}{c}(0.01 \\
)\end{array}$ & 8,30 & $\begin{array}{c}(0.01 \\
)\end{array}$ & 4,99 & $\begin{array}{c}(0.01 \\
)\end{array}$ & 4,16 & $\begin{array}{c}(0.01 \\
)\end{array}$ \\
\hline Elementary occupations & 7,74 & $\begin{array}{c}(0.00 \\
)\end{array}$ & 12,64 & $\begin{array}{c}(0.00 \\
)\end{array}$ & 19,24 & $\begin{array}{c}(0.00 \\
)\end{array}$ & 8,59 & $\begin{array}{c}(0.00 \\
)\end{array}$ & 5,84 & $\begin{array}{c}(0.00 \\
)\end{array}$ \\
\hline Industry (\% of employment) & & & & & & & & & & \\
\hline Agriculture, forestry and fishing & 1,33 & $\begin{array}{c}(0.01 \\
)\end{array}$ & 1,25 & $\begin{array}{c}(0.01 \\
)\end{array}$ & 0,26 & $\begin{array}{c}(0.00 \\
)\end{array}$ & 1,98 & $\begin{array}{c}(0.02 \\
)\end{array}$ & 12,06 & $\begin{array}{c}(0.12 \\
)\end{array}$ \\
\hline Manufacturing, mining and quarrying & 20,29 & $\begin{array}{c}(0.20 \\
)\end{array}$ & 21,46 & $\begin{array}{c}(0.21 \\
)\end{array}$ & 20,40 & $\begin{array}{c}(0.20 \\
)\end{array}$ & 9,77 & $\begin{array}{c}(0.10 \\
)\end{array}$ & 11,05 & $\begin{array}{c}(0.11 \\
) \\
\end{array}$ \\
\hline Construction & 2,51 & $\begin{array}{c}(0.03 \\
)\end{array}$ & 5,55 & $\begin{array}{c}(0.06 \\
)\end{array}$ & 4,97 & $\begin{array}{c}(0.05 \\
)\end{array}$ & 5,36 & $\begin{array}{c}(0.05 \\
)\end{array}$ & 4,73 & $\begin{array}{c}(0.05 \\
)\end{array}$ \\
\hline Wholesale and retail, trans. and food services & 18,62 & $\begin{array}{c}(0.19 \\
)\end{array}$ & 41,42 & $\begin{array}{c}(0.41 \\
)\end{array}$ & 40,39 & $\begin{array}{c}(0.40 \\
)\end{array}$ & 24,22 & $\begin{array}{c}(0.24 \\
)\end{array}$ & 46,84 & $\begin{array}{c}(0.47 \\
)\end{array}$ \\
\hline Information and communications & 3,42 & $\begin{array}{c}(0.03 \\
)\end{array}$ & 2,12 & $\begin{array}{c}(0.02 \\
)\end{array}$ & 2,10 & $\begin{array}{c}(0.02 \\
)\end{array}$ & 3,12 & $\begin{array}{c}(0.03 \\
) \\
\end{array}$ & 1,68 & $\begin{array}{c}(0.02 \\
) \\
\end{array}$ \\
\hline Financial and insurance activities & 3,96 & $\begin{array}{c}(0.04 \\
)\end{array}$ & 1,52 & $\begin{array}{c}(0.02 \\
)\end{array}$ & 0,95 & $\begin{array}{c}(0.01 \\
)\end{array}$ & 4,21 & $\begin{array}{c}(0.04 \\
)\end{array}$ & 1,76 & $\begin{array}{c}(0.02 \\
)\end{array}$ \\
\hline Real estate activities & 0,16 & $\begin{array}{c}(0.00 \\
)\end{array}$ & 0,44 & $\begin{array}{c}(0.00 \\
)\end{array}$ & 0,23 & $\begin{array}{c}(0.00 \\
)\end{array}$ & 0,43 & $\begin{array}{c}(0.00 \\
)\end{array}$ & - & - \\
\hline Professional and related service activities & 4,44 & $\begin{array}{c}(0.04 \\
)\end{array}$ & 3,88 & $\begin{array}{c}(0.04 \\
)\end{array}$ & 7,90 & $\begin{array}{c}(0.08 \\
)\end{array}$ & 3,47 & $\begin{array}{c}(0.03 \\
)\end{array}$ & 3,19 & $\begin{array}{c}(0.03 \\
)\end{array}$ \\
\hline $\begin{array}{l}\text { Public administration, education, human health } \\
\text { and social work }\end{array}$ & 37,58 & $\begin{array}{c}0.38 \\
)\end{array}$ & 15,18 & $\begin{array}{c}(0.15 \\
)\end{array}$ & 10,45 & $\begin{array}{c}(0.10 \\
)\end{array}$ & 38,84 & $\begin{array}{c}0.39 \\
)\end{array}$ & 12,96 & $\begin{array}{c}(0.13 \\
)\end{array}$ \\
\hline Other service activities & 7,70 & $\begin{array}{c}0.08 \\
)\end{array}$ & 7,20 & $\begin{array}{c}(0.07 \\
)\end{array}$ & 12,35 & $\begin{array}{c}(0.12 \\
)\end{array}$ & 8,60 & $\begin{array}{c}(0.09 \\
)\end{array}$ & 5,73 & $\begin{array}{c}(0.06 \\
)\end{array}$ \\
\hline Observations (number of individuals) & \multicolumn{2}{|c|}{2992} & \multicolumn{2}{|c|}{2433} & \multicolumn{2}{|c|}{2596} & \multicolumn{2}{|c|}{2996} & \multicolumn{2}{|c|}{2987} \\
\hline
\end{tabular}

\begin{tabular}{|c|c|c|c|c|c|c|c|c|c|c|}
\hline & \multicolumn{2}{|c|}{ Lao PDR } & \multicolumn{2}{|c|}{ Kenya } & \multicolumn{2}{|c|}{ FYR Macedonia } & \multicolumn{2}{|c|}{ Sri Lanka } & \multicolumn{2}{|c|}{ Vietnam } \\
\hline Variable & Mean & SD & Mean & SD & Mean & SD & Mean & SD & Mean & SD \\
\hline Gender (proportion women) & 0.60 & $\begin{array}{c}(0.02 \\
)\end{array}$ & 0.53 & $(0.01)$ & 0.53 & $(0.01)$ & 0.60 & $(0.02)$ & 0.59 & $(0.01)$ \\
\hline
\end{tabular}




\begin{tabular}{|c|c|c|c|c|c|c|c|c|c|c|}
\hline Age (average years) & 35.15 & $\begin{array}{c}(0.43 \\
)\end{array}$ & 29.69 & $(0.28)$ & 40.01 & $(0.31)$ & 36.82 & $(0.63)$ & 38.31 & $(0.37)$ \\
\hline Labor force participation (\%) & 84,47 & $\begin{array}{c}0.01 \\
)\end{array}$ & 72,68 & $(0.01)$ & 65,55 & $(0.01)$ & 53,06 & $(0.01)$ & 69,81 & $(0.01)$ \\
\hline Employment rate (\%) & 83,31 & $\begin{array}{c}0.01 \\
)\end{array}$ & 58,35 & $(0.01)$ & 51,61 & $(0.01)$ & 50,21 & $(0.01)$ & 67,58 & $(0.01)$ \\
\hline Unemployment rate (\%) & 1,37 & $\begin{array}{c}0.00 \\
)\end{array}$ & 19,71 & $(0.01)$ & 21,26 & $(0.01)$ & 5,37 & $(0.01)$ & 3,19 & $(0.00)$ \\
\hline $\begin{array}{l}\text { Median hourly earnings (USD } 2010 \\
\text { constant) }\end{array}$ & 0.63 & $\begin{array}{c}0.02 \\
)\end{array}$ & 0.94 & $(0.04)$ & 2.05 & $(0.04)$ & 0.97 & $(0.05)$ & 1.22 & $(0.03)$ \\
\hline \multicolumn{11}{|l|}{ Occupations (\% of employment) } \\
\hline Armed forces & 2,44 & $\begin{array}{c}0.01 \\
)\end{array}$ & 0,09 & $(0.00)$ & 0,90 & $(0.00)$ & 0,66 & $(0.00)$ & 0,88 & $(0.00)$ \\
\hline Managers & 4,36 & $\begin{array}{c}(0.01 \\
)\end{array}$ & 2,34 & $(0.00)$ & 7,04 & $(0.01)$ & 10,98 & $(0.02)$ & 3,35 & $(0.00)$ \\
\hline Professionals & 5,80 & $\begin{array}{c}0.01 \\
)\end{array}$ & 10,41 & $(0.01)$ & 22,59 & $(0.01)$ & 17,11 & $(0.02)$ & 15,79 & $(0.01)$ \\
\hline Technicians and associate professionals & 4,59 & $\begin{array}{c}0.01 \\
)\end{array}$ & 5,94 & $(0.01)$ & 13,30 & $(0.01)$ & 3,77 & $(0.01)$ & 5,94 & $(0.01)$ \\
\hline Clerical support workers & 2,07 & $\begin{array}{c}(0.00 \\
)\end{array}$ & 5,39 & $(0.01)$ & 7,97 & $(0.01)$ & 9,04 & $(0.02)$ & 5,56 & $(0.01)$ \\
\hline Service and sales workers & 25,69 & $\begin{array}{c}0.02 \\
)\end{array}$ & 45,75 & $(0.01)$ & 16,95 & $(0.01)$ & 16,32 & $(0.02)$ & 36,46 & $(0.02)$ \\
\hline $\begin{array}{l}\text { Skilled agricultural, forestry and fishery } \\
\text { workers }\end{array}$ & 35,59 & $\begin{array}{c}0.03 \\
)\end{array}$ & 2,26 & $(0.00)$ & 0,79 & $(0.00)$ & 3,59 & $(0.01)$ & 0,97 & $(0.00)$ \\
\hline Craft and related trades workers & 8,47 & $\begin{array}{c}0.01 \\
)\end{array}$ & 10,88 & $(0.01)$ & 13,00 & $(0.01)$ & 19,44 & $(0.02)$ & 14,27 & $(0.01)$ \\
\hline $\begin{array}{l}\begin{array}{l}\text { Plant and machine operators, and } \\
\text { assemblers }\end{array} \\
\end{array}$ & 1,46 & $\begin{array}{c}0.00 \\
)\end{array}$ & 3,77 & $(0.00)$ & 9,54 & $(0.01)$ & 6,45 & $(0.01)$ & 5,52 & $(0.01)$ \\
\hline Elementary occupations & 9,53 & $\begin{array}{c}0.00 \\
)\end{array}$ & 13,17 & $(0.00)$ & 7,94 & $(0.00)$ & 12,65 & $(0.00)$ & 11,26 & $(0.00)$ \\
\hline \multicolumn{11}{|l|}{ Economic sector (\% of employment) } \\
\hline Agriculture, forestry and fishing & 36,57 & $\begin{array}{c}0.37 \\
)\end{array}$ & 2,70 & $(0.03)$ & 3,16 & $(0.03)$ & 4,29 & $(0.04)$ & 3,94 & $(0.04)$ \\
\hline
\end{tabular}




\begin{tabular}{|c|c|c|c|c|c|c|c|c|c|c|}
\hline Manufacturing, mining and quarrying & 9,09 & $\begin{array}{c}(0.09 \\
)\end{array}$ & 9,42 & $(0.09)$ & 24,39 & $(0.24)$ & 22,01 & $(0.22)$ & 20,25 & $(0.20)$ \\
\hline Construction & 5,90 & $\begin{array}{c}(0.06 \\
)\end{array}$ & 4,91 & $(0.05)$ & 4,65 & $(0.05)$ & 5,51 & $(0.06)$ & 5,36 & $(0.05)$ \\
\hline $\begin{array}{l}\text { Wholesale and retail, trans. and food } \\
\text { services }\end{array}$ & 26,07 & $\begin{array}{c}0.26 \\
)\end{array}$ & 37,03 & $(0.37)$ & 26,63 & $(0.27)$ & 33,80 & $(0.34)$ & 40,84 & $(0.41)$ \\
\hline Information and communications & 1,15 & $\begin{array}{c}0.01 \\
)\end{array}$ & 2,52 & $(0.03)$ & 2,99 & $(0.03)$ & 3,12 & $(0.03)$ & 2,35 & $(0.02)$ \\
\hline Financial and insurance activities & 0,98 & $\begin{array}{c}0.01 \\
)\end{array}$ & 2,90 & $(0.03)$ & 2,78 & $(0.03)$ & 3,97 & $(0.04)$ & 1,75 & $(0.02)$ \\
\hline Real estate activities & 0,52 & $\begin{array}{c}0.01 \\
)\end{array}$ & 0,35 & $(0.00)$ & 0,53 & $(0.01)$ & 0,14 & $(0.00)$ & 1,40 & $(0.01)$ \\
\hline Professional and related service activities & 5,73 & $\begin{array}{c}0.06 \\
)\end{array}$ & 15,25 & $(0.15)$ & 5,97 & $(0.06)$ & 5,58 & $(0.06)$ & 4,80 & $(0.05)$ \\
\hline $\begin{array}{l}\text { Public administration, education, human } \\
\text { health and social work }\end{array}$ & 8,33 & $\begin{array}{c}0.08 \\
)\end{array}$ & 8,04 & $(0.08)$ & 24,51 & $(0.25)$ & 15,74 & $(0.16)$ & 13,11 & $(0.13)$ \\
\hline Other service activities & 5,65 & $\begin{array}{c}(0.06 \\
)\end{array}$ & 16,82 & $(0.17)$ & 4,34 & $(0.04)$ & 5,73 & $(0.06)$ & 6,20 & $(0.06)$ \\
\hline Observations & \multicolumn{2}{|c|}{2032} & \multicolumn{2}{|c|}{3894} & \multicolumn{2}{|c|}{4009} & \multicolumn{2}{|c|}{1196} & \multicolumn{2}{|c|}{3405} \\
\hline
\end{tabular}




\section{a. Mapping Occupations to Skills: the "Task Approach"}

Following the literature, we apply a "task approach" to describe a job as a series of tasks, each of which can be mapped to a particular skill in the ALM categorization. First, we discuss alternative survey questions used in the literature to identify the relevant tasks for each skill category. Then we discuss the final mapping of tasks to skills used in this paper, based on the existing literature and the questions available in STEP.

Mapping tasks to skills

To map different tasks to skill categories, the literature has followed two approaches. The first one has produced the Dictionary of Occupational Titles -DOT- survey and the updated version, the O*NET. This approach uses experts to evaluate more than 12,000 occupations along 44 different tasks, following the guidelines in the Handbook for Analyzing Jobs. For each occupation, experts assign a score-between 1 and 5 - to the 44 tasks, where the scale reflects the importance of the task for the type of job (5 is "extremely important”). Tasks can then be grouped into skill categories, and an aggregate score by skill category can be computed for each occupation. The summary of the DOT and O*NET skill categories used by ALM, (2003) and Acemoglu and Autor (2011) is reported in Table A in the Annex. The main limitation of this approach is that the skill intensity is derived from experts' assessments at the occupational level, rather than by collecting observations directly from workers. Beyond any measurement errors that can arise, there is no variation in the taks scores within occupations.

The second approach uses detailed worker surveys, and was pioneered in Handel (2010), who uses the Skills, Technology, and Management Practices (STAMP) survey from the US. This survey was explicitly designed to overcome the limitations of the O*NET by capturing tasks at the worker level. For each worker, the survey covers skills and task requirements; ICT and non-ICT technology; employee involvement practices; autonomy, supervision and authority. The STAMP questions were later revised in PDII (Princeton Data Improvement Initiative). Table A in the Annex reports the relevant questions from PDII.

An example might be useful to better understand the two different approaches. The O*NET survey features, for example, a set of items describing the intensity of analytical tasks in a given occupation. One of these is "Analyzing data/information" and each occupation is given a score from experts for this task. Since there are several items per skill dimension, the scores of the different questions need to be aggregated to come up with a synthetic score for the analytical intensity of the job.

In the case of the STAMP or PDII questionnaires - as for STEP, questions about tasks performed under each skill bracket are asked directly to workers. For instance, for analytical tasks, the worker is asked about the "length of the longest document read at work". Hence, for each question, there are as many scores as surveyed workers. In order to construct, for each occupation, an index of analytical skill intensity, two steps are followed. Firstly, for each worker, answers are aggregated by skill bracket. Secondly, the aggregate score for workers is further aggregated by occupation within each skill bracket. As a result, worker-level surveys provide the full distribution of skill content within occupations, and not just one or few expert observations.

\section{Our approach: Measuring skill-content of occupations with STEP skill measurement surveys}

The STEP survey module on tasks at work was developed to be consistent with both O*NET and the STAMP/PDII surveys, and allows for worker-level measurement of tasks performed within the standard skill categories. Several questions are nearly identical to those in PDII or O*NET, increasing the ease of 
allocation of questions into skill categories, and the level of comparison with Autor and Handel (2013). There are also some questions that differ in wording, and some questions that are new to the STEP surveys (see table 2). By using questions from both O*NET and STAMP/PDII, plus some new ones, the methodology developed in this paper uses more questions that the previous literature to proxy for the skills intensity of an occupation. However, as discussed below, this paper also uses more aggregate skill categories than past work.

Table 2. Tasks to skill mapping using STEP skill measurement surveys

\begin{tabular}{|c|c|c|c|c|c|}
\hline $\begin{array}{l}\text { Broad } \\
\text { Category }\end{array}$ & $\begin{array}{l}\text { Relevant Skill } \\
\text { Bracket }\end{array}$ & STEP Task & Question & Autor and Handel Task & Coding \\
\hline \multirow{10}{*}{$\begin{array}{l}\text { New } \\
\text { Economy } \\
\text { Skills }\end{array}$} & \multirow{6}{*}{$\begin{array}{l}\text { Non-routine } \\
\text { analytical }\end{array}$} & Type of document read & m5a_q05 & $\begin{array}{l}\text { Analyzing data/information } \\
\text { - O*NET }\end{array}$ & Summation of "Yes" \\
\hline & & $\begin{array}{l}\begin{array}{l}\text { Length of longest document } \\
\text { typically read }\end{array} \\
\end{array}$ & m5a_q06 & $\begin{array}{l}\text { Length of longest document } \\
\text { typically read - PDII }\end{array}$ & Categorical (0-5) \\
\hline & & \begin{tabular}{|l|} 
Length of longest document \\
typically written
\end{tabular} & m5a_q13 & NEW & Categorical (0-5) \\
\hline & & Math tasks ${ }^{1}$ & m5a_q18 & $\begin{array}{l}\text { Frequency of math tasks } \\
\text { involving High School or } \\
\text { Higher math - PDII } \\
\end{array}$ & $\begin{array}{l}\text { Dummy whether any is } \\
\text { "Yes" and separate dummy } \\
\text { for advanced use. }\end{array}$ \\
\hline & & $\begin{array}{l}\text { Thinking for at least } 30 \\
\text { minutes to do tasks. }\end{array}$ & m5b_q10 & $\begin{array}{l}\text { Frequency of problem } \\
\text { solving tasks that require at } \\
\text { least } 30 \text { min - PDII }\end{array}$ & Categorical (1-5) \\
\hline & & \begin{tabular}{|l} 
How often your works \\
involves learning new things
\end{tabular} & m5b_q17 & NEW & Categorical (0-5) \\
\hline & \multirow{4}{*}{$\begin{array}{l}\text { Non-routine } \\
\text { interpersonal }\end{array}$} & Supervising coworkers & m5b_q13 & subordinates- & Dummy \\
\hline & & Making presentations & m5b_q12 & NEW & Dummy \\
\hline & & Contact with clients & m5b_q06 & $\begin{array}{l}\text { Establishing personal } \\
\text { relationships - O*NET }\end{array}$ & Categorical (0-10) \\
\hline & & $\begin{array}{|lcr|}\begin{array}{l}\text { Collaborating } \\
\text { workers }^{2}\end{array} & \text { with } \quad \text { co- } \\
\end{array}$ & m5b_q04 & NEW & Categorical (1-5) \\
\hline \multirow{6}{*}{$\begin{array}{l}\text { Old } \\
\text { Economy } \\
\text { Skills }\end{array}$} & \multirow{6}{*}{$\begin{array}{l}\text { Routine \& } \\
\text { Manual }\end{array}$} & Autonomy & m5b_q14 & $\begin{array}{l}\text { Structured vs unstructured } \\
\text { work- } \text { O*NET }^{*}\end{array}$ & Categorical (1-10) \\
\hline & & Repetitiveness & m5b_q16 & $\begin{array}{l}\text { Proportion of the workday } \\
\text { spent doing short, repetitive } \\
\text { tasks - PDII }\end{array}$ & Categorical (1-4) \\
\hline & & Operate & m5b_q09 & $\begin{array}{l}\text { Controlling Machines and } \\
\text { processes - O*NET }\end{array}$ & Dummy \\
\hline & & Driving & m5b_q07 & $\begin{array}{ll}\text { Operating vehicles } \\
\text { O*NET }\end{array}$ & Dummy \\
\hline & & Repair & m5b_q08 & Manual dexterity - O*NET & Dummy \\
\hline & & Physical demanding & m5b_q03 & NEW & Categorical (1-10) \\
\hline \multicolumn{6}{|c|}{$\begin{array}{l}\text { 1) Math tasks involve: measure sizes, weights, distances; calculate prices; use fractions or percentages; use any form of multiplication, } \\
\text { using advanced math (this is used as a separate task). } \\
\text { 2) This is present only in wave } 2 \text { of STEP so is not available for Bolivia and Colombia }\end{array}$} \\
\hline
\end{tabular}

To exploit the STEP data as much as possible, this paper focuses on three skill categories (table 2): Nonroutine analytical, Non-routine interpersonal, and Routine \& manual skills. In constrast to other data sources, the STEP survey does not allow to appropriately capture Routine cognitive/manual skills, or Routine/Non-routine manual skills. ${ }^{6}$ For instance, we lack a question that distinguish repetitive motions

\footnotetext{
${ }^{6}$ The wide scope of the STEP survey for measuring cognitive, socio-emotional, and technical skills implies that the length of the task module was less extensive than in other surveys, like STAMP.
} 
from other types of repetitive tasks. Similarly, while questions on manual tasks capture the degree of physical strength that is needed in the job, and whether a job requires a worker to drive or repair things, they do not capture routine manual tasks that do not necessarily require a lot of physical strength. For example, supermarket cashiers or hairdressers. At the same time, there are not enough questions to capture manual tasks that require making non-routine decisions (where to spend more time cleaning, how to accommodate a special customer request, etc.)

Table 2 summarizes how we allocated the task variables into relative skills brackets; to verify their consistency with the previous literature, it also reports the analogous measures from other questionnaires. Some variables are introduced for the first time following Handel's STAMP categories.

\section{b. Methodology to construct the skill content scores}

Our methodology involves two main steps: first, we estimate the 3 skills indexes at the individual level; second, these indexes are aggregated to the occupation level (at a 3-digit ISCO 08 level), using a standardized summation as in Acemoglu and Autor (2011). ${ }^{7}$

The estimation procedure follows these steps:

1. Standardize each task variable to have mean zero and standard deviation one in the whole sample for each individual country.

2. Add the corresponding task variables to estimate an individual level skill score, for each skill category.

3. Estimate the occupation level average score (at 3-, 2- and 1-digit, separately) using as weights the contribution of each occupation on total hours worked last week. ${ }^{8}$

4. Standarize the occupation-level skill score to have mean zero and standard deviation one.

The main virtues of this method is that the first standarization converts all variables into a common scale and makes the summation between them possible. The common criticisim of standarization comes from “(...) their dependence on the sample variation in the inputs, lack of inherent meaning for categorical inputs, and difficulties in dealing with input transformations and interactions” (Gelman \& Pardoe, 2007, p. 30). Finally, we exclude those occupations with less than 10 observations to reduce noise in the sample variation.

\footnotetext{
${ }^{7}$ Two main estimation techniques that were used for robustness: i) use a PCA estimation following Autor and Handel (2013); and ii) a measure of occupational skill requirements following Spitz-Oener (2006). In the Principal Component Analysis (PCA), the result form the estimation is a standardized scale of each of the categories' tasks using the first component of a Principal Component Analysis. For Spitz-Oener's methodology, the estimate is a percentage of tasks performed by individual in each of skill categories. This estimation procedure is relatively straightforward in terms of interpretation. However, it is up to the researcher to decide how the scale of each variable relates to the intensity of skill use.

${ }^{8}$ The hours worked last week had no missing values for Ghana and Macedonia, and only 1 for Bolivia in the sample of employed workers with 10 or more observations per occupation. An analysis of the densities suggested that for Bolivia and Ghana, the distribution was almost normal, whereas for Macedonia, it was bimodal with peaks at 40 and 48 hours a week. There is second variable available (hours worked daily). The distributions follow the same pattern. However, the decision was to use the hours worked last week.
} 


\section{Results}

In this section we report the results of our estimates of the skill content of occupations. First, we present the skill intensity by occupations. Second, we discuss the similarities across countries in our sample. Third, we compare the ranking of occupations along the skills dimension in STEP countries to the one produced with US data (PDII and O*Net). Indeed, the advantage of using the skill content of occupations estimated for a set of developing countries (rather than the U.S. one) is particularly important if there are significant differences across the STEP countries and the U.S. Finally, we look into the existence of any regularities in the skill intensity of occupations along the course of development.

\section{a. The Skill Content of Occupations}

In order to give an overall assessment of the skill content of occupations in our sample, we construct the "average STEP country" by pooling the different countries together. ${ }^{9}$ Recall that each occupation is characterized by 3 indexes, each of which measures the intensity of a given skill category (and they do not necesarrily allow to characterize an occupation by a particular skill set). In Figure 1, we plot the indexes of the 3 skill dimensions (analytical, interpersonal, routine/manual) of occupations at the 1-digit level. Based on these results, the skill mix of the workforce is very unequal across occupations. For instance, Managers, Professionals and Associate Professionals mostly use analytical and interpersonal skills. Instead, Clerical occupations rely on a mixture of analytical, interpersonal and routine-manual skills. On the other hand, Service and Sales occupations are characterized by a low level of specialization, using a combination of low levels of all skills. Finally, Craft and Related, Plant and Machine and Elementary occupations are highly intensive in manual and routine skills

Figure 1. Skill Intensity Indexes of Occupations at the 1-digit level. (Pooled STEP Sample).

\footnotetext{
The indexes are standardized measures with respect to the occupation that scores the average index (for details, refer to the metholodogy explained in Section 3B). Scores represent the distance -expressed in units of a standard normal- in the skillintensity occupational distribution from an hypothetical “average occupation”. Source: authors' elaboration on STEP data (all countries).
}

\footnotetext{
${ }^{9}$ The "average STEP country" is built by pooling the data from all STEP countries and by using the same methodology described above. This exercise is equivalent to assuming that all STEP countries are one large country composed of many regions. We use the sample weights of each STEP dataset, therefore implicitly giving the same weight to each STEP country.
} 


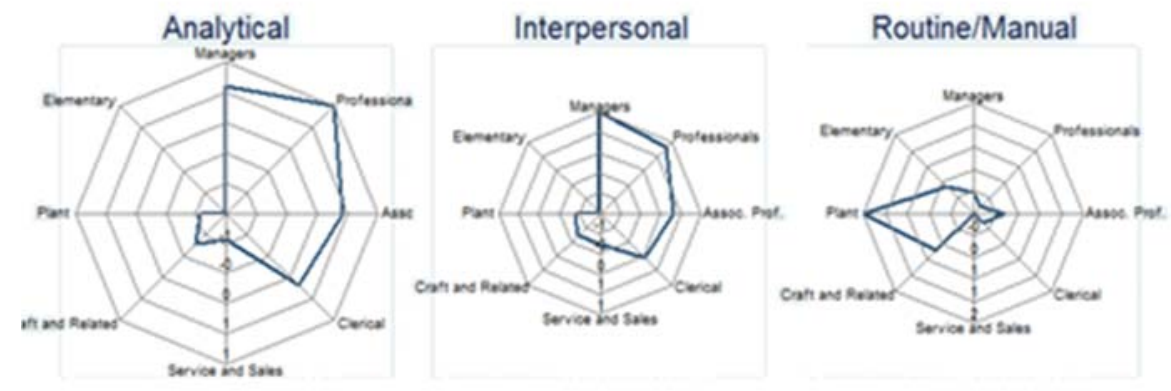

This general trend is confirmed if we look at the estimates of the skill content for the different countries (Figure A in the Annex). Even though with some heterogeneity across countries, it is the case that analytical and interpersonal skills are dominant in high-paying occupations (such as Managers and Professionals), whereas manual and routine skills are most important for low-paying occupations (Elementary, Craft and Related, Plant and Machine). Table 3 shows the occupations that are more frequently in the top/bottom 10 in each of the 3 skill dimensions in the different countries. A number of occupations have a skill mix that is highly concentrated in a particular skill category. Teachers, Architects and Professionals score the highest scores in analytical and interpersonal skills, whereas they are consistently at the bottom of the manual skill distribution. At the same time, occupations such as Drivers, Repairers and other Elementary Occupations score highest in routine and manual skills, and lowest in analytical and interpersonal skills.

Table 3. Top and Bottom Occupations by Skill Dimension

Source: authors' elaboration on STEP data (all countries).

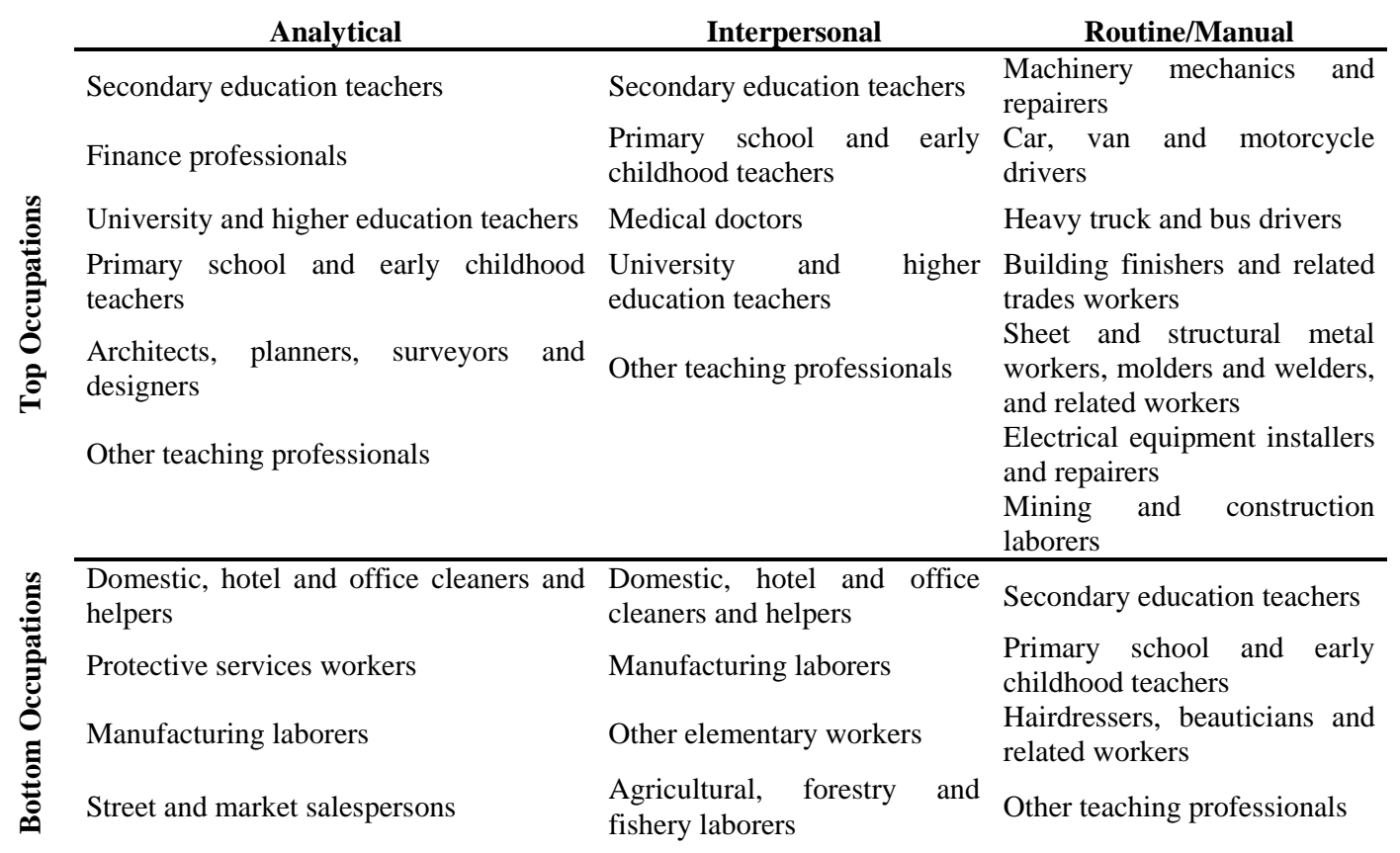




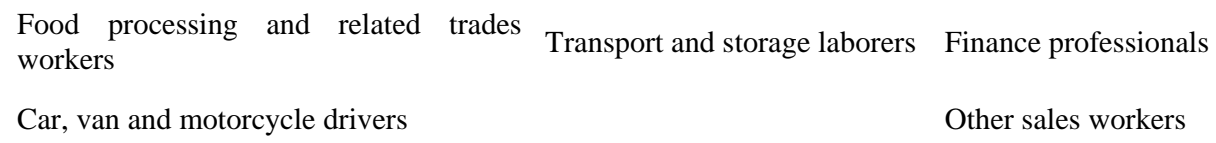

Agricultural, forestry and fishery laborers

The differences in the estimated indexes stem from differences in the tasks that workers report to perform at work. It is, therefore, pertinent to look into which ones are the tasks that account for the largest part of these differentials. In Table 4, we plot the sample means of all the task variables used in our estimation. For what concerns analytical skills, reading and writing tasks seem to be particularly concentrated in few occupations, as well as the use of advanced math (but not the use of "some" math). Learning and thinking tasks are concentrated to a lesser extent. Turning to interpersonal skills, supervision and presentation tasks are highly concentrated, while having contact with clients and collaborating with coworkers are tasks that characterize a large amount of occupations. Finally, for the routine/manual index, what drives most of the variation across occupations are tasks such as driving and operating heavy machines, as well as the answer to "How physically demanding is the job?". We find relatively little variation in the autonomy and repetitiveness of the job. 
Table 4. Sample Mean and SD of Tasks Variables, by Occupation. (Pooled STEP Sample)

Sample means of task variables, coded such that the higher the intensity (or the frequency) the higher the score. Source: authors' elaboration on STEP data (all countries).

\begin{tabular}{|c|c|c|c|c|c|c|c|c|c|}
\hline & Variable & Managers & Professionals & $\begin{array}{c}\text { Associate } \\
\text { Prof. }\end{array}$ & Clerical & $\begin{array}{c}\text { Service } \\
\text { and } \\
\text { Related }\end{array}$ & $\begin{array}{c}\text { Crafts } \\
\text { and } \\
\text { Related }\end{array}$ & $\begin{array}{c}\text { Plant } \\
\text { and } \\
\text { Machine }\end{array}$ & Elementary \\
\hline \multirow{14}{*}{ 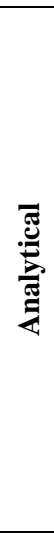 } & Reading: complexity of material read (0-5) & 2.995 & 2.992 & 3.048 & 3.054 & 1.125 & 0.881 & 1.166 & 0.595 \\
\hline & & $(0.161)$ & $(0.063)$ & $(0.129)$ & $(0.095)$ & $(0.048)$ & $(0.060)$ & $(0.143)$ & $(0.079)$ \\
\hline & Reading: length of longest document typically read (0-5) & 2.918 & 3.584 & 2.786 & 2.698 & 1.003 & 0.927 & 0.974 & 0.598 \\
\hline & & $(0.139)$ & $(0.058)$ & $(0.129)$ & $(0.097)$ & $(0.035)$ & $(0.059)$ & $(0.079)$ & $(0.063)$ \\
\hline & Writing: length of longest document typically written (0-5) & 1.995 & 2.772 & 1.899 & 1.830 & 0.826 & 0.734 & 0.611 & 0.467 \\
\hline & & $(0.104)$ & $(0.053)$ & $(0.085)$ & $(0.067)$ & $(0.024)$ & $(0.027)$ & $(0.082)$ & $(0.044)$ \\
\hline & Use some math (dummy) & 0.968 & 0.828 & 0.943 & 0.847 & 0.900 & 0.950 & 0.838 & 0.663 \\
\hline & & $(0.008)$ & $(0.016)$ & $(0.010)$ & $(0.023)$ & $(0.011)$ & $(0.009)$ & $(0.027)$ & $(0.028)$ \\
\hline & Use of advanced math (dummy) & 0.228 & 0.249 & 0.174 & 0.121 & 0.017 & 0.065 & 0.103 & 0.022 \\
\hline & & $(0.048)$ & $(0.015)$ & $(0.028)$ & $(0.020)$ & $(0.003)$ & $(0.009)$ & $(0.060)$ & $(0.005)$ \\
\hline & How often does the job involve learning? (0-5) & 3.146 & 3.575 & 3.210 & 2.719 & 2.105 & 2.937 & 2.531 & 1.889 \\
\hline & & $(0.134)$ & $(0.048)$ & $(0.095)$ & $(0.095)$ & $(0.038)$ & $(0.092)$ & $(0.144)$ & $(0.081)$ \\
\hline & Thinking for at least 30 minutes (1-5) & 3.982 & 4.071 & 3.850 & 3.578 & 2.814 & 3.265 & 2.942 & 2.574 \\
\hline & & $(0.100)$ & $(0.043)$ & $(0.087)$ & $(0.086)$ & $(0.049)$ & $(0.087)$ & $(0.128)$ & $(0.114)$ \\
\hline \multirow{8}{*}{ 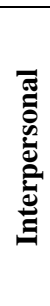 } & Supervision of other workers (dummy) & 0.780 & 0.528 & 0.574 & 0.478 & 0.218 & 0.326 & 0.282 & 0.164 \\
\hline & & $(0.046)$ & $(0.019)$ & $(0.033)$ & $(0.032)$ & $(0.011)$ & $(0.020)$ & $(0.056)$ & $(0.030)$ \\
\hline & Presentation (dummy) & 0.545 & 0.634 & 0.440 & 0.453 & 0.240 & 0.217 & 0.135 & 0.086 \\
\hline & & $(0.049)$ & $(0.018)$ & $(0.035)$ & $(0.031)$ & $(0.011)$ & $(0.016)$ & $(0.022)$ & $(0.010)$ \\
\hline & Contact with clients $(0-10)$ & 7.091 & 7.230 & 6.526 & 5.864 & 6.290 & 4.915 & 4.907 & 3.266 \\
\hline & & $(0.195)$ & $(0.106)$ & $(0.209)$ & $(0.204)$ & $(0.098)$ & $(0.160)$ & $(0.392)$ & $(0.161)$ \\
\hline & Collaboration with coworkers (1-5) & 4.258 & 4.502 & 4.627 & 4.344 & 3.004 & 3.317 & 3.934 & 3.270 \\
\hline & & $(0.128)$ & $(0.041)$ & $(0.096)$ & $(0.115)$ & $(0.049)$ & $(0.088)$ & $(0.123)$ & $(0.120)$ \\
\hline \multirow{12}{*}{ 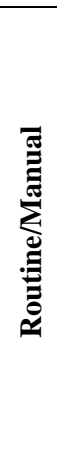 } & Autonomy (1-10) & 3.148 & 4.584 & 4.155 & 4.909 & 3.307 & 3.493 & 4.138 & 4.227 \\
\hline & & $(0.181)$ & $(0.100)$ & $(0.153)$ & $(0.131)$ & $(0.060)$ & $(0.131)$ & $(0.164)$ & $(0.104)$ \\
\hline & Repetitiveness (1-4) & 3.217 & 3.196 & 3.367 & 3.404 & 3.431 & 3.354 & 3.390 & 3.501 \\
\hline & & $(0.088)$ & $(0.038)$ & $(0.062)$ & $(0.053)$ & $(0.023)$ & $(0.055)$ & $(0.102)$ & $(0.042)$ \\
\hline & Operate heavy machines (dummy) & 0.077 & 0.030 & 0.067 & 0.018 & 0.009 & 0.179 & 0.247 & 0.075 \\
\hline & & $(0.019)$ & $(0.005)$ & $(0.015)$ & $(0.006)$ & $(0.002)$ & $(0.016)$ & $(0.054)$ & $(0.019)$ \\
\hline & Driving (dummy) & 0.266 & 0.070 & 0.110 & 0.075 & 0.060 & 0.074 & 0.622 & 0.044 \\
\hline & & $(0.035)$ & $(0.008)$ & $(0.018)$ & $(0.016)$ & $(0.007)$ & $(0.009)$ & $(0.050)$ & $(0.007)$ \\
\hline & Repairing (dummy) & 0.110 & 0.105 & 0.172 & 0.084 & 0.033 & 0.122 & 0.074 & 0.018 \\
\hline & & $(0.024)$ & $(0.010)$ & $(0.028)$ & $(0.015)$ & $(0.004)$ & $(0.012)$ & $(0.013)$ & $(0.005)$ \\
\hline & How physical demanding is the job? $(1-10)$ & 4.076 & 3.771 & 4.572 & 3.821 & 4.873 & 5.533 & 5.749 & 6.163 \\
\hline & & (0.198) & $(0.096)$ & $(0.235)$ & $(0.185)$ & $(0.064)$ & (0.169) & $(0.263)$ & $(0.132)$ \\
\hline
\end{tabular}




\section{b. Cross-country Comparisons}

To shed some light on the use of different skills across countries, we compare the answers on the tasks performed by workers. Table 5 shows selected task questions used for the estimation of the skill indexes. We choose to compare directly the sample means of the task variables, as the indexes we construct will not be comparable across countries (a discussion on this below).

We can see that despite a substantial degree of heterogeneity across the STEP countries, workers in higher income countries tend to report using analytical and interpersonal skills more frequently. Task variables that measure the use of reading and writing skills on a scale from 0 to 5 can be as low as $0.66 / 0.86$ in Ghana, as opposed to 2.04/2.1 in Armenia or 2.24/2.19 in Macedonia. Regarding the use of math, the great majority of the labor force reports using some math:62\% in Georgia, 92\% in Laos and Bolivia, with most countries recording an average of $80 \%$ On the other hand, only a limited subsample use advanced math: 3\% in Ghana, 6\% in Kenya and Laos, $13 \%$ in Armenia. Supervision of other workers (task that require interpersonal skills) is performed by 22\% of the workforce in Kenya, 38\% in Vietnam and 36\% in Armenia. Presentations are made by only $10 \%$ of the workers in Laos and $13 \%$ in Ghana, in contrast to $58 \%$ in Sri Lanka and 57\% in Vietnam.

An even larger degree of heterogeneity characterizes routine/manual skills. For instance, the degree of autonomy of the job (on a scale from 1 to) is on average 3.08 in Laos, whereas it is 5.62 in Georgia. The fraction of workers who operate heavy machines is as low as 5\% in Armenia and Vietnam, but reaches $10 \%$ in Colombia and 13\% in Sri Lanka. Finally, driving is a task reported by $6 \%$ of the workers in Vietnam, in contrast to 19\% in Sri Lanka and 34\% in Macedonia. 
Table 5. Sample Mean and SD of Tasks Variables, by country

\begin{tabular}{|c|c|c|c|c|c|c|c|c|c|c|c|}
\hline & Variable & ARM & BOL & COL & GEO & GHA & KEN & LAO & LKA & MKD & VNM \\
\hline \multirow{13}{*}{ 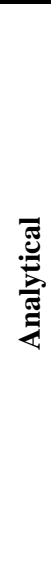 } & Reading: complexity of material read (0-5) & $\begin{array}{c}2.04 \\
(1.79)\end{array}$ & $\begin{array}{c}1.62 \\
(1.81)\end{array}$ & $\begin{array}{c}1.71 \\
(1.76)\end{array}$ & $\begin{array}{c}1.69 \\
(1.73)\end{array}$ & $\begin{array}{c}0.66 \\
(1.19)\end{array}$ & $\begin{array}{c}1.61 \\
(1.83)\end{array}$ & $\begin{array}{c}1.42 \\
(1.62)\end{array}$ & $\begin{array}{c}1.83 \\
(2.00)\end{array}$ & $\begin{array}{c}2.24 \\
(1.95)\end{array}$ & $\begin{array}{c}1.77 \\
(1.76)\end{array}$ \\
\hline & Reading: length of longest document typically read (0-5) & 2.1 & 1.86 & 1.58 & 1.95 & 0.86 & 1.62 & 1.04 & 1.5 & 2.19 & 1.79 \\
\hline & & (1.85) & $(2.01)$ & $(1.64)$ & (1.90) & $(1.43)$ & $(1.84)$ & $(1.10)$ & (1.73) & $(1.94)$ & $(1.75)$ \\
\hline & Writing: length of longest document typically written (0-5) & 1.73 & 1.4 & 1.11 & 1.14 & 0.86 & 1.23 & 0.88 & 1.11 & 1.6 & 1.2 \\
\hline & & $(1.52)$ & $(1.51)$ & $(1.19)$ & $(1.46)$ & $(1.20)$ & $(1.46)$ & $(0.97)$ & (1.34) & $(1.60)$ & (1.33) \\
\hline & Use some math (dummy) & 0.74 & 0.9 & 0.85 & 0.64 & 0.9 & 0.86 & 0.92 & 0.83 & 0.73 & 0.85 \\
\hline & & $(0.44)$ & $(0.30)$ & $(0.36)$ & $(0.48)$ & $(0.30)$ & $(0.35)$ & $(0.27)$ & $(0.38)$ & $(0.44)$ & $(0.36)$ \\
\hline & Use of advanced math (dummy) & 0.13 & 0.13 & 0.08 & 0.07 & 0.03 & 0.07 & 0.06 & 0.12 & 0.1 & 0.08 \\
\hline & & $(0.33)$ & $(0.33)$ & $(0.27)$ & $(0.26)$ & $(0.17)$ & $(0.25)$ & $(0.24)$ & $(0.33)$ & $(0.30)$ & $(0.28)$ \\
\hline & How often does the job involve learning? $(0-5)$ & 2.69 & 2.79 & 2.6 & 2.08 & 2.33 & 2.74 & 1.68 & 2.8 & 2.93 & 2.11 \\
\hline & & $(1.55)$ & (1.53) & $(1.60)$ & $(1.44)$ & $(1.52)$ & $(1.55)$ & $(1.04)$ & (1.54) & $(1.66)$ & $(1.37)$ \\
\hline & Thinking for at least 30 minutes (1-5) & 3.41 & 3.36 & 3.5 & 2.64 & 2.68 & 3 & 2.41 & 3.17 & 3.08 & 2.96 \\
\hline & & $(1.73)$ & (1.57) & $(1.61)$ & $(1.52)$ & $(1.67)$ & $(1.60)$ & $(1.52)$ & $(1.54)$ & $(1.59)$ & $(1.68)$ \\
\hline \multirow{7}{*}{ 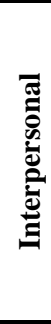 } & Supervision of other workers (dummy) & 0.36 & 0.34 & 0.34 & 0.27 & 0.27 & 0.22 & 0.35 & 0.4 & 0.31 & 0.38 \\
\hline & & $(0.48)$ & $(0.47)$ & $(0.47)$ & $(0.44)$ & $(0.44)$ & $(0.41)$ & $(0.48)$ & $(0.49)$ & $(0.46)$ & $(0.49)$ \\
\hline & Presentation (dummy) & 0.19 & 0.22 & 0.25 & 0.24 & 0.13 & 0.31 & 0.1 & 0.58 & 0.28 & 0.57 \\
\hline & & $(0.39)$ & $(0.42)$ & $(0.43)$ & $(0.43)$ & $(0.34)$ & $(0.46)$ & $(0.30)$ & $(0.49)$ & $(0.45)$ & $(0.49)$ \\
\hline & & $(4.02)$ & $(3.47)$ & $(3.80)$ & (3.97) & $(3.23)$ & $(3.45)$ & (3.23) & (3.34) & $(4.05)$ & $(3.17)$ \\
\hline & Collaboration with coworkers (1-5) & 4.46 & - & - & 4.35 & 3.11 & 3.7 & - & - & 4.49 & - \\
\hline & & $(1.22)$ & - & - & $(1.36)$ & $(1.81)$ & $(1.79)$ & - & - & $(1.23)$ & - \\
\hline \multirow{12}{*}{ 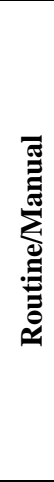 } & Autonomy (1-10) & 5.28 & 3.63 & 3.41 & 5.62 & 4.19 & 4.34 & 3.08 & 4.12 & 4.48 & 4.36 \\
\hline & & $(2.92)$ & $(2.48)$ & $(2.48)$ & $(3.06)$ & $(3.06)$ & $(2.81)$ & $(2.31)$ & $(2.55)$ & $(3.05)$ & $(2.48)$ \\
\hline & Repetitiveness (1-4) & 3.72 & 3.26 & 3.6 & 3.31 & 3.39 & 3.49 & 3.51 & 3.08 & 3.68 & 2.93 \\
\hline & & $(0.70)$ & $(0.98)$ & $(0.82)$ & $(1.06)$ & $(1.00)$ & $(0.86)$ & $(0.87)$ & $(1.14)$ & $(0.69)$ & $(1.14)$ \\
\hline & Operate heavy machines (dummy) & 0.05 & 0.08 & 0.1 & 0.07 & 0.06 & 0.07 & 0.05 & 0.13 & 0.09 & 0.05 \\
\hline & & $(0.22)$ & $(0.26)$ & $(0.30)$ & $(0.25)$ & $(0.24)$ & $(0.26)$ & $(0.21)$ & $(0.33)$ & $(0.28)$ & $(0.21)$ \\
\hline & Driving (dummy) & 0.14 & 0.16 & 0.11 & 0.12 & 0.09 & 0.1 & 0.11 & 0.19 & 0.34 & 0.06 \\
\hline & & $(0.35)$ & $(0.36)$ & $(0.31)$ & $(0.33)$ & $(0.28)$ & $(0.30)$ & $(0.31)$ & $(0.39)$ & $(0.47)$ & $(0.24)$ \\
\hline & Repairing (dummy) & 0.25 & 0.06 & 0.06 & 0.06 & 0.06 & 0.07 & 0.03 & 0.28 & 0.1 & 0.08 \\
\hline & & $(0.43)$ & $(0.23)$ & $(0.23)$ & $(0.24)$ & $(0.25)$ & $(0.26)$ & $(0.17)$ & $(0.45)$ & $(0.30)$ & $(0.27)$ \\
\hline & How physical demanding is the job? $(1-10)$ & 4.18 & 4.87 & 5.58 & 4.45 & 5.5 & 4.92 & 5.13 & 4.67 & 4.57 & 4.19 \\
\hline & & $(2.86)$ & (2.39) & $(2.70)$ & $(3.07)$ & $(2.65)$ & (2.43) & (2.49) & (2.45) & $(2.88)$ & $(2.08)$ \\
\hline
\end{tabular}


We now look at how these variables aggregate into our skill indexes. When performing the cross-country comparison, one important caveat of our analysis is that the estimated levels of skill intensity indexes cannot be directly compared. This is because, due to the normalization (which depends on the actual countryspecific skill distribution), the estimated indexes are expressed in different scales. For the sake of concreteness, if an occupation has an index of 1.96 in a given skill dimension, it means that it is 1.96 standard deviation more intensive of that skill than the benchmark occupation. Due to the fact that the benchmark occupation differs across countries, it follows that the indexes cannot be directly compared.

Nonetheless, we investigate whether the skill content of occupations presents similarities within groups of countries. In particular, we cluster countries by region and income level and compare the shape of the spider-webs plots of occupations at the 1-digit level (Figures 2 and 3). For both aggregations, we find more similarities in the relative intensity of skills in the case of analytical and interpersonal skills with respect to the case of routine/manual. More specifically, if we focus on the shape of the spider-webs, we can observe very similar patterns between regions (or income groups) when we compare the analytical dimension. In turn, in the case of the interpersonal dimension, one thing that can be noticed is that European countries in the regional classification (or Upper Middle income countries, in the second classification) tend to have relatively lower levels in the occupations Plan and Machine and Craft and Related. In terms of routine and manual skills, we again find important similarities, even though they seem to be somewhat weaker.

Still, despite the overall similarities across countries, it is unclear that the relative intensity of skills is systematically related to regional characteristics or income level. To test more formally for this hypothesis, we compute pair-wise Spearman correlations of the skill indexes at the 3-digit level and we order the countries according to region and income group. The Spearman correlation measures the degree of similarity in the order of occupations along the skill relative intensity. To ease the reading of the results, Spearman correlations are shaded in a heat map such that the color intensity correspond to the correlation level (see Tables 6 and 7), the darker the shade the higher the correlation. In this analysis, we would expect to find diagonal submatrices with higher correlation levels respect to off-diagonal submatrices. However, we do not find that correlations are higher within groups. Instead, we obtain that in general the correlations are positive and high, which confirms the existence of important similarities in the skill content of occupations within our sample of developing countries, regardless of their level of income or geographic region. Nonetheless, it is important to stress that the size of our sample does not allow us to estimate the indexes at the occupation level for all 3-digit occupations. As a consequence, when computing the Spearman correlations for each pair of countries we are constraining our sample to the occupations for which an index has been estimated for both countries. This implies that in several cases we estimate the Spearman correlations based on a limited number of occupations (see Table 8 for details). 
Figure 2. Radar Graph of Skill Intensity Index of Occupations at the 1-digit level, by Region.

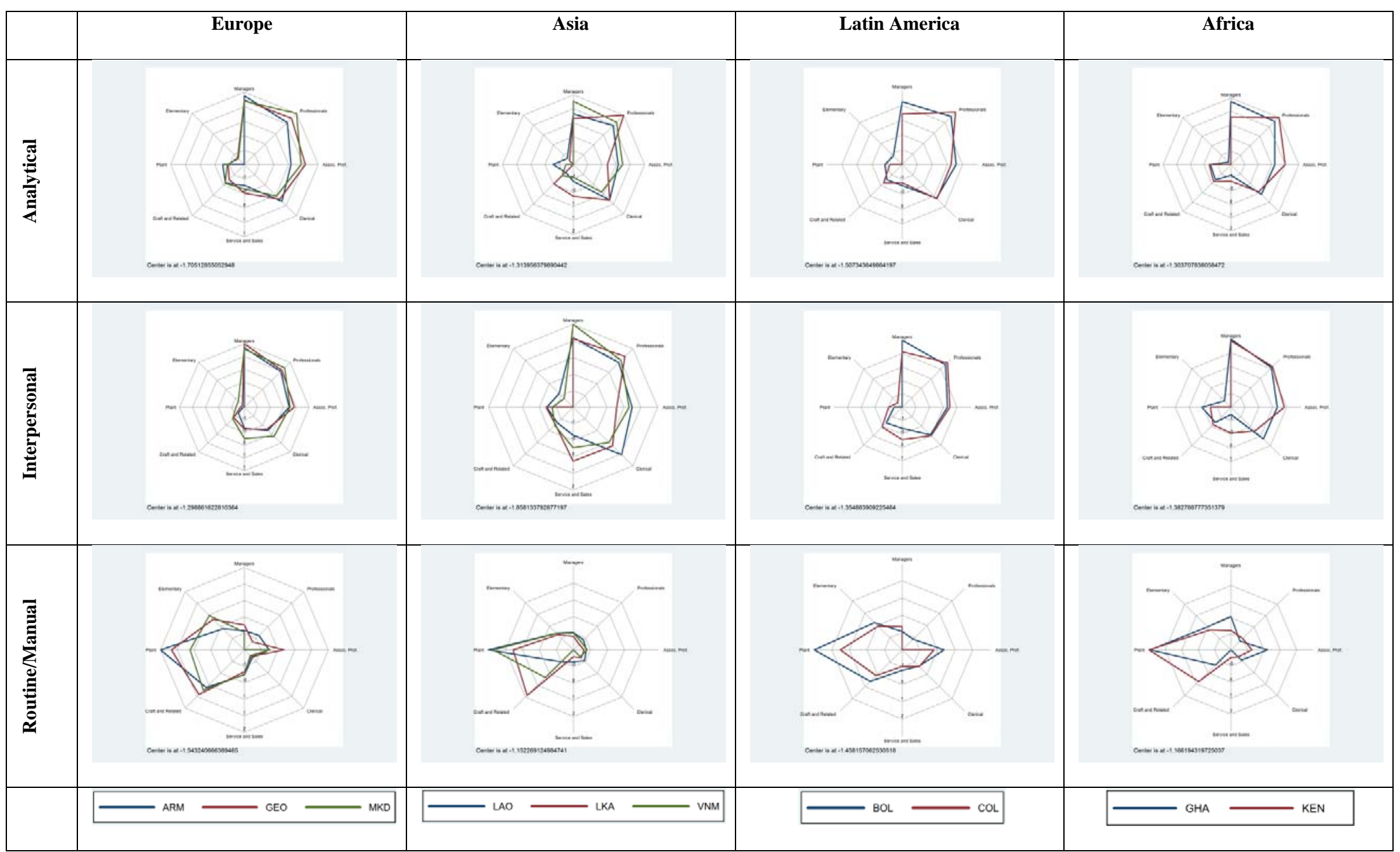


Figure 3. Radar Graph of Skill Intensity Index of Occupations at the 1-digit level, by Income Group.

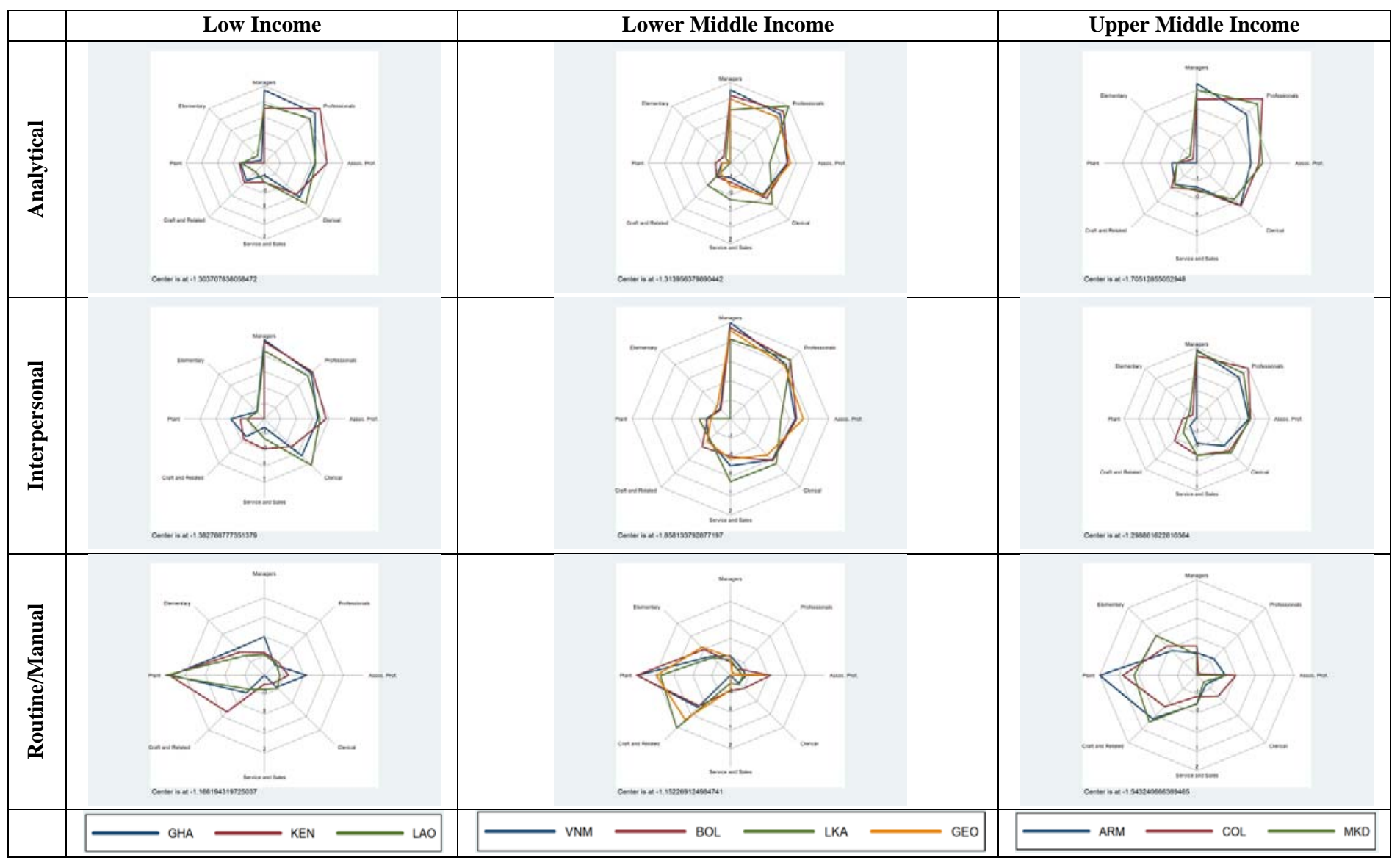


Table 6. Pair-wise Spearman Correlations of Skill Intensity Indexes at the 3-Digit level, by Skill Dimension. Countries are sorted by Income groups.

\begin{tabular}{|c|c|c|c|c|c|c|c|c|c|c|}
\hline & GHA & \multicolumn{8}{|c|}{ Analytical } & MKD \\
\hline GHA & 1.00 & 0.92 & 0.66 & 0.83 & 0.76 & 0.69 & 0.72 & 0.81 & 0.81 & 0.80 \\
\hline KEN & & 1.00 & 0.87 & 0.86 & 0.80 & 0.87 & 0.78 & 0.81 & 0.91 & 0.85 \\
\hline LAO & & & 1.00 & 0.82 & 0.83 & 0.77 & 0.90 & 0.68 & 0.87 & 0.70 \\
\hline VNM & & & & 1.00 & 0.86 & 0.77 & 0.89 & 0.78 & 0.86 & 0.89 \\
\hline BOL & & & & & 1.00 & 0.82 & 0.83 & 0.85 & 0.77 & 0.86 \\
\hline LKA & & & & & & 1.00 & 0.74 & 0.74 & 0.86 & 0.82 \\
\hline GEO & & & & & & & 1.00 & 0.81 & 0.95 & 0.80 \\
\hline COL & & & & & & & & 1.00 & 0.84 & 0.76 \\
\hline ARM & & & & & & & & & 1.00 & 0.82 \\
\hline \multirow[t]{2}{*}{ MKD } & & & & & & & & & & 1.00 \\
\hline & \multicolumn{10}{|c|}{ Interpersonal } \\
\hline GHA & 1.00 & 0.63 & 0.66 & 0.71 & 0.62 & 0.64 & 0.70 & 0.72 & 0.62 & 0.67 \\
\hline KEN & & 1.00 & 0.73 & 0.78 & 0.72 & 0.88 & 0.81 & 0.66 & 0.53 & 0.77 \\
\hline LAO & & & 1.00 & 0.81 & 0.84 & 0.84 & 0.93 & 0.76 & 0.88 & 0.76 \\
\hline VNM & & & & 1.00 & 0.81 & 0.89 & 0.89 & 0.82 & 0.75 & 0.77 \\
\hline BOL & & & & & 1.00 & 0.82 & 0.78 & 0.82 & 0.71 & 0.79 \\
\hline LKA & & & & & & 1.00 & 0.71 & 0.90 & 0.48 & 0.89 \\
\hline GEO & & & & & & & 1.00 & 0.83 & 0.77 & 0.82 \\
\hline COL & & & & & & & & 1.00 & 0.89 & 0.68 \\
\hline ARM & & & & & & & & & 1.00 & 0.66 \\
\hline \multirow[t]{2}{*}{ MKD } & & & & & & & & & & 1.00 \\
\hline & \multicolumn{10}{|c|}{ Routine } \\
\hline GHA & 1.00 & 0.66 & 0.62 & 0.76 & 0.70 & 0.41 & 0.52 & 0.73 & 0.76 & 0.46 \\
\hline KEN & & 1.00 & 0.70 & 0.53 & 0.42 & 0.26 & 0.41 & 0.70 & 0.61 & 0.54 \\
\hline LAO & & & 1.00 & 0.49 & 0.67 & 0.74 & 0.62 & 0.73 & 0.70 & 0.80 \\
\hline VNM & & & & 1.00 & 0.50 & -0.07 & 0.52 & 0.72 & 0.43 & 0.53 \\
\hline BOL & & & & & 1.00 & 0.79 & 0.69 & 0.65 & 0.70 & 0.62 \\
\hline LKA & & & & & & 1.00 & 0.67 & 0.35 & 0.67 & 0.55 \\
\hline GEO & & & & & & & 1.00 & 0.63 & 0.71 & 0.66 \\
\hline COL & & & & & & & & 1.00 & 0.74 & 0.67 \\
\hline ARM & & & & & & & & & 1.00 & 0.52 \\
\hline MKD & & & & & & & & & & 1.00 \\
\hline
\end{tabular}


Table 7. Pair-wise Spearman Correlations of Skill Intensity Indexes at the 3-Digit level, by Skill Dimension. Countries are sorted by Region groups.

\begin{tabular}{|c|c|c|c|c|c|c|c|c|c|c|}
\hline & BOL & COL & ARM & GEO & $\begin{array}{r}\text { MKD } \\
\text { Ana }\end{array}$ & $\begin{array}{l}\text { GHA } \\
\text { tical }\end{array}$ & KEN & LAO & LKA & VNM \\
\hline BOL & 1.00 & 0.85 & 0.77 & 0.83 & 0.86 & 0.76 & 0.80 & 0.83 & 0.82 & 0.86 \\
\hline COL & & 1.00 & 0.84 & 0.81 & 0.76 & 0.81 & 0.81 & 0.68 & 0.74 & 0.78 \\
\hline ARM & & & 1.00 & 0.95 & 0.82 & 0.81 & 0.91 & 0.87 & 0.86 & 0.86 \\
\hline GEO & & & & 1.00 & 0.80 & 0.72 & 0.78 & 0.90 & 0.74 & 0.89 \\
\hline MKD & & & & & 1.00 & 0.80 & 0.85 & 0.70 & 0.82 & 0.89 \\
\hline GHA & & & & & & 1.00 & 0.92 & 0.66 & 0.69 & 0.83 \\
\hline KEN & & & & & & & 1.00 & 0.87 & 0.87 & 0.86 \\
\hline LAO & & & & & & & & 1.00 & 0.77 & 0.82 \\
\hline LKA & & & & & & & & & 1.00 & 0.77 \\
\hline VNM & & & & & & & & & & 1.00 \\
\hline & \multicolumn{10}{|c|}{ Interpersonal } \\
\hline BOL & 1.00 & 0.82 & 0.71 & 0.78 & 0.79 & 0.62 & 0.72 & 0.84 & 0.82 & 0.81 \\
\hline COL & & 1.00 & 0.89 & 0.83 & 0.68 & 0.72 & 0.66 & 0.76 & 0.90 & 0.82 \\
\hline ARM & & & 1.00 & 0.77 & 0.66 & 0.62 & 0.53 & 0.88 & 0.48 & 0.75 \\
\hline GEO & & & & 1.00 & 0.82 & 0.70 & 0.81 & 0.93 & 0.71 & 0.89 \\
\hline MKD & & & & & 1.00 & 0.67 & 0.77 & 0.76 & 0.89 & 0.77 \\
\hline GHA & & & & & & 1.00 & 0.63 & 0.66 & 0.64 & 0.71 \\
\hline KEN & & & & & & & 1.00 & 0.73 & 0.88 & 0.78 \\
\hline LAO & & & & & & & & 1.00 & 0.84 & 0.81 \\
\hline LKA & & & & & & & & & 1.00 & 0.89 \\
\hline VNM & & & & & & & & & & 1.00 \\
\hline BOL & 1.00 & 0.65 & 0.70 & 0.69 & 0.62 & 0.70 & 0.42 & 0.67 & 0.79 & 0.50 \\
\hline COL & & 1.00 & 0.74 & 0.63 & 0.67 & 0.73 & 0.70 & 0.73 & 0.35 & 0.72 \\
\hline ARM & & & 1.00 & 0.71 & 0.52 & 0.76 & 0.61 & 0.70 & 0.67 & 0.43 \\
\hline GEO & & & & 1.00 & 0.66 & 0.52 & 0.41 & 0.62 & 0.67 & 0.52 \\
\hline MKD & & & & & 1.00 & 0.46 & 0.54 & 0.80 & 0.55 & 0.53 \\
\hline GHA & & & & & & 1.00 & 0.66 & 0.62 & 0.41 & 0.76 \\
\hline KEN & & & & & & & 1.00 & 0.70 & 0.26 & 0.53 \\
\hline LAO & & & & & & & & 1.00 & 0.74 & 0.49 \\
\hline LKA & & & & & & & & & 1.00 & -0.07 \\
\hline VNM & & & & & & & & & & 1.00 \\
\hline
\end{tabular}

Table 8. Number of occupations used for estimation of pair-wise Spearman correlations

\begin{tabular}{l|l|lll|ll|lll} 
GHA \\
KEN
\end{tabular}




\section{ARM \\ MKD}

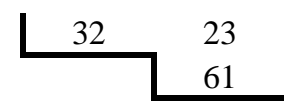

\section{c. Comparison to the U.S. skill content of occupations}

We now compare the skill content of occupations estimated for the STEP countries to the one estimated with US data (PDII). We compute the Spearman correlations between every single STEP country and the U.S. for each skill group (see Table 9). Our estimates show that the correlation is highest for the analytical skill (ranging between 0.53 and 0.74 ), whereas it is much lower for the other skill groups (never above 0.61 and in most of the cases between 0.1 and 0.3). Overall, the average Spearman correlation ranges between 0.28 and 0.58 . These results suggest that using the appropriate skill content measures, depending on the country we want to study, is of great importance. In particular, using the U.S. skill content in order to study economic dynamics in developing countries might lead to misleading predictions.

Table 9. Spearman Correlation of Skill Intensity Indexes of STEP countries with respect to the US (PDII) at the 3-Digit level, by Skill Dimension.

\begin{tabular}{|c|c|c|c|c|}
\hline Country & Analytical & Interpersonal & Routine & Average \\
\hline Armenia & 0.7266 & 0.4025 & 0.2217 & 0.45 \\
\hline Bolivia & 0.6762 & 0.3571 & 0.2738 & 0.44 \\
\hline Colombia & 0.719 & 0.243 & 0.3232 & 0.43 \\
\hline Georgia & 0.7417 & 0.3875 & 0.6174 & 0.58 \\
\hline Ghana & 0.6284 & 0.1902 & 0.0732 & 0.30 \\
\hline Kenya & 0.529 & 0.1271 & 0.1785 & 0.28 \\
\hline Laos & 0.667 & 0.3583 & 0.1245 & 0.38 \\
\hline Sri Lanka & 0.7036 & 0.4719 & -0.0286 & 0.38 \\
\hline Macedonia & 0.585 & 0.2934 & 0.3704 & 0.42 \\
\hline Vietnam & 0.6259 & 0.3944 & 0.1153 & 0.38 \\
\hline
\end{tabular}

Having found large differences in the skill content of occupations across countries, we now investigate how these differences behave along the development process. Indeed, if these differences are due to different technologies being used in different countries, one could expect that they shrink as countries grow richer. The process of development is characterized by a process of technological progress that could potentially make developing economies look more and more alike developed ones if they are catching up. We test this by plotting the Spearman correlation against the level of development (as measured by log GDP per capita in 2010). Figure 4 shows that the average Spearman correlation with the U.S. is indeed increasing over development. This lends some support to the hypothesis of skills convergence of economies. Repeating the same exercise for the 3 disaggregate indexes (Figure 4) reveals that the positive overall correlation is observed in all skill dimensions.

This is seemingly in contradiction with the conclusions of last section, where we found that the Spearman correlations are not higher within income groups. However, notice that in this exercise we are imposing fewer restrictions on the final number of occupations used in our calculations, due to the fact that the US classifications covers all occupations. Hence, our analysis here is inconclusive. 
Figure 4. Scatter plots of Spearman Correlation with US ranking (O*Net) and Log GDP per capita, by Skill Dimension.

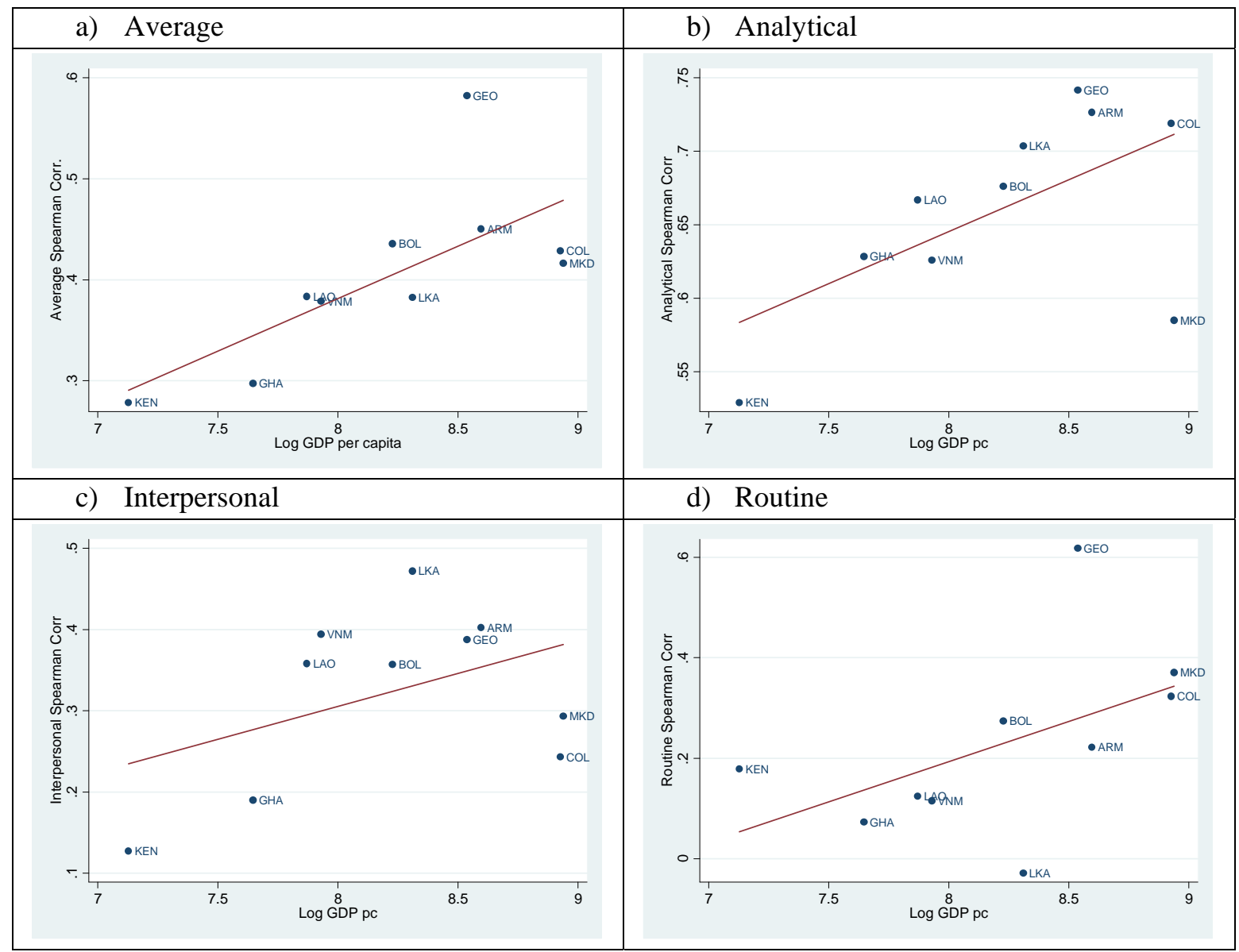

\section{d. Skills Specialization and Development}

This section asks whether countries follow a similar path of specialization as they become richer. That is, whether the skills mix used by workers tends to converge to become more (or less) alike. We focus on two distinct margins:

1) "Concentration of skills" across occupations: This margin seeks to answer the question of whether jobs are more skill-intensive across different levels of development. In other words, do jobs rely on more unbalanced combination of skills as countries develop? We focus on the evolution of the variance of occupation-specific skill indexes ${ }^{10}$ across the different countries available.

2) "Specialization of workers" within occupations: This margin aimes to identify whether workers become more heterogeous in their skill mix within occupations as countries develop. For this, we fix the job categories in our data to study the evolution of within-occupation heterogeneity.

\footnotetext{
${ }^{10}$ We perform this exercise before Step 4 of our methodology. Otherwise, the within-country variance of skill intensity of occupations would be normalized to 1 by construction.
} 
The results for the analysis on concentration of skills are presented in Figure 5. They suggest that the standard deviation of skill intensity across occupations is decreasing with the level of GDP per capita. Richer countries tend to have occupations that rely on a more homogeneous mix of skills. The trend appears to be quite strong: in the case of the 1-digit aggregation, the standard deviation decreases from a level of 3.5 and 1.6 (respectively, for the analytical and interpersonal score) to a level of less than 2.5 and 1.2. The trend in the routine score is not apparent at the 1-digit aggregation. Results are robust to finer aggregations (2-digit and 3-digit). The trends for analytical and interpersonal scores appear to be very similar (both in absolute and relative terms); moreover, the same negative trend is now also apparent for the routine-manual score.

Figure 5. Standard Deviations of different skill scores and GDP per capita by different levels of aggregation
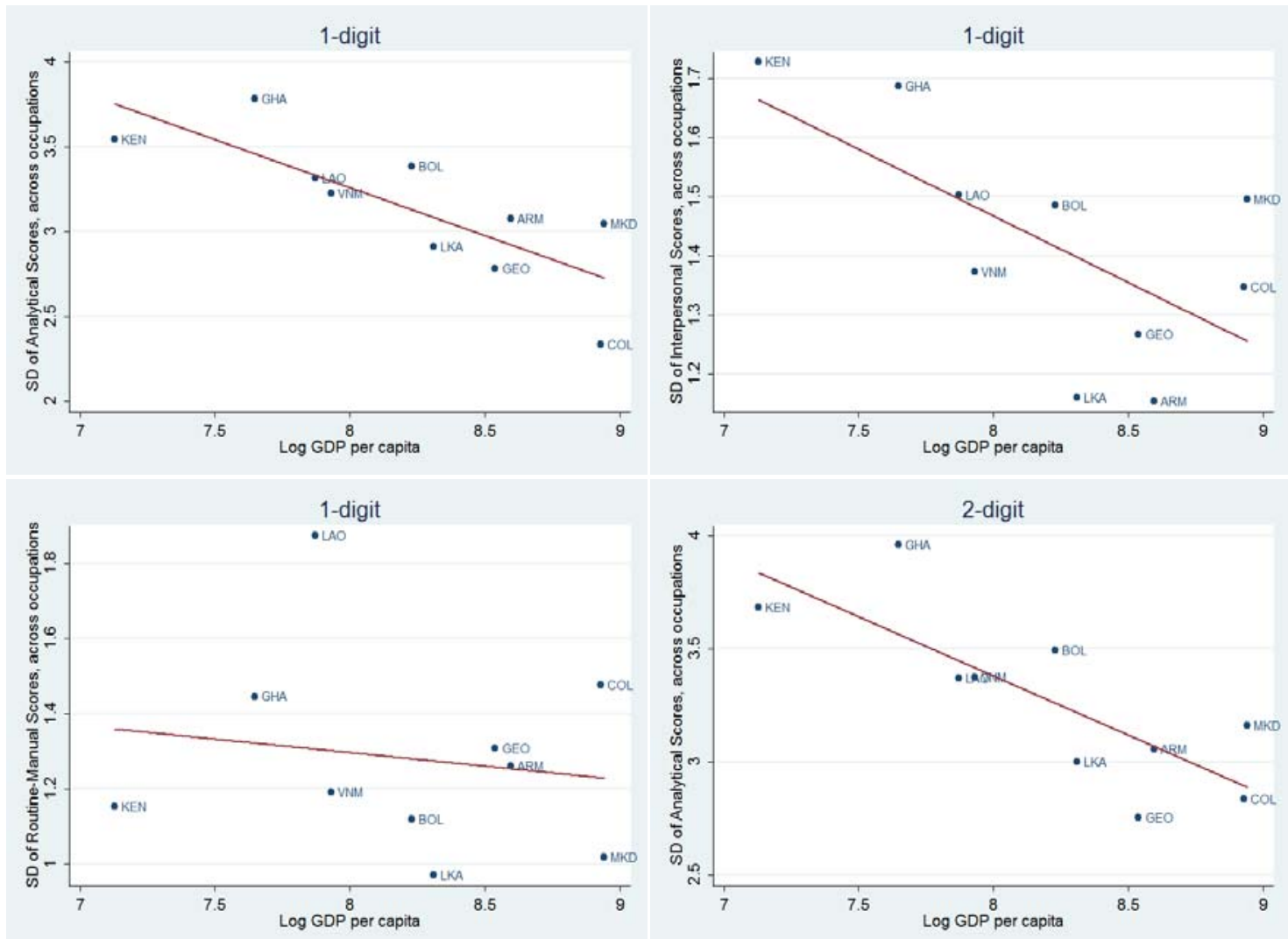

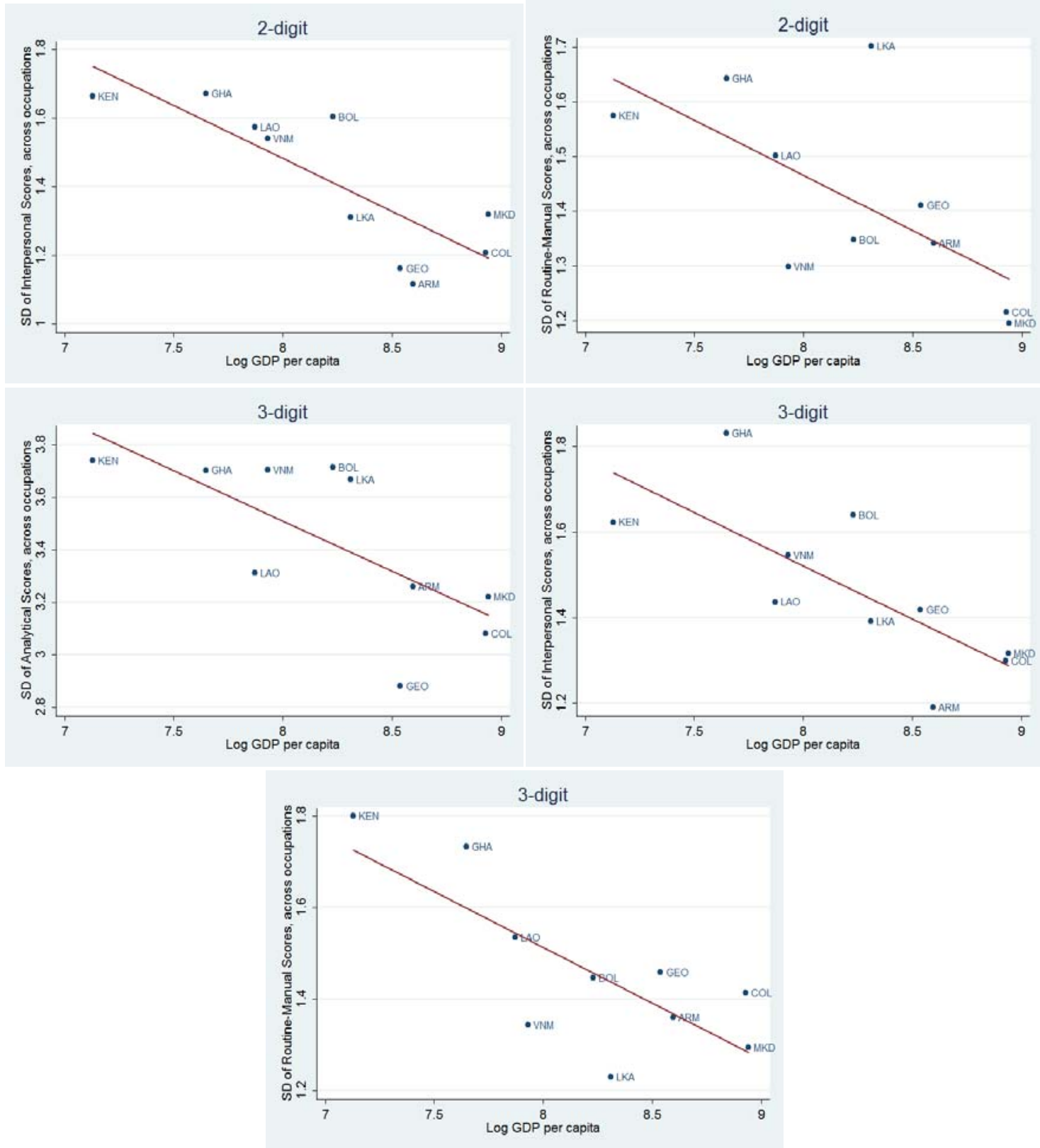

Turning to within-occupation heterogeneity, we find only a weakly decreasing standard deviation as GDP per capita increases. In the majority of cases the slope is (weakly) negative, in other cases it is essentially zero and in a few cases it is positive. We report the graphs of this exercise at the 1-digit level ${ }^{11}$ in the Annex. We interpret this result as a sign that there is still significant heterogeneity in the nature of the tasks that workers perform, even within occupations (for instance, due to the intrinsic differences between formal and informal firms). However, this is also a reflection of the limitations of the data, as sample sizes are too small for some occupations within countries.

${ }^{11}$ Due to the limited sample, it is not possible to perform it at a finer aggregation. 
In sum, we find that the variance of skill intensity across occupations decreases with development, whereas we only find a weak trend in the variance of skill intensity within occupations.

\section{Conclusions}

This paper seeks to elucidate the question of whether the skill content of occupations in low and middle income countries resembles that of the United States, as several papers have assumed in the past, for lack of proper data.

To answer the question, we use the World Bank's STEP survey data for 10 countries to construct, for the first time, a measure of skill content of occupations using worker-level data (as opposed to at the occupation level). This enables us to better understand the distribution of the skill content of occupations across countries and the skills used by workers in a given occupations. We use a similar methodology to that used by Handel (2010) and Autor and Handel (2013) for the United States.

The paper compares the distribution of skill intensities of occupations across developing countries and with the US. It then looks at whether richer countries display lower heterogeneity in the skills mix used, either between or within occupations. We find that occupations display similar patterns of skill content across countries. Indeed, occupations, such as managers and professionals - mostly "white-collar", tend to have higher analytical and interpersonal skill content, and lower routine/manual skill content, whereas occupations such as machine operators or clerical workers-mostly "blue-collar" but not only, tend to have a higher routine/manual skill content. This is consistent for most countries in our sample.

Importantly, the frequency of the tasks intensive in analytical and interpersonal skills tend to increase with a country's income level, and the occupation-level distribution of analytical and interpersonal skill content is highly correlated across countries, as is (to a lesser degree) the distribution of routine/manual skill content. However, correlations do not increase among countries of similar incomes (they are high for the entire sample).

On the other hand, these correlations are significantly higher between middle- and low-income countries than between them and the US. As a result, assuming countries have the same skill intensity levels as the US, as is done in much of the literature to date, does not necessarily reflect the actual skill intensity of occupations in developing countries.

Another important result is that the heterogeneity of skill content across occupations (within countries) tends to decrease with the level of income, while heterogeneity within occupations decreases only weakly (or not at all) with the level of income. Taken together, these results suggest that as countries develop, they tend to adopt and use certain skills more widely (presumably analytical or interpersonal) across occupations (and to come extent within occupations). This may also suggest some degree of specialization in certain occupations as countries develop. Unfortunately, we cannot confirm these hypotheses as the country level samples are too limited to enable us to perform sufficient robustness checks.

More generally, we find that while the STEP survey data is a tremendous first step in sheding light on these important questions, features of the data, in particular sample sizes and the extent of the task questionnaire module, limit our ability to characterize more fully the skill content of occupations, and to be able to compare a significant number of occupations across the 10 countries. This limitation calls for improving future data collection by 1) increasing the number of questions capturing the use of skills at work, and 2) 
mainstreaming these questions into nationally representative Labor Force Surveys, so that sample sizes can be significantly larger than the STEP survey samples. 


\section{Annex}

\section{Table A Specifications used in the literature}

\begin{tabular}{|c|c|c|c|c|}
\hline Author & Broad Category & Category & What measures & Task \\
\hline \multirow{5}{*}{ ALM (2003) } & \multirow[b]{2}{*}{ Non-routine cognitive } & Non-routine interactive & $\begin{array}{l}\text { Interactive, communication and } \\
\text { managerial skills }\end{array}$ & Direction, Direction Control and Planning \\
\hline & & Non-routine analytic & \multirow{2}{*}{$\begin{array}{l}\text { Analytic reasoning } \\
\text { Adaptability to situations requiring the } \\
\text { precise attainment of set limits, tolerances } \\
\text { or standards }\end{array}$} & GED Math \\
\hline & Routine cognitive & Routine cognitive & & Set Limits, Tolerances or Standards \\
\hline & Routine manual & Routine manual & $\begin{array}{l}\text { Ability to move fingers and manipulate } \\
\text { small objects with fingers rapidly or } \\
\text { accurately }\end{array}$ & Finger Dexterity \\
\hline & Non-routine manual & Non-routine manual & $\begin{array}{l}\text { ability to move the hand and foot } \\
\text { coordinately with each other in } \\
\text { accordance with visual stimuli }\end{array}$ & Eye-Hand-Foot Coordination \\
\hline \multirow{10}{*}{$\begin{array}{l}\text { Autor \& Handel (2013) - } \\
\text { PDII }\end{array}$} & \multirow{4}{*}{ Abstract } & \multirow{4}{*}{ Abstract } & \multirow[t]{4}{*}{$\begin{array}{l}\text { Problem solving } \begin{array}{c}\text { and } \\
\text { creative, }\end{array} \\
\text { organizational and managerial tasks. }\end{array}$} & Length of longest document typically read \\
\hline & & & & $\begin{array}{l}\text { frequency of mathematics tasks involving High School or } \\
\text { Higher Math's }\end{array}$ \\
\hline & & & & $\begin{array}{l}\text { Frequency of Problem Solving tasks requiring at least } 30 \\
\text { minutes }\end{array}$ \\
\hline & & & & $\begin{array}{l}\text { Proportion of workday managing or supervising other } \\
\text { workers }\end{array}$ \\
\hline & \multirow{4}{*}{ Routine } & \multirow{4}{*}{ Routine } & \multirow[t]{4}{*}{$\begin{array}{l}\text { Routine, codifiable cognitive and manual } \\
\text { tasks that follow explicit procedures }\end{array}$} & $\begin{array}{l}\text { Proportion of the day spent performing short, repetitive } \\
\text { tasks }\end{array}$ \\
\hline & & & & Absence of interactions with costumers \\
\hline & & & & Absence of interactions with suppliers \\
\hline & & & & Absence of interactions with students or trainees \\
\hline & Manual & Manual & $\begin{array}{l}\text { Non-routine manual job tasks that require } \\
\text { physical adaptability }\end{array}$ & Proportion of workday spent performing physical tasks \\
\hline & Abstract & Analytical & & Analyzing data/information \\
\hline
\end{tabular}




\begin{tabular}{|c|c|c|c|}
\hline \multirow{15}{*}{$\begin{array}{l}\text { Autor \& Handel (2013) - } \\
\text { O*Net }\end{array}$} & & & Thinking creatively \\
\hline & & & interpreting information for others \\
\hline & & \multirow{3}{*}{ Interpersonal } & Establishing and maintaining personal relationships \\
\hline & & & Guiding, directing and motivating subordinates \\
\hline & & & Coaching and developing others \\
\hline & \multirow{6}{*}{ Routine } & \multirow{3}{*}{ Cognitive } & Importance of repeating the same task \\
\hline & & & Importance of being exact and accurate \\
\hline & & & Structured versus unstructured work \\
\hline & & \multirow{3}{*}{ Manual } & Controlling machines and processes \\
\hline & & & Keeping a pace set by machinery or equipment \\
\hline & & & Time spent making repetitive motions \\
\hline & \multirow{4}{*}{ Non-routine } & \multirow{4}{*}{ Manual } & Operating vehicles, mechanized devices or equipment \\
\hline & & & $\begin{array}{l}\text { Time spent using hands to handle, control, or feel objects, } \\
\text { tools or controls }\end{array}$ \\
\hline & & & Manual dexterity \\
\hline & & & Spatial orientation \\
\hline \multirow{16}{*}{ Handel (2010) } & \multirow{9}{*}{ Cognitive Skills } & \multirow{3}{*}{ Academic } & Reading length and type \\
\hline & & & Writing \\
\hline & & & Math \\
\hline & & Problem solving & $\begin{array}{l}\text { Frequency to solve easy problems (little time and } \\
\text { assistance from others) }\end{array}$ \\
\hline & & & Frequency to solve hard problems \\
\hline & & Required education & Job required education \\
\hline & & & Experience \\
\hline & & Specific Human Capital & Learning time \\
\hline & & & Training \\
\hline & & & Give Information \\
\hline & & & Counsel people \\
\hline & & & Deal with tense situations \\
\hline & $\begin{array}{l}\text { physical } \\
\text { phersol and }\end{array}$ & Interpersonal & Teach or train \\
\hline & & & Interview People \\
\hline & & & Presentations \\
\hline & & & Public Contact \\
\hline
\end{tabular}




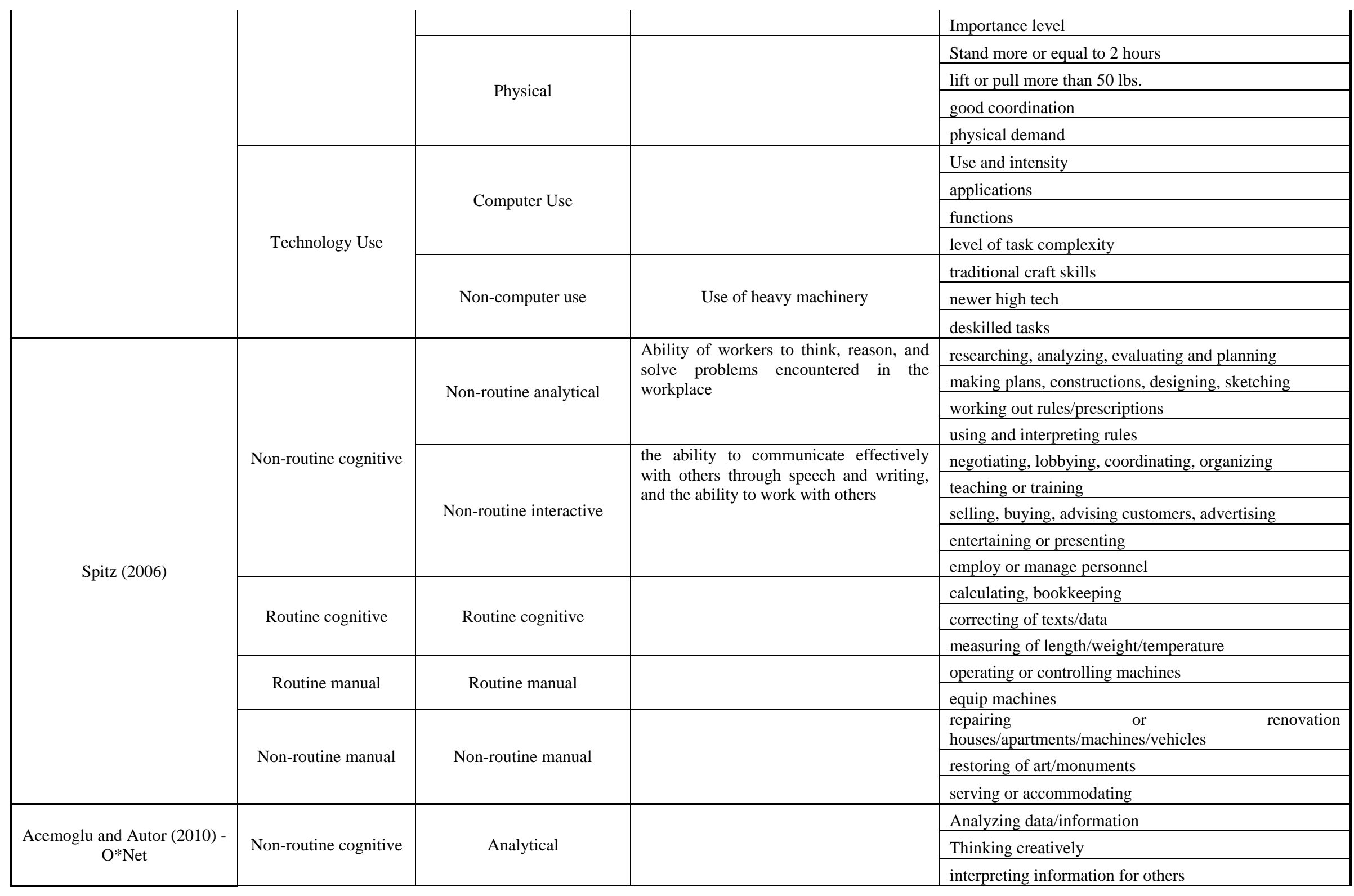




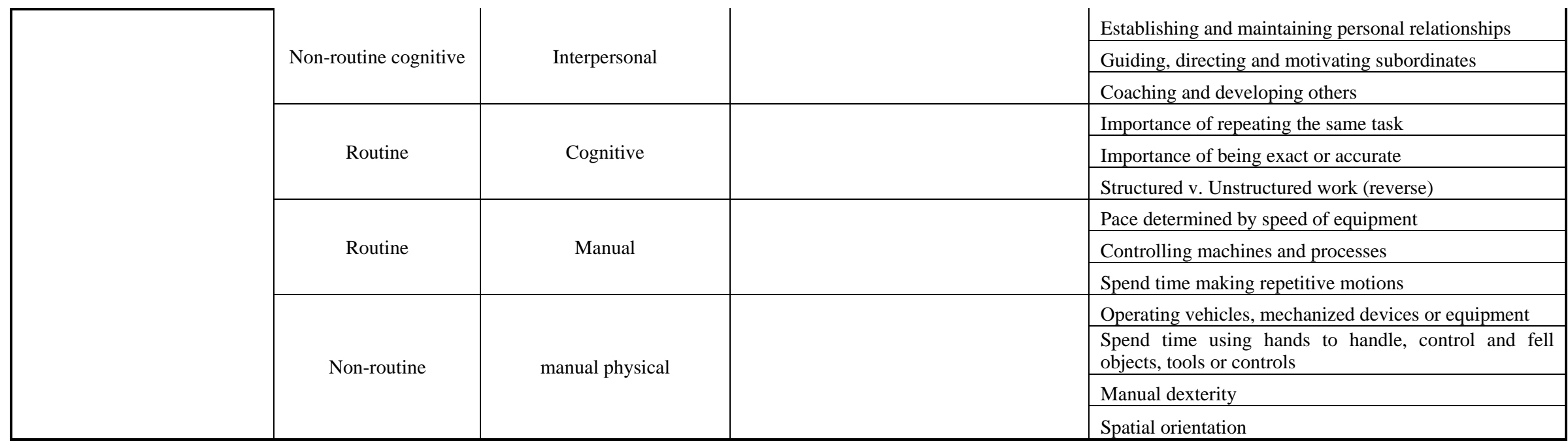


Figure A. Radar Graph of Skill Intensity Index of Occupations at the 1-digit level, by Country. The indexes are standardized measures with respect to the occupation that scores the average index (for details, refer to the metholodogy explained in Section 3B). Scores represent the distance -expressed in units of a standard normal- in the skill-intensity occupational distribution from an hypothetical "average occupation". Source: authors' elaboration on STEP data (country abbreviations: ARM=Armentia; BOL=Bolivia; $\mathrm{COL}=\mathrm{Colombia;} \mathrm{GEO}=\mathrm{Georgia}$; GHA=Ghana; KEN=Kenya; LAO=Laos; LKA=Sri Lanka; MKD=Macedonia; VNM=Vietnam). 


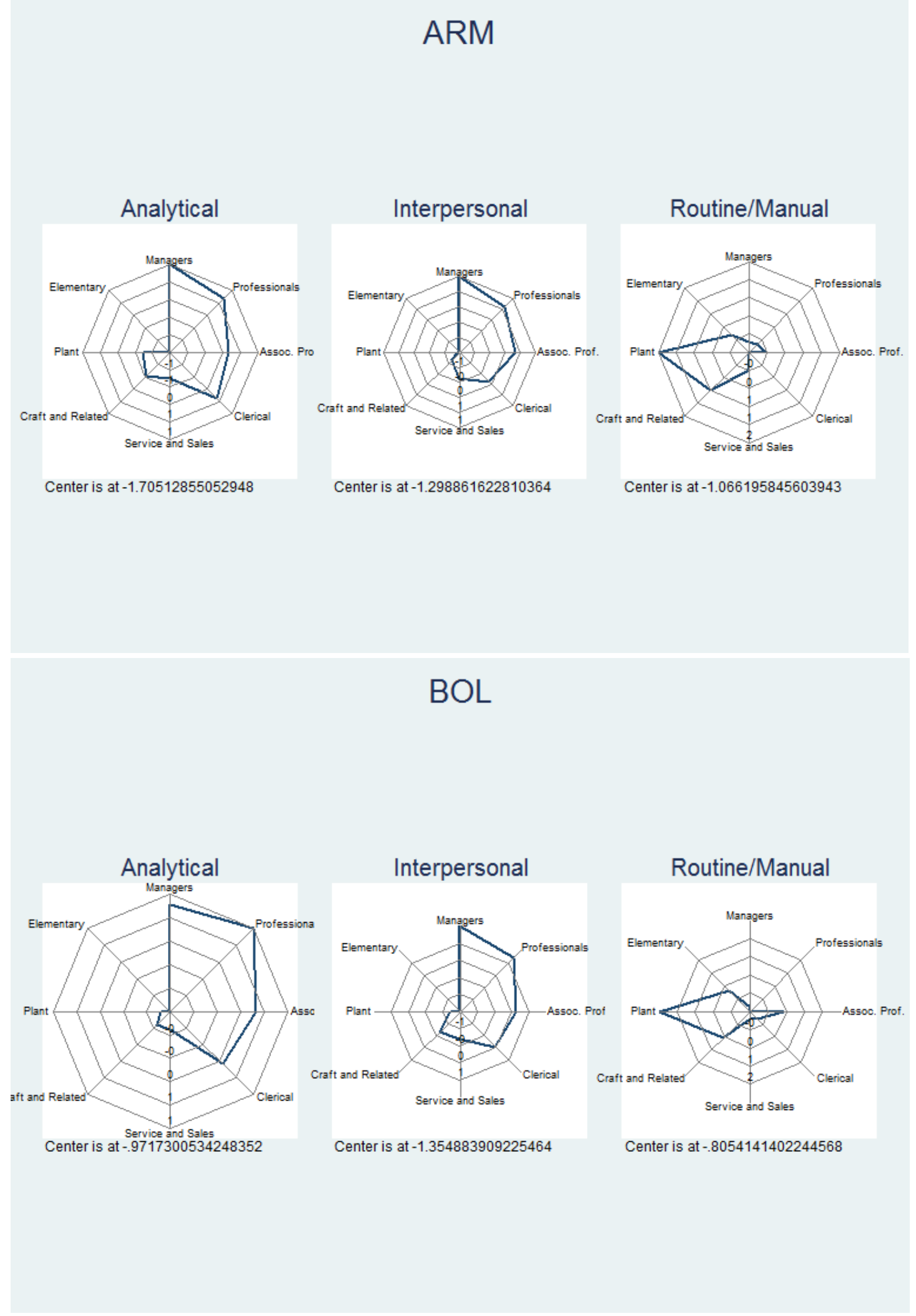




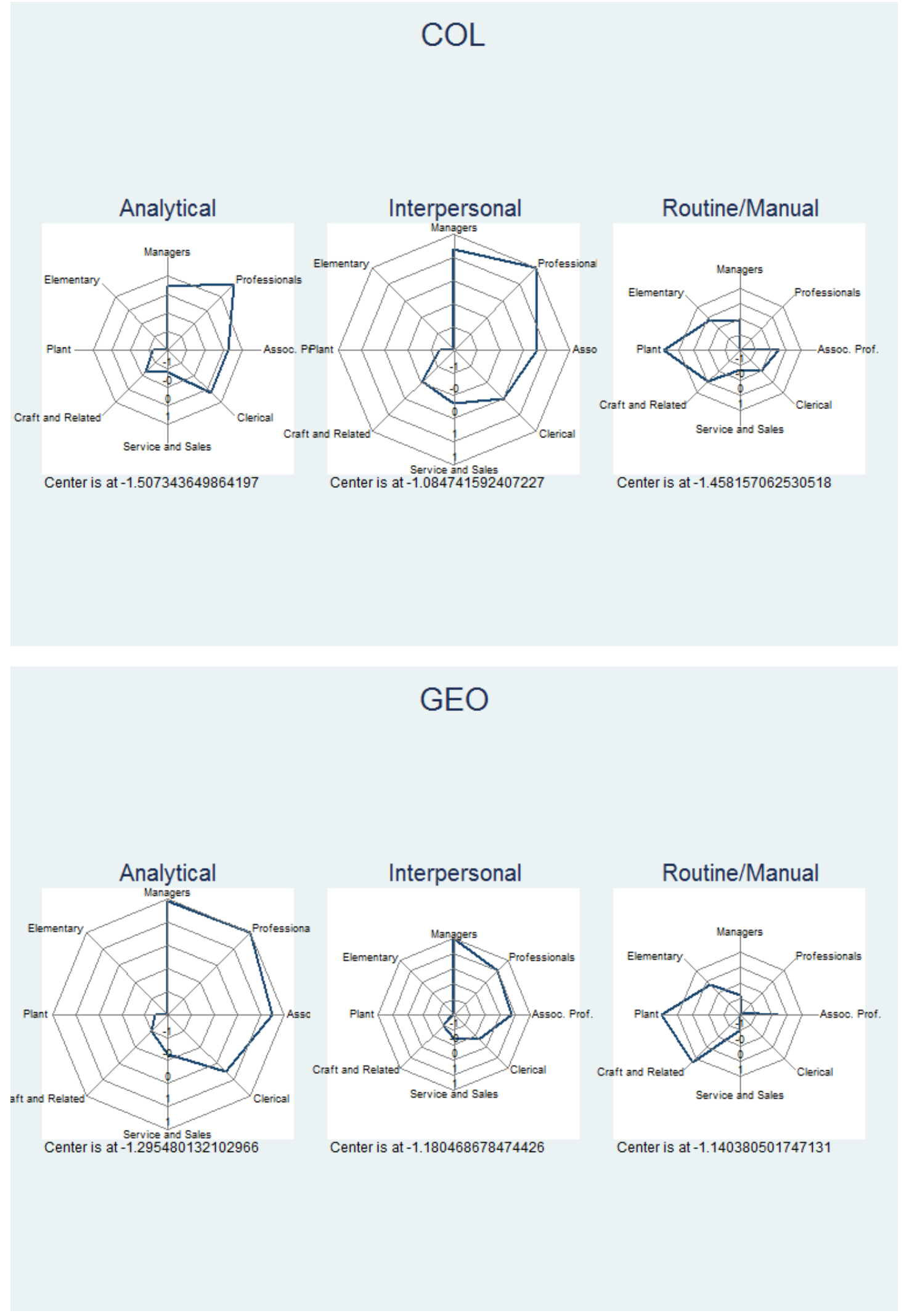




\section{GHA}
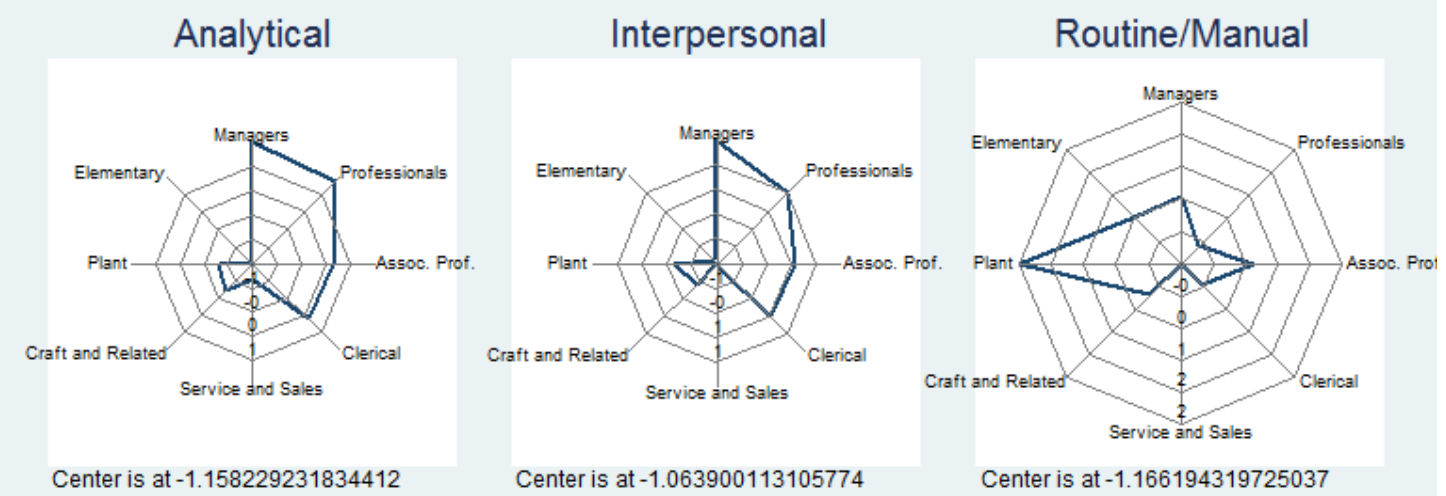

KEN

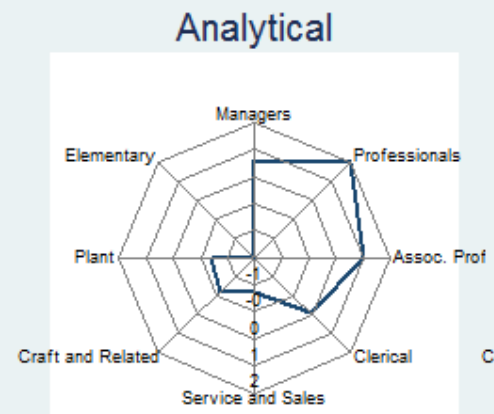

Center is at -1.303707838058472

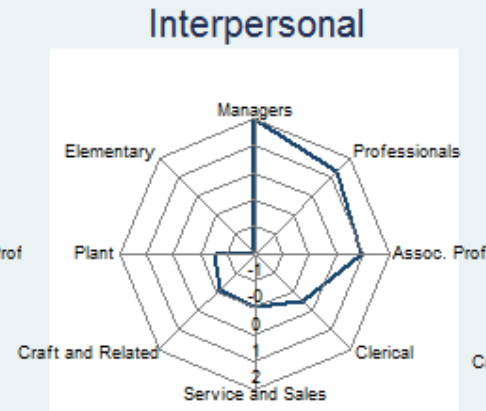

Center is at -1.382788777351379
Routine/Manual

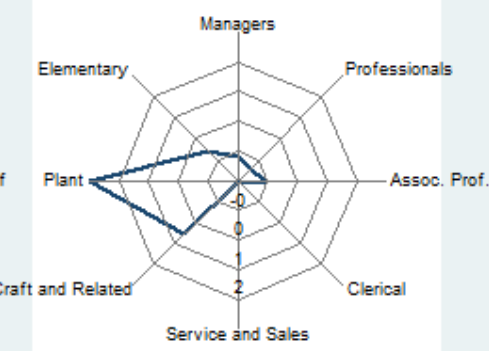

Center is at -.8333760499954224 


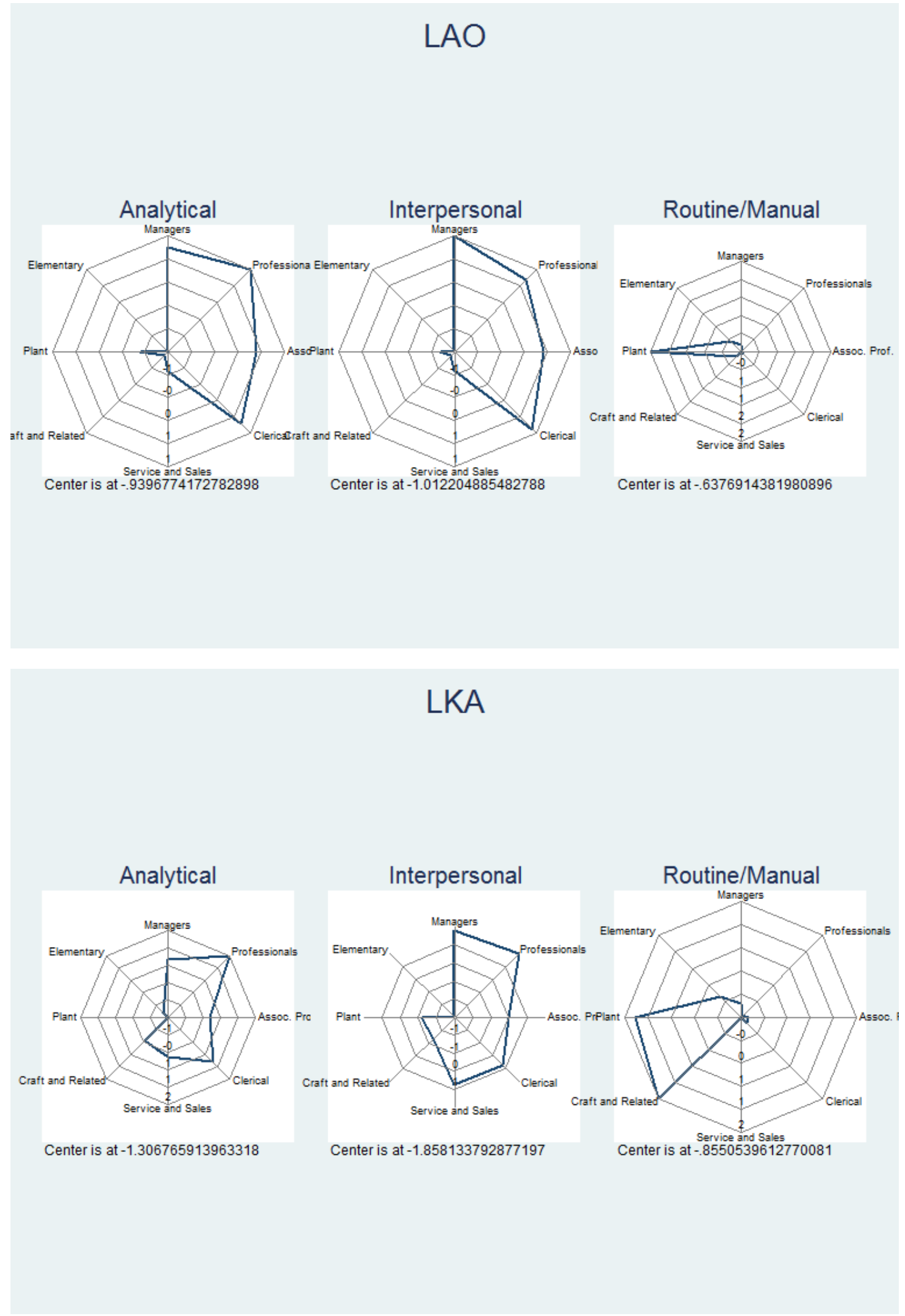




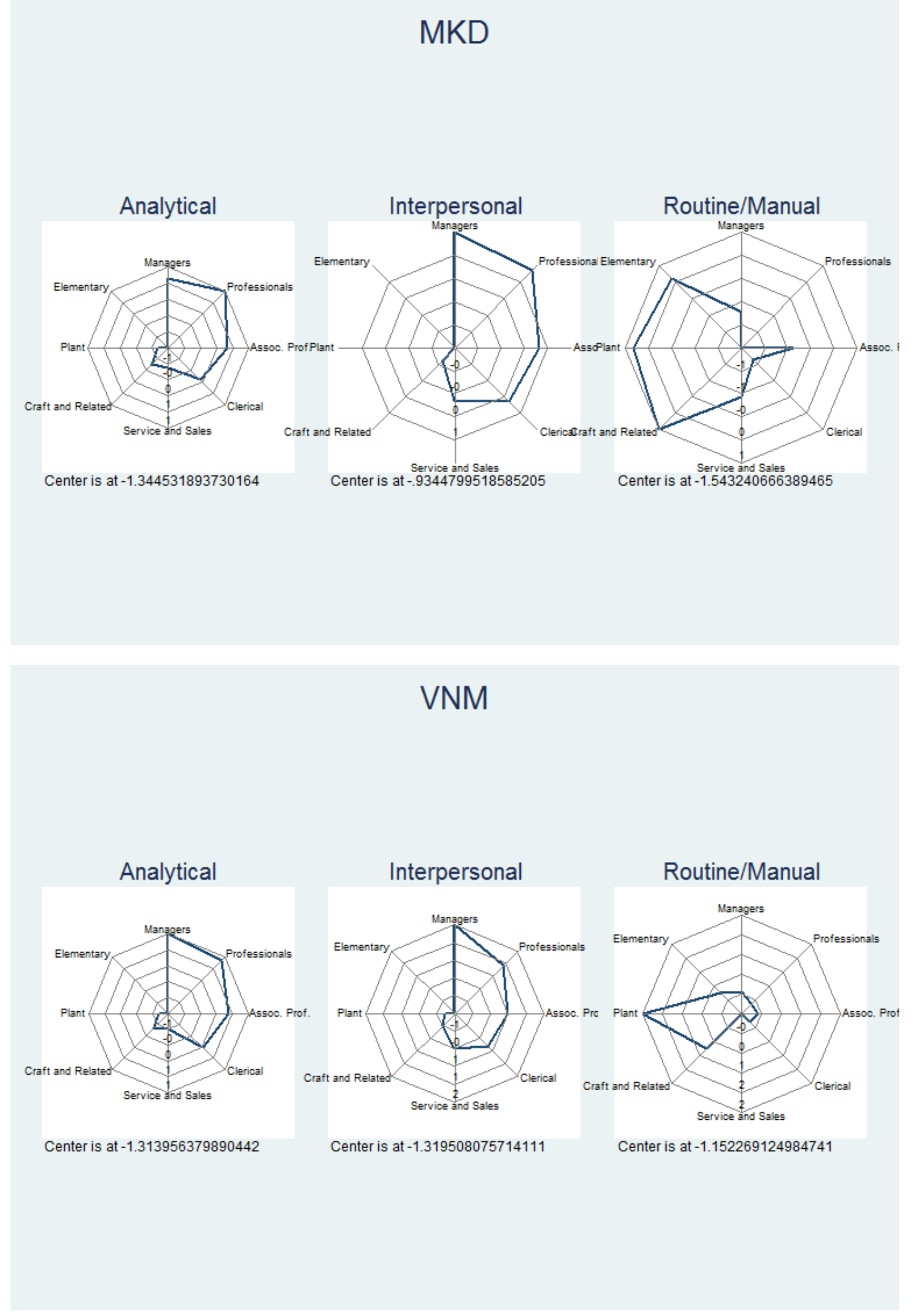




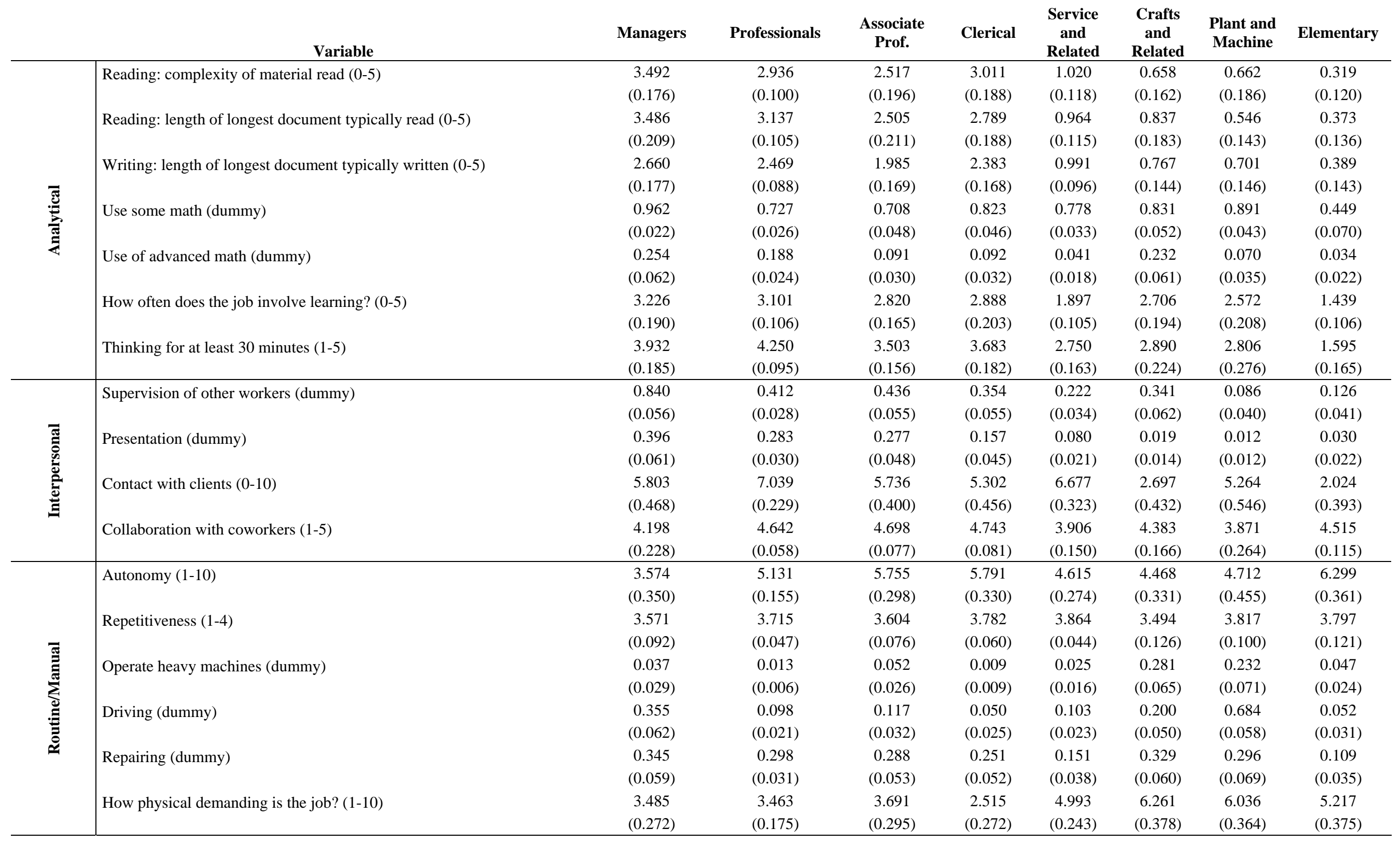


Sample Mean and SD of Tasks Variables, by Occupation (Bolivia).

\begin{tabular}{|c|c|c|c|c|c|c|c|c|c|}
\hline & Variable & Managers & Professionals & $\begin{array}{c}\text { Associate } \\
\text { Prof. }\end{array}$ & Clerical & $\begin{array}{c}\text { Service } \\
\text { and } \\
\text { Related }\end{array}$ & $\begin{array}{c}\text { Crafts } \\
\text { and } \\
\text { Related }\end{array}$ & $\begin{array}{l}\text { Plant and } \\
\text { Machine }\end{array}$ & Elementary \\
\hline \multirow{14}{*}{ 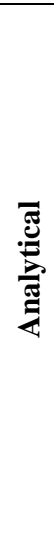 } & Reading: complexity of material read (0-5) & 3.290 & 3.285 & 3.028 & 3.225 & 1.052 & 0.694 & 0.754 & 0.542 \\
\hline & & $(0.199)$ & $(0.111)$ & $(0.166)$ & $(0.159)$ & $(0.078)$ & $(0.102)$ & $(0.179)$ & $(0.120)$ \\
\hline & Reading: length of longest document typically read (0-5) & 3.379 & 4.141 & 3.490 & 2.967 & 1.119 & 0.829 & 0.803 & 0.611 \\
\hline & & $(0.264)$ & $(0.107)$ & $(0.175)$ & $(0.191)$ & $(0.083)$ & $(0.117)$ & $(0.178)$ & $(0.108)$ \\
\hline & Writing: length of longest document typically written $(0-5)$ & 2.720 & 3.385 & 2.105 & 1.925 & 0.995 & 0.635 & 0.618 & 0.462 \\
\hline & & $(0.174)$ & $(0.138)$ & $(0.152)$ & $(0.117)$ & $(0.054)$ & $(0.072)$ & $(0.081)$ & $(0.065)$ \\
\hline & Use some math (dummy) & 1.000 & 0.883 & 0.883 & 0.927 & 0.939 & 0.963 & 0.949 & 0.784 \\
\hline & & $(0.000)$ & $(0.031)$ & $(0.035)$ & $(0.031)$ & $(0.017)$ & $(0.014)$ & $(0.025)$ & $(0.001)$ \\
\hline & Use of advanced math (dummy) & 0.344 & 0.331 & 0.239 & 0.131 & 0.035 & 0.073 & 0.028 & 0.043 \\
\hline & & $(0.067)$ & $(0.042)$ & $(0.044)$ & $(0.043)$ & $(0.011)$ & $(0.027)$ & $(0.013)$ & $(0.024)$ \\
\hline & How often does the job involve learning? (0-5) & 4.022 & 3.996 & 3.311 & 3.172 & 2.444 & 2.602 & 2.625 & 1.948 \\
\hline & & $(0.161)$ & $(0.117)$ & $(0.179)$ & $(0.216)$ & $(0.094)$ & $(0.105)$ & $(0.178)$ & $(0.124)$ \\
\hline & Thinking for at least 30 minutes (1-5) & 3.859 & 4.133 & 3.757 & 3.594 & 2.942 & 3.200 & 2.771 & 2.684 \\
\hline & & $(0.172)$ & $(0.118)$ & $(0.162)$ & $(0.220)$ & $(0.112)$ & $(0.130)$ & $(0.242)$ & $(0.162)$ \\
\hline \multirow{8}{*}{ 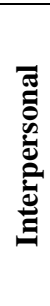 } & Supervision of other workers (dummy) & 0.854 & 0.438 & 0.538 & 0.516 & 0.258 & 0.319 & 0.164 & 0.092 \\
\hline & & $(0.045)$ & $(0.046)$ & $(0.051)$ & $(0.074)$ & $(0.027)$ & $(0.038)$ & $(0.053)$ & $(0.022)$ \\
\hline & Presentation (dummy) & 0.600 & 0.644 & 0.333 & 0.336 & 0.071 & 0.078 & 0.054 & 0.016 \\
\hline & & $(0.074)$ & $(0.041)$ & $(0.052)$ & $(0.073)$ & $(0.017)$ & $(0.020)$ & $(0.024)$ & $(0.012)$ \\
\hline & Contact with clients $(0-10)$ & 7.684 & 7.750 & 6.622 & 6.338 & 5.562 & 4.255 & 4.316 & 2.446 \\
\hline & & $(0.354)$ & $(0.252)$ & $(0.325)$ & $(0.466)$ & $(0.185)$ & $(0.299)$ & $(0.462)$ & $(0.265)$ \\
\hline & Collaboration with coworkers (1-5) & - & - & - & - & - & - & - & - \\
\hline & & - & - & - & - & - & - & - & - \\
\hline \multirow{12}{*}{ 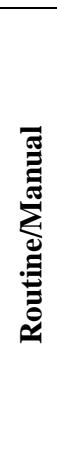 } & Autonomy (1-10) & 2.916 & 3.586 & 4.182 & 4.929 & 3.116 & 3.253 & 3.330 & 4.274 \\
\hline & & $(0.309)$ & $(0.189)$ & $(0.278)$ & $(0.388)$ & $(0.120)$ & $(0.177)$ & $(0.212)$ & $(0.209)$ \\
\hline & Repetitiveness (1-4) & 3.012 & 2.956 & 3.193 & 3.329 & 3.379 & 3.362 & 3.486 & 3.383 \\
\hline & & $(0.207)$ & $(0.093)$ & $(0.091)$ & $(0.137)$ & $(0.067)$ & $(0.089)$ & $(0.135)$ & $(0.106)$ \\
\hline & Operate heavy machines (dummy) & 0.140 & 0.022 & 0.060 & 0.005 & 0.007 & 0.196 & 0.288 & 0.089 \\
\hline & & $(0.047)$ & $(0.010)$ & $(0.024)$ & $(0.006)$ & $(0.004)$ & $(0.032)$ & $(0.059)$ & $(0.027)$ \\
\hline & Driving (dummy) & 0.217 & 0.091 & 0.148 & 0.053 & 0.073 & 0.137 & 0.744 & 0.098 \\
\hline & & $(0.053)$ & $(0.026)$ & $(0.035)$ & $(0.021)$ & $(0.015)$ & $(0.031)$ & $(0.053)$ & $(0.037)$ \\
\hline & Repairing (dummy) & 0.091 & 0.110 & 0.207 & 0.039 & 0.019 & 0.033 & 0.121 & 0.005 \\
\hline & & $(0.035)$ & $(0.029)$ & $(0.046)$ & $(0.022)$ & $(0.008)$ & $(0.013)$ & $(0.056)$ & $(0.005)$ \\
\hline & How physical demanding is the job? $(1-10)$ & 4.427 & 4.048 & 4.285 & 4.174 & 5.385 & 5.461 & 5.304 & 5.352 \\
\hline & & $(0.421)$ & $(0.196)$ & $(0.248)$ & $(0.404)$ & $(0.170)$ & $(0.192)$ & $(0.257)$ & $(0.246)$ \\
\hline
\end{tabular}

* Standard Errors in parentheses 
Sample Mean and SD of Tasks Variables, by Occupation (Colombia).

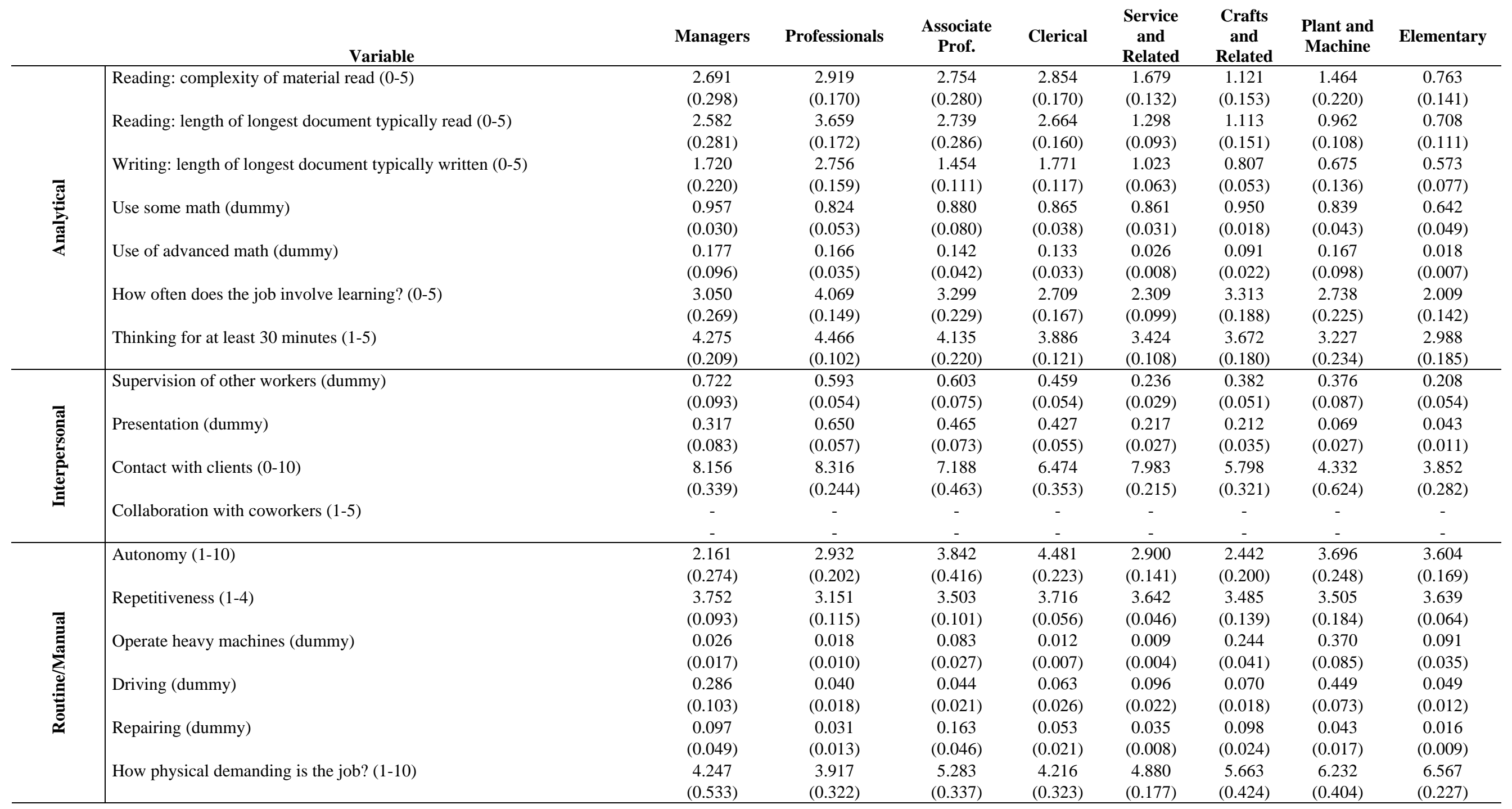




\begin{tabular}{|c|c|c|c|c|c|c|c|c|c|}
\hline & Variable & Managers & Professionals & $\begin{array}{c}\text { Associate } \\
\text { Prof. }\end{array}$ & Clerical & $\begin{array}{l}\text { Service } \\
\text { and } \\
\text { Related }\end{array}$ & $\begin{array}{c}\text { Crafts } \\
\text { and } \\
\text { Related }\end{array}$ & $\begin{array}{l}\text { Plant and } \\
\text { Machine }\end{array}$ & Elementary \\
\hline \multirow{6}{*}{ 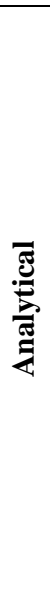 } & Reading: complexity of material read (0-5) & $\begin{array}{c}2.882 \\
(0.211)\end{array}$ & $\begin{array}{c}2.491 \\
(0.105)\end{array}$ & $\begin{array}{c}2.468 \\
(0.235)\end{array}$ & $\begin{array}{c}2.610 \\
(0.224)\end{array}$ & $\begin{array}{c}1.196 \\
(0.133)\end{array}$ & $\begin{array}{c}0.539 \\
(0.165)\end{array}$ & $\begin{array}{c}0.522 \\
(0.218)\end{array}$ & $\begin{array}{c}0.359 \\
(0.123)\end{array}$ \\
\hline & Reading: length of longest document typically read $(0-5)$ & $\begin{array}{c}2.798 \\
(0.223)\end{array}$ & $\begin{array}{c}3.320 \\
(0.125)\end{array}$ & $\begin{array}{c}2.895 \\
(0.284)\end{array}$ & $\begin{array}{c}2.983 \\
(0.255)\end{array}$ & $\begin{array}{c}1.171 \\
(0.134)\end{array}$ & $\begin{array}{c}0.504 \\
(0.157)\end{array}$ & $\begin{array}{c}0.343 \\
(0.163)\end{array}$ & $\begin{array}{c}0.373 \\
(0.137)\end{array}$ \\
\hline & Writing: length of longest document typically written (0-5) & $\begin{array}{c}1.751 \\
(0.222)\end{array}$ & $\begin{array}{c}1.946 \\
(0.110)\end{array}$ & $\begin{array}{c}1.739 \\
(0.235)\end{array}$ & $\begin{array}{c}1.181 \\
(0.190)\end{array}$ & $\begin{array}{c}0.519 \\
(0.076)\end{array}$ & $\begin{array}{c}0.346 \\
(0.085)\end{array}$ & $\begin{array}{c}0.272 \\
(0.119)\end{array}$ & $\begin{array}{c}0.229 \\
(0.109)\end{array}$ \\
\hline & Use of advanced math (dummy) & $\begin{array}{c}0.142 \\
(0.046)\end{array}$ & $\begin{array}{c}0.144 \\
(0.024)\end{array}$ & $\begin{array}{c}0.075 \\
(0.034)\end{array}$ & $\begin{array}{c}0.099 \\
(0.052)\end{array}$ & $\begin{array}{c}0.054 \\
(0.021)\end{array}$ & $\begin{array}{c}0.029 \\
(0.021)\end{array}$ & $\begin{array}{c}0.000 \\
(0.000)\end{array}$ & $\begin{array}{c}0.013 \\
(0.000)\end{array}$ \\
\hline & How often does the job involve learning? (0-5) & $\begin{array}{c}2.703 \\
(0.192)\end{array}$ & $\begin{array}{c}2.552 \\
(0.104)\end{array}$ & $\begin{array}{c}2.428 \\
(0.241)\end{array}$ & $\begin{array}{c}1.895 \\
(0.180)\end{array}$ & $\begin{array}{c}1.616 \\
(0.100)\end{array}$ & $\begin{array}{c}2.340 \\
(0.226)\end{array}$ & $\begin{array}{c}1.548 \\
(0.201)\end{array}$ & $\begin{array}{c}1.465 \\
(0.116)\end{array}$ \\
\hline & Thinking for at least 30 minutes (1-5) & $\begin{array}{c}2.904 \\
(0.185)\end{array}$ & $\begin{array}{c}3.307 \\
(0.099)\end{array}$ & $\begin{array}{c}3.178 \\
(0.222)\end{array}$ & $\begin{array}{c}2.850 \\
(0.250)\end{array}$ & $\begin{array}{c}2.437 \\
(0.129)\end{array}$ & $\begin{array}{c}1.864 \\
(0.173)\end{array}$ & $\begin{array}{c}1.801 \\
(0.239)\end{array}$ & $\begin{array}{c}1.619 \\
(0.151)\end{array}$ \\
\hline \multirow{4}{*}{ 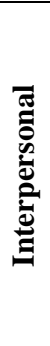 } & Supervision of other workers (dummy) & $\begin{array}{c}0.704 \\
(0.059)\end{array}$ & $\begin{array}{c}0.261 \\
(0.029)\end{array}$ & $\begin{array}{c}0.401 \\
(0.071)\end{array}$ & $\begin{array}{c}0.179 \\
(0.054)\end{array}$ & $\begin{array}{c}0.170 \\
(0.035)\end{array}$ & $\begin{array}{c}0.155 \\
(0.055)\end{array}$ & $\begin{array}{c}0.104 \\
(0.055)\end{array}$ & $\begin{array}{c}0.080 \\
(0.034)\end{array}$ \\
\hline & Presentation (dummy) & $\begin{array}{c}0.424 \\
(0.052)\end{array}$ & $\begin{array}{c}0.417 \\
(0.033)\end{array}$ & $\begin{array}{c}0.347 \\
(0.073)\end{array}$ & $\begin{array}{c}0.133 \\
(0.056)\end{array}$ & $\begin{array}{c}0.145 \\
(0.032)\end{array}$ & $\begin{array}{c}0.075 \\
(0.039)\end{array}$ & $\begin{array}{c}0.025 \\
(0.024)\end{array}$ & $\begin{array}{c}0.047 \\
(0.023)\end{array}$ \\
\hline & Contact with clients $(0-10)$ & $\begin{array}{c}5.962 \\
(0.419)\end{array}$ & $\begin{array}{c}6.751 \\
(0.230)\end{array}$ & $\begin{array}{c}5.320 \\
(0.619)\end{array}$ & $\begin{array}{c}5.405 \\
(0.595)\end{array}$ & $\begin{array}{c}6.167 \\
(0.316)\end{array}$ & $\begin{array}{c}3.515 \\
(0.496)\end{array}$ & $\begin{array}{c}5.368 \\
(0.796)\end{array}$ & $\begin{array}{c}1.919 \\
(0.392)\end{array}$ \\
\hline & Collaboration with coworkers (1-5) & $\begin{array}{c}4.573 \\
(0.111)\end{array}$ & $\begin{array}{c}4.724 \\
(0.054)\end{array}$ & $\begin{array}{c}4.801 \\
(0.085)\end{array}$ & $\begin{array}{c}4.760 \\
(0.081)\end{array}$ & $\begin{array}{c}3.920 \\
(0.136)\end{array}$ & $\begin{array}{c}4.251 \\
(0.218)\end{array}$ & $\begin{array}{c}3.460 \\
(0.352)\end{array}$ & $\begin{array}{c}4.037 \\
(0.241)\end{array}$ \\
\hline \multirow{4}{*}{ 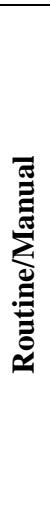 } & $\begin{array}{l}\text { Autonomy (1-10) } \\
\text { Repetitiveness (1-4) }\end{array}$ & $\begin{array}{c}5.137 \\
(0.292) \\
3.016 \\
(0.129)\end{array}$ & $\begin{array}{c}5.445 \\
(0.169) \\
3.259 \\
(0.068)\end{array}$ & $\begin{array}{c}5.981 \\
(0.516) \\
3.356 \\
(0.136)\end{array}$ & $\begin{array}{c}6.187 \\
(0.456) \\
3.447 \\
(0.129)\end{array}$ & $\begin{array}{c}5.595 \\
(0.293) \\
3.313 \\
(0.104)\end{array}$ & $\begin{array}{c}4.976 \\
(0.424) \\
3.163 \\
(0.130)\end{array}$ & $\begin{array}{c}5.687 \\
(0.725) \\
3.326 \\
(0.210)\end{array}$ & $\begin{array}{c}5.862 \\
(0.293) \\
3.387 \\
(0.111)\end{array}$ \\
\hline & Operate heavy machines (dummy) & $\begin{array}{c}0.036 \\
(0.017)\end{array}$ & $\begin{array}{c}0.001 \\
(0.001)\end{array}$ & $\begin{array}{c}0.129 \\
(0.047)\end{array}$ & $\begin{array}{c}0.012 \\
(0.012)\end{array}$ & $\begin{array}{c}0.025 \\
(0.013)\end{array}$ & $\begin{array}{c}0.322 \\
(0.068)\end{array}$ & $\begin{array}{c}0.291 \\
(0.080)\end{array}$ & $\begin{array}{c}0.116 \\
(0.036)\end{array}$ \\
\hline & Driving (dummy) & $\begin{array}{c}0.330 \\
(0.052)\end{array}$ & $\begin{array}{c}0.061 \\
(0.017)\end{array}$ & $\begin{array}{c}0.149 \\
(0.044)\end{array}$ & $\begin{array}{c}0.068 \\
(0.045)\end{array}$ & $\begin{array}{c}0.082 \\
(0.022)\end{array}$ & $\begin{array}{c}0.185 \\
(0.055)\end{array}$ & $\begin{array}{c}0.599 \\
(0.099)\end{array}$ & $\begin{array}{c}0.062 \\
(0.030)\end{array}$ \\
\hline & Repairing (dummy) & $\begin{array}{c}0.098 \\
(0.032)\end{array}$ & $\begin{array}{c}0.040 \\
(0.014)\end{array}$ & $\begin{array}{c}0.137 \\
(0.049)\end{array}$ & $\begin{array}{c}0.020 \\
(0.015)\end{array}$ & $\begin{array}{c}0.037 \\
(0.014)\end{array}$ & $\begin{array}{c}0.225 \\
(0.065)\end{array}$ & $\begin{array}{c}0.000 \\
(0.000)\end{array}$ & $\begin{array}{c}0.064 \\
(0.001)\end{array}$ \\
\hline
\end{tabular}




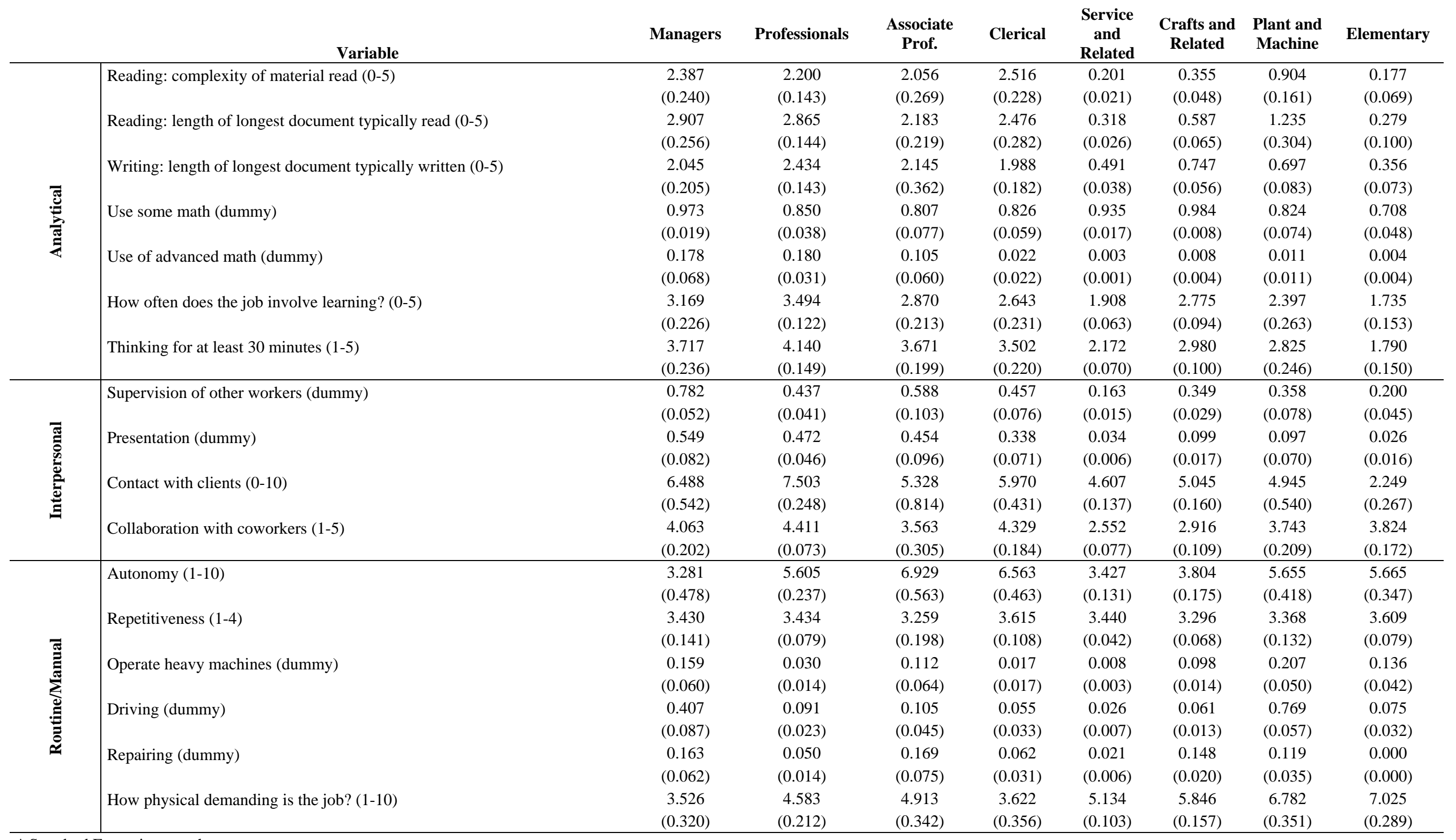




\begin{tabular}{|c|c|c|c|c|c|c|c|c|c|}
\hline & Variable & Managers & Professionals & $\begin{array}{c}\text { Associate } \\
\text { Prof. }\end{array}$ & Clerical & $\begin{array}{c}\text { Service } \\
\text { and } \\
\text { Related }\end{array}$ & $\begin{array}{c}\text { Crafts and } \\
\text { Related }\end{array}$ & $\begin{array}{l}\text { Plant and } \\
\text { Machine }\end{array}$ & Elementary \\
\hline \multirow{12}{*}{ 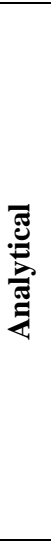 } & Reading: complexity of material read (0-5) & 3.035 & 3.442 & 3.466 & 3.279 & 1.160 & 1.069 & 1.435 & 0.418 \\
\hline & & $(0.239)$ & $(0.115)$ & $(0.164)$ & $(0.208)$ & $(0.064)$ & $(0.104)$ & $(0.232)$ & $(0.077)$ \\
\hline & & $(0.237)$ & $(0.118)$ & $(0.163)$ & $(0.166)$ & $(0.059)$ & $(0.099)$ & (0.199) & $(0.109)$ \\
\hline & Writing: length of longest document typically written (0-5) & 2.220 & 3.240 & 2.206 & 2.014 & 0.827 & 0.757 & 0.836 & 0.398 \\
\hline & & $(0.204)$ & $(0.127)$ & $(0.153)$ & $(0.128)$ & $(0.040)$ & $(0.064)$ & $(0.116)$ & $(0.065)$ \\
\hline & Use some math (dummy) & 0.969 & 0.887 & 0.946 & 0.787 & 0.910 & 0.963 & 0.914 & 0.595 \\
\hline & Use of advanced math (dummy) & 0.183 & 0.307 & 0.150 & 0.078 & 0.014 & 0.031 & 0.024 & 0.004 \\
\hline & & $(0.058)$ & $(0.031)$ & $(0.034)$ & $(0.026)$ & $(0.005)$ & $(0.011)$ & $(0.019)$ & $(0.004)$ \\
\hline & How often does the job involve learning? $(0-5)$ & 3.279 & 4.021 & 3.440 & 2.852 & 2.366 & 3.461 & 3.003 & 2.021 \\
\hline & & $(0.180)$ & $(0.099)$ & $(0.134)$ & $(0.162)$ & $(0.064)$ & $(0.109)$ & $(0.150)$ & $(0.107)$ \\
\hline & Thinking for at least 30 minutes (1-5) & 3.840 & 4.129 & 3.743 & 3.353 & 2.721 & 3.426 & 3.113 & 2.162 \\
\hline & & $(0.177)$ & $(0.099)$ & $(0.132)$ & $(0.158)$ & $(0.069)$ & $(0.092)$ & $(0.166)$ & $(0.119)$ \\
\hline \multirow{7}{*}{ 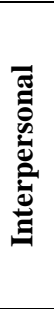 } & Supervision of other workers (dummy) & 0.875 & 0.395 & 0.416 & 0.265 & 0.172 & 0.217 & 0.123 & 0.073 \\
\hline & & $(0.049)$ & $(0.039)$ & $(0.050)$ & $(0.042)$ & $(0.014)$ & $(0.032)$ & $(0.038)$ & $(0.018)$ \\
\hline & Presentation (dummy) & 0.699 & 0.751 & 0.568 & 0.443 & 0.216 & 0.243 & 0.127 & 0.087 \\
\hline & Contact with clients $(0-10)$ & 6.995 & 7.176 & 6.828 & 5.333 & 7.091 & 5.425 & 5.453 & 2.998 \\
\hline & & $(0.409)$ & $(0.191)$ & $(0.284)$ & $(0.308)$ & $(0.127)$ & $(0.255)$ & $(0.475)$ & $(0.276)$ \\
\hline & Collaboration with coworkers (1-5) & 4.631 & 4.428 & 4.576 & 4.201 & 3.342 & 3.937 & 4.273 & 3.059 \\
\hline & & $(0.128)$ & $(0.080)$ & $(0.108)$ & $(0.157)$ & $(0.059)$ & $(0.116)$ & $(0.172)$ & $(0.151)$ \\
\hline \multirow{12}{*}{ 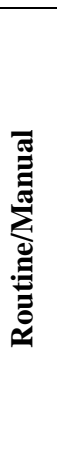 } & Autonomy (1-10) & 3.873 & 4.482 & 4.398 & 5.403 & 3.609 & 4.511 & 4.770 & 5.469 \\
\hline & & $(0.308)$ & $(0.173)$ & $(0.230)$ & $(0.268)$ & $(0.101)$ & $(0.208)$ & $(0.256)$ & $(0.205)$ \\
\hline & Repetitiveness (1-4) & 2.947 & 3.205 & 3.259 & 3.446 & 3.608 & 3.378 & 3.489 & 3.516 \\
\hline & & $(0.148)$ & $(0.076)$ & $(0.102)$ & $(0.092)$ & $(0.029)$ & $(0.071)$ & $(0.071)$ & $(0.078)$ \\
\hline & Operate heavy machines (dummy) & 0.066 & 0.086 & 0.103 & 0.021 & 0.010 & 0.226 & 0.355 & 0.049 \\
\hline & & $(0.031)$ & $(0.018)$ & $(0.036)$ & $(0.013)$ & $(0.003)$ & $(0.029)$ & $(0.057)$ & $(0.014)$ \\
\hline & Driving (dummy) & 0.380 & 0.141 & 0.204 & 0.097 & 0.045 & 0.079 & 0.678 & 0.043 \\
\hline & & $(0.086)$ & $(0.026)$ & $(0.041)$ & $(0.033)$ & $(0.008)$ & $(0.017)$ & $(0.057)$ & $(0.015)$ \\
\hline & Repairing (dummy) & 0.071 & 0.137 & 0.132 & 0.090 & 0.026 & 0.165 & 0.101 & 0.016 \\
\hline & & $(0.032)$ & $(0.024)$ & $(0.034)$ & $(0.029)$ & $(0.006)$ & $(0.025)$ & $(0.036)$ & $(0.007)$ \\
\hline & How physical demanding is the job? $(1-10)$ & 4.387 & 3.502 & 3.742 & 3.177 & 4.954 & 6.042 & 4.891 & 5.869 \\
\hline & & $(0.396)$ & $(0.208)$ & $(0.249)$ & $(0.217)$ & $(0.099)$ & $(0.174)$ & $(0.258)$ & $(0.187)$ \\
\hline
\end{tabular}




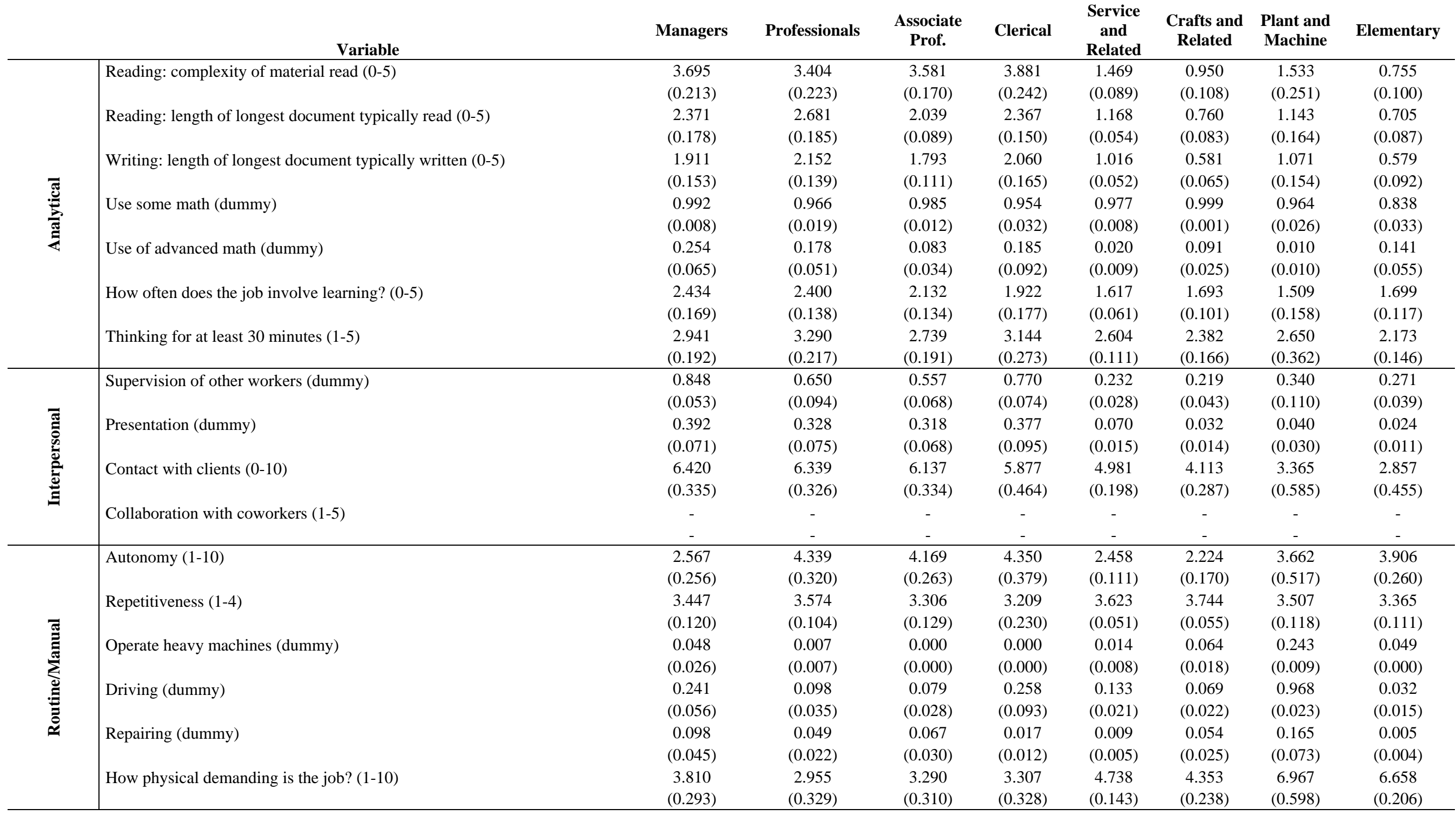

* Standard Errors in parentheses 


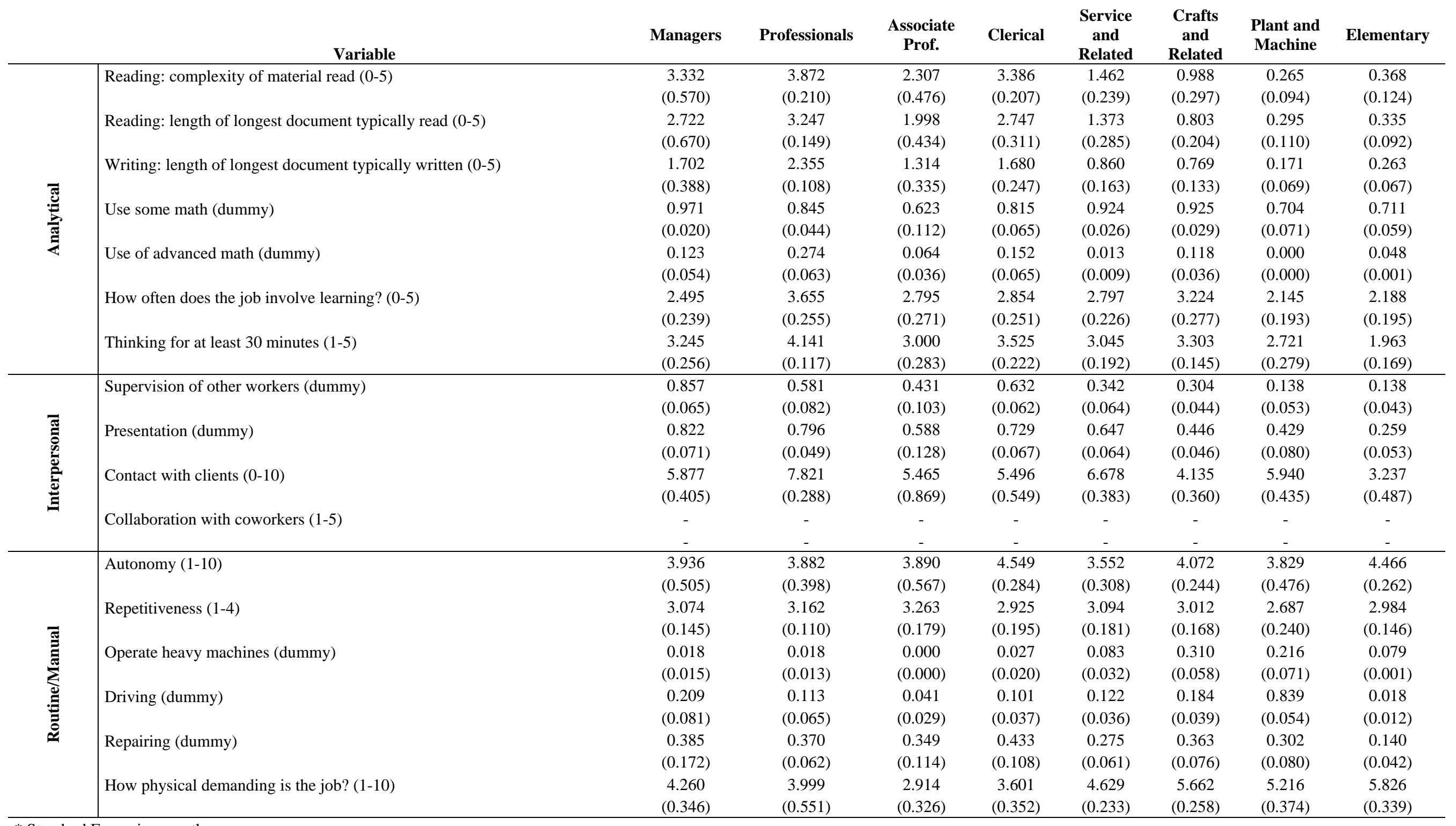




\begin{tabular}{|c|c|c|c|c|c|c|c|c|c|}
\hline & Variable & Managers & Professionals & $\begin{array}{c}\text { Associate } \\
\text { Prof. }\end{array}$ & Clerical & $\begin{array}{c}\text { Service } \\
\text { and } \\
\text { Related }\end{array}$ & $\begin{array}{c}\text { Crafts } \\
\text { and } \\
\text { Related }\end{array}$ & $\begin{array}{l}\text { Plant and } \\
\text { Machine }\end{array}$ & Elementary \\
\hline \multirow{13}{*}{ 気 } & Reading: complexity of material read (0-5) & 3.925 & 3.618 & 3.216 & 2.846 & 1.768 & 1.006 & 0.912 & 0.621 \\
\hline & & $(0.120)$ & $(0.097)$ & $(0.118)$ & $(0.241)$ & $(0.117)$ & $(0.120)$ & $(0.156)$ & $(0.091)$ \\
\hline & Reading: length of longest document typically read (0-5) & $\begin{array}{c}3.290 \\
(0.151)\end{array}$ & $\begin{array}{c}3.911 \\
(0.090)\end{array}$ & $\begin{array}{c}3.035 \\
(0.127)\end{array}$ & $\begin{array}{c}2.973 \\
(0.235)\end{array}$ & $\begin{array}{l}1.550 \\
(0.107)\end{array}$ & $\begin{array}{l}1.036 \\
(0.111)\end{array}$ & $\begin{array}{c}0.827 \\
(0.143)\end{array}$ & $\begin{array}{c}0.566 \\
(0.082)\end{array}$ \\
\hline & Writing: length of longest document typically written (0-5) & $\begin{array}{c}(0.151) \\
2.282\end{array}$ & $\begin{array}{c}(0.090) \\
2.976\end{array}$ & $\begin{array}{c}(0.127) \\
2.035\end{array}$ & $\begin{array}{c}(0.235) \\
2.081\end{array}$ & $\begin{array}{c}(0.107) \\
1.069\end{array}$ & $\begin{array}{c}(0.111) \\
0.834\end{array}$ & $\begin{array}{c}(0.143) \\
0.569\end{array}$ & $\begin{array}{c}(0.082) \\
0.486\end{array}$ \\
\hline & & $(0.161)$ & $(0.086)$ & $(0.095)$ & $(0.173)$ & $(0.081)$ & $(0.090)$ & $(0.092)$ & $(0.071)$ \\
\hline & Use some math (dummy) & 0.887 & 0.753 & 0.833 & 0.657 & 0.743 & 0.857 & 0.668 & 0.528 \\
\hline & & $(0.033)$ & $(0.026)$ & $(0.026)$ & $(0.059)$ & $(0.030)$ & $(0.030)$ & $(0.038)$ & $(0.050)$ \\
\hline & Use of advanced math (dummy) & 0.174 & 0.260 & 0.132 & 0.066 & 0.007 & 0.111 & 0.039 & 0.011 \\
\hline & & $(0.037)$ & $(0.027)$ & $(0.027)$ & $(0.025)$ & $(0.004)$ & $(0.027)$ & $(0.017)$ & $(0.008)$ \\
\hline & How often does the job involve learning? (0-5) & 3.710 & 3.990 & 3.511 & 3.020 & 2.303 & 3.006 & 2.239 & 1.957 \\
\hline & & $(0.155)$ & $(0.091)$ & $(0.120)$ & $(0.173)$ & $(0.116)$ & $(0.141)$ & $(0.166)$ & $(0.153)$ \\
\hline & Thinking for at least 30 minutes (1-5) & 3.658 & 4.017 & 3.569 & 3.008 & 2.565 & 2.714 & 2.468 & 1.857 \\
\hline & & $(0.142)$ & $(0.077)$ & $(0.114)$ & $(0.139)$ & $(0.108)$ & $(0.130)$ & $(0.155)$ & $(0.130)$ \\
\hline \multirow{8}{*}{ 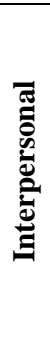 } & Supervision of other workers (dummy) & 0.703 & 0.436 & 0.377 & 0.371 & 0.216 & 0.299 & 0.147 & 0.111 \\
\hline & & $(0.049)$ & $(0.028)$ & $(0.036)$ & $(0.047)$ & $(0.027)$ & $(0.038)$ & $(0.031)$ & $(0.035)$ \\
\hline & Presentation (dummy) & 0.520 & 0.574 & 0.369 & 0.313 & 0.246 & 0.171 & 0.047 & 0.065 \\
\hline & & $(0.060)$ & $(0.034)$ & $(0.039)$ & $(0.050)$ & $(0.027)$ & $(0.033)$ & $(0.018)$ & $(0.021)$ \\
\hline & Contact with clients $(0-10)$ & 7.462 & 7.555 & 6.884 & 6.701 & 7.573 & 3.089 & 3.151 & 2.900 \\
\hline & & $(0.344)$ & $(0.181)$ & $(0.289)$ & $(0.368)$ & $(0.240)$ & $(0.292)$ & $(0.400)$ & $(0.379)$ \\
\hline & Collaboration with coworkers (1-5) & 4.325 & 4.726 & 4.799 & 4.777 & 4.330 & 4.557 & 4.434 & 4.449 \\
\hline & & $(0.137)$ & $(0.052)$ & $(0.050)$ & $(0.097)$ & $(0.092)$ & $(0.091)$ & $(0.110)$ & $(0.128)$ \\
\hline \multirow{12}{*}{ 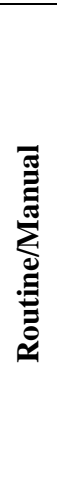 } & Autonomy (1-10) & 2.108 & 3.893 & 4.728 & 4.560 & 4.213 & 4.748 & 5.959 & 4.728 \\
\hline & & $(0.201)$ & $(0.163)$ & $(0.217)$ & $(0.282)$ & $(0.228)$ & $(0.256)$ & $(0.349)$ & $(0.306)$ \\
\hline & Repetitiveness (1-4) & 3.523 & 3.476 & 3.605 & 3.765 & 3.855 & 3.695 & 3.748 & 3.843 \\
\hline & & $(0.089)$ & $(0.051)$ & $(0.058)$ & $(0.072)$ & $(0.032)$ & $(0.052)$ & $(0.079)$ & $(0.046)$ \\
\hline & Operate heavy machines (dummy) & 0.041 & 0.008 & 0.057 & 0.023 & 0.018 & 0.244 & 0.196 & 0.153 \\
\hline & & $(0.021)$ & $(0.005)$ & $(0.018)$ & $(0.016)$ & $(0.010)$ & $(0.035)$ & $(0.037)$ & $(0.031)$ \\
\hline & Driving (dummy) & 0.716 & 0.305 & 0.394 & 0.251 & 0.252 & 0.326 & 0.398 & 0.256 \\
\hline & & $(0.050)$ & $(0.027)$ & $(0.041)$ & $(0.039)$ & $(0.030)$ & $(0.037)$ & $(0.051)$ & $(0.044)$ \\
\hline & Repairing (dummy) & 0.091 & 0.109 & 0.144 & 0.061 & 0.089 & 0.109 & 0.032 & 0.035 \\
\hline & & $(0.027)$ & $(0.019)$ & $(0.025)$ & $(0.024)$ & $(0.017)$ & $(0.022)$ & $(0.015)$ & $(0.013)$ \\
\hline & How physical demanding is the job? (1-10) & 3.993 & 3.215 & 3.621 & 3.057 & 4.827 & 6.131 & 5.060 & 6.483 \\
\hline & & $(0.284)$ & (0.153) & $(0.173)$ & $(0.236)$ & (0.188) & $(0.252)$ & $(0.284)$ & $(0.260)$ \\
\hline
\end{tabular}

* Standard Errors in parentheses 


\begin{tabular}{|c|c|c|c|c|c|c|c|c|c|}
\hline & Variable & Managers & Professionals & $\begin{array}{c}\text { Associate } \\
\text { Prof. }\end{array}$ & Clerical & $\begin{array}{l}\text { Service } \\
\text { and } \\
\text { Related }\end{array}$ & $\begin{array}{c}\text { Crafts } \\
\text { and } \\
\text { Related }\end{array}$ & $\begin{array}{l}\text { Plant and } \\
\text { Machine }\end{array}$ & Elementary \\
\hline \multirow{14}{*}{ 胥 } & Reading: complexity of material read (0-5) & 3.900 & 3.211 & 3.138 & 3.038 & 1.163 & 0.993 & 0.975 & 0.465 \\
\hline & & $(0.247)$ & $(0.081)$ & $(0.150)$ & $(0.149)$ & $(0.057)$ & $(0.081)$ & $(0.136)$ & $(0.058)$ \\
\hline & Reading: length of longest document typically read (0-5) & 3.465 & 3.614 & 3.219 & 2.681 & 1.124 & 1.056 & 0.983 & 0.532 \\
\hline & & $(0.249)$ & $(0.087)$ & $(0.150)$ & $(0.160)$ & $(0.059)$ & $(0.092)$ & $(0.124)$ & $(0.068)$ \\
\hline & Writing: length of longest document typically written (0-5) & 2.533 & 2.627 & 2.036 & 1.891 & 0.788 & 0.614 & 0.377 & 0.330 \\
\hline & & $(0.174)$ & $(0.080)$ & $(0.119)$ & $(0.097)$ & $(0.032)$ & $(0.043)$ & $(0.063)$ & $(0.041)$ \\
\hline & Use some math (dummy) & 0.932 & 0.845 & 0.828 & 0.810 & 0.900 & 0.906 & 0.778 & 0.738 \\
\hline & & $(0.026)$ & $(0.020)$ & $(0.036)$ & $(0.038)$ & $(0.013)$ & $(0.020)$ & $(0.046)$ & $(0.033)$ \\
\hline & Use of advanced math (dummy) & 0.239 & 0.249 & 0.105 & 0.090 & 0.015 & 0.068 & 0.022 & 0.020 \\
\hline & & $(0.051)$ & $(0.025)$ & $(0.027)$ & $(0.028)$ & $(0.005)$ & $(0.015)$ & $(0.011)$ & $(0.013)$ \\
\hline & How often does the job involve learning? (0-5) & 3.414 & 3.127 & 2.788 & 2.227 & 1.676 & 2.044 & 1.765 & 1.403 \\
\hline & & $(0.190)$ & $(0.073)$ & $(0.131)$ & $(0.132)$ & $(0.050)$ & $(0.102)$ & $(0.128)$ & $(0.058)$ \\
\hline & Thinking for at least 30 minutes (1-5) & 3.954 & 3.926 & 3.794 & 3.150 & 2.595 & 2.842 & 2.497 & 2.146 \\
\hline & & $(0.144)$ & $(0.083)$ & $(0.127)$ & $(0.192)$ & $(0.074)$ & $(0.108)$ & $(0.183)$ & $(0.126)$ \\
\hline \multirow{8}{*}{ 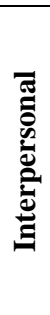 } & Supervision of other workers (dummy) & 0.973 & 0.736 & 0.549 & 0.510 & 0.285 & 0.270 & 0.179 & 0.138 \\
\hline & & $(0.021)$ & $(0.025)$ & $(0.049)$ & $(0.060)$ & $(0.020)$ & $(0.029)$ & $(0.041)$ & $(0.028)$ \\
\hline & Presentation (dummy) & 0.893 & 0.785 & 0.686 & 0.656 & 0.604 & 0.453 & 0.358 & 0.251 \\
\hline & & $(0.033)$ & $(0.023)$ & $(0.050)$ & $(0.064)$ & $(0.021)$ & $(0.034)$ & $(0.055)$ & $(0.032)$ \\
\hline & Contact with clients $(0-10)$ & 6.257 & 5.720 & 5.147 & 4.456 & 4.652 & 3.070 & 3.184 & 2.475 \\
\hline & & $(0.321)$ & $(0.180)$ & $(0.293)$ & $(0.306)$ & $(0.118)$ & $(0.213)$ & $(0.373)$ & $(0.239)$ \\
\hline & Collaboration with coworkers (1-5) & - & - & - & - & - & - & - & - \\
\hline & & - & - & - & - & - & - & - & - \\
\hline \multirow{12}{*}{ 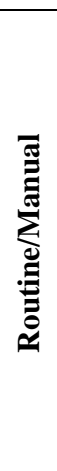 } & Autonomy (1-10) & 4.072 & 4.969 & 4.882 & 5.053 & 3.557 & 4.801 & 5.160 & 4.182 \\
\hline & & $(0.277)$ & $(0.115)$ & $(0.218)$ & $(0.233)$ & $(0.104)$ & $(0.189)$ & $(0.329)$ & $(0.199)$ \\
\hline & Repetitiveness (1-4) & 2.257 & 2.722 & 2.742 & 2.683 & 2.845 & 3.170 & 3.303 & 3.163 \\
\hline & & $(0.148)$ & $(0.065)$ & $(0.130)$ & $(0.122)$ & $(0.050)$ & $(0.071)$ & $(0.099)$ & $(0.081)$ \\
\hline & Operate heavy machines (dummy) & 0.067 & 0.036 & 0.022 & 0.037 & 0.005 & 0.146 & 0.222 & 0.040 \\
\hline & & $(0.040)$ & $(0.010)$ & $(0.013)$ & $(0.021)$ & $(0.002)$ & $(0.024)$ & $(0.052)$ & $(0.013)$ \\
\hline & Driving (dummy) & 0.275 & 0.037 & 0.034 & 0.038 & 0.025 & 0.031 & 0.364 & 0.012 \\
\hline & & $(0.055)$ & $(0.012)$ & $(0.015)$ & $(0.016)$ & $(0.006)$ & $(0.014)$ & $(0.049)$ & $(0.006)$ \\
\hline & Repairing (dummy) & 0.120 & 0.146 & 0.161 & 0.072 & 0.042 & 0.122 & 0.074 & 0.020 \\
\hline & & $(0.035)$ & $(0.020)$ & $(0.031)$ & $(0.022)$ & $(0.007)$ & $(0.024)$ & $(0.025)$ & $(0.011)$ \\
\hline & How physical demanding is the job? (1-10) & 3.035 & 3.272 & 3.365 & 3.239 & 4.265 & 4.762 & 5.058 & 5.249 \\
\hline & & $(0.255)$ & $(0.111)$ & $(0.180)$ & $(0.171)$ & $(0.084)$ & $(0.134)$ & $(0.185)$ & $(0.178)$ \\
\hline
\end{tabular}


Figure B. Densities for skill intensities across occupations: Some examples

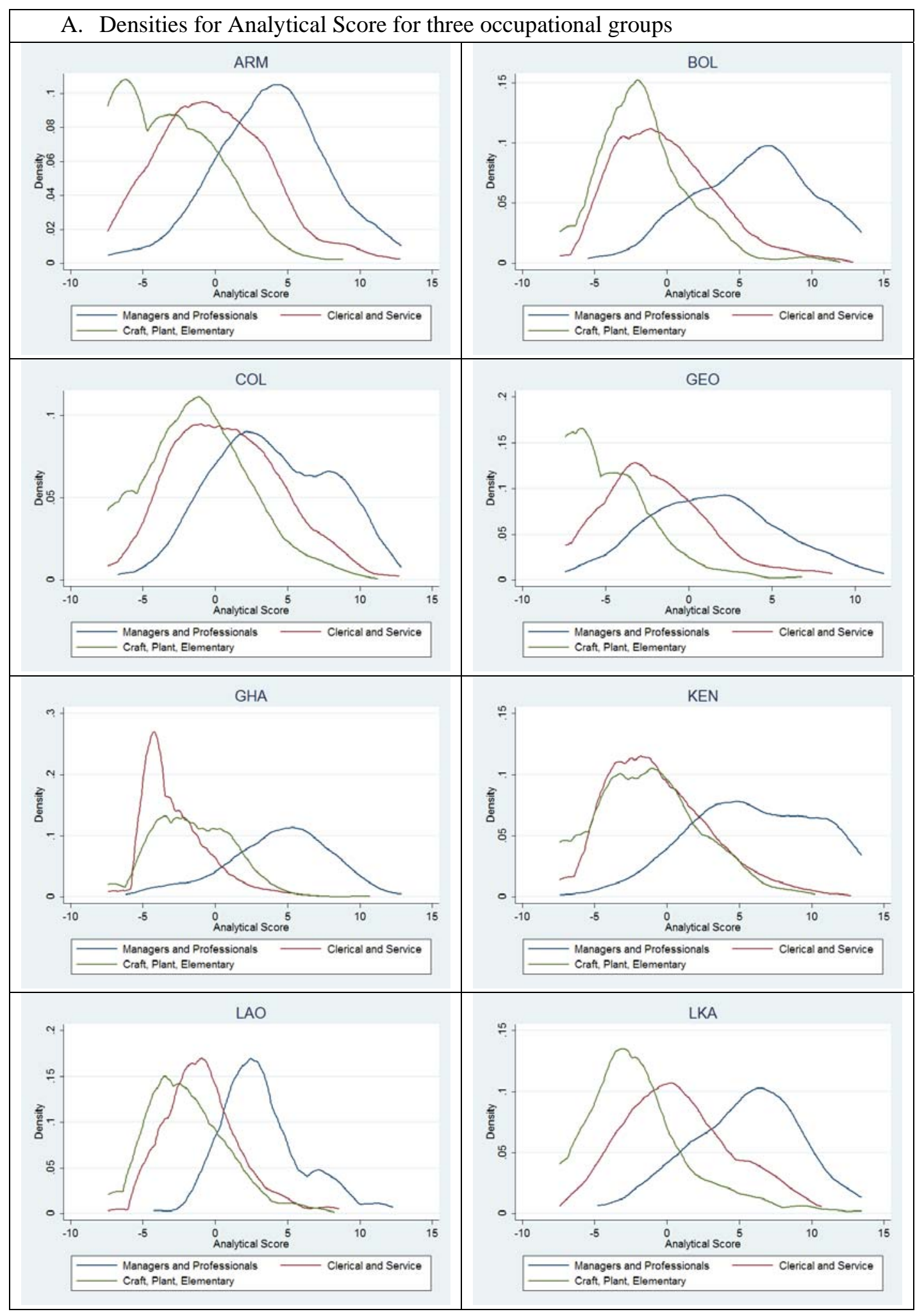




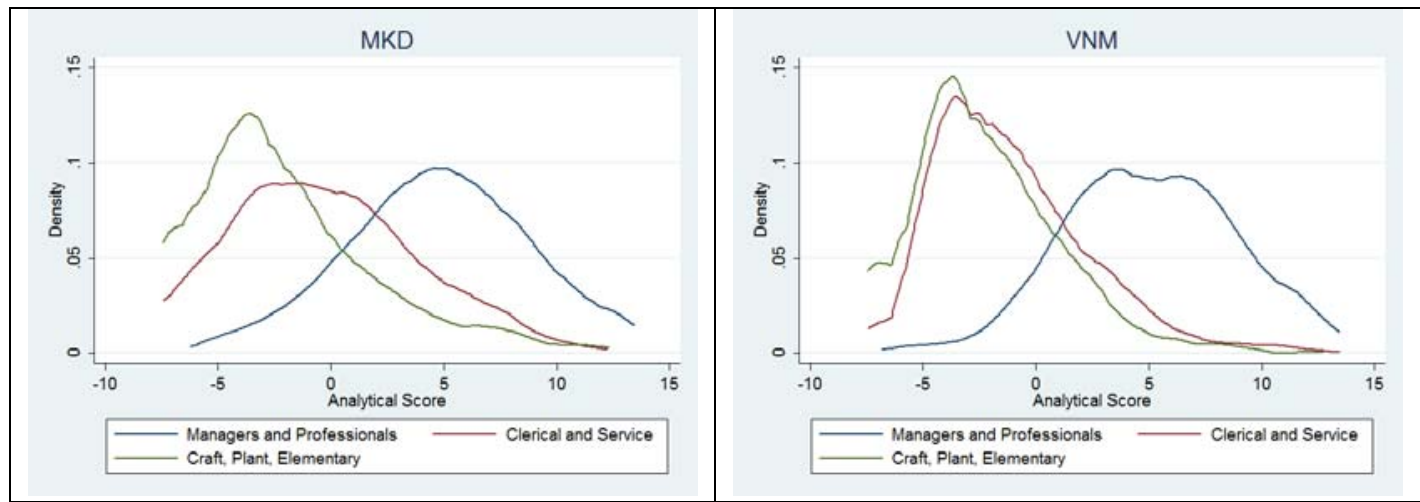

B. Densities for Interpersonal Score for three occupational groups

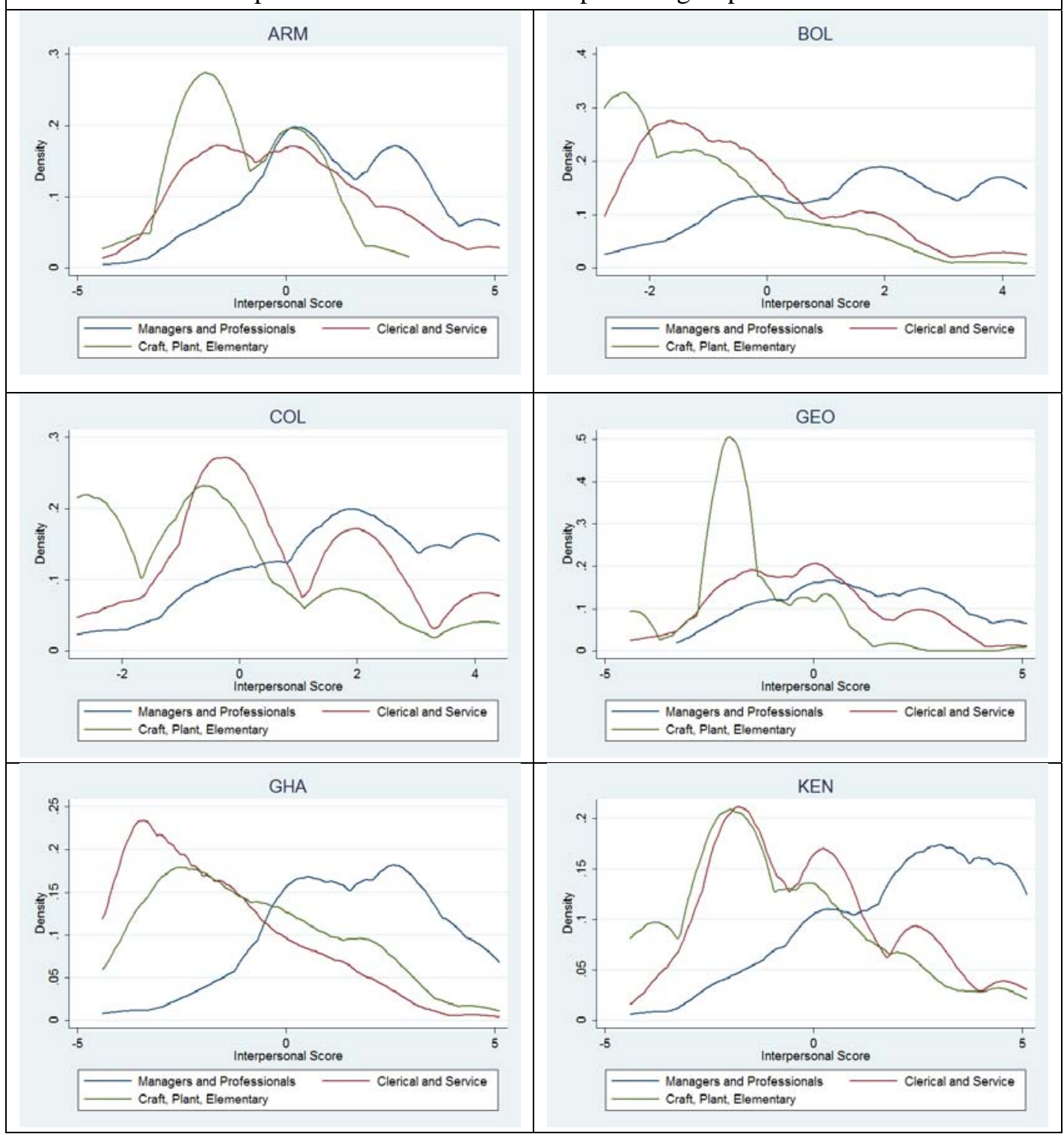




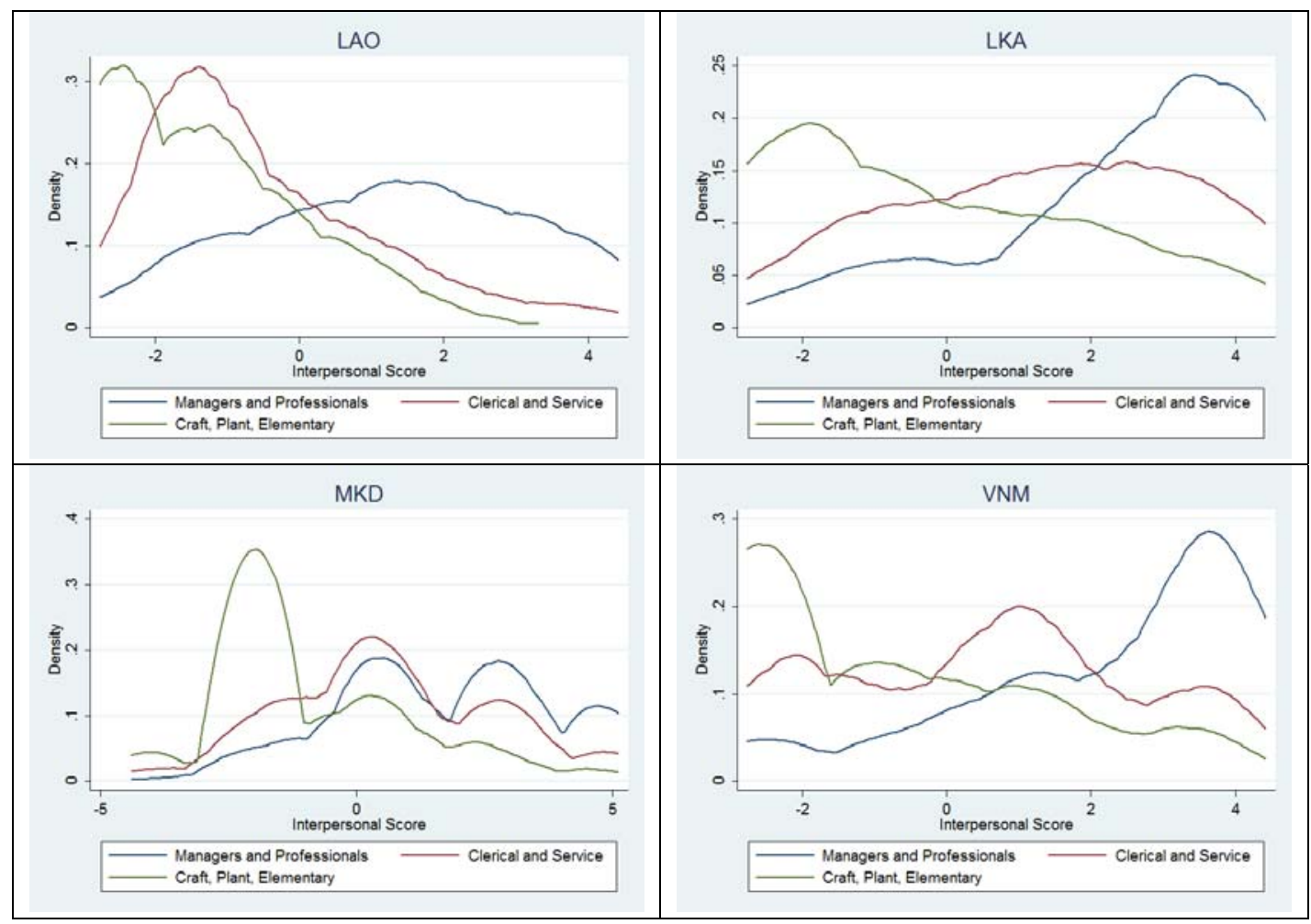

C. Densities for Routine \& Manual score for three occupational groups

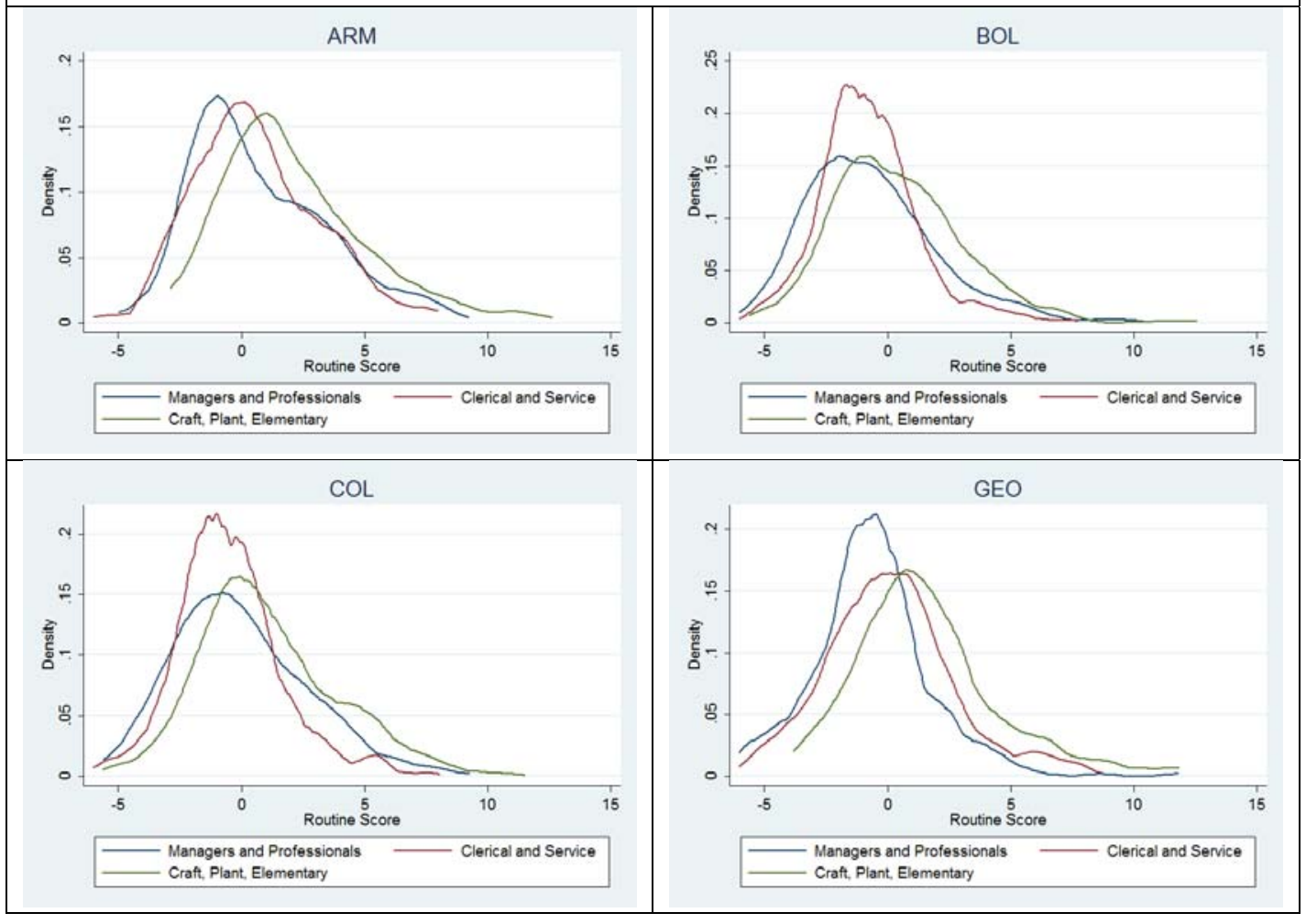




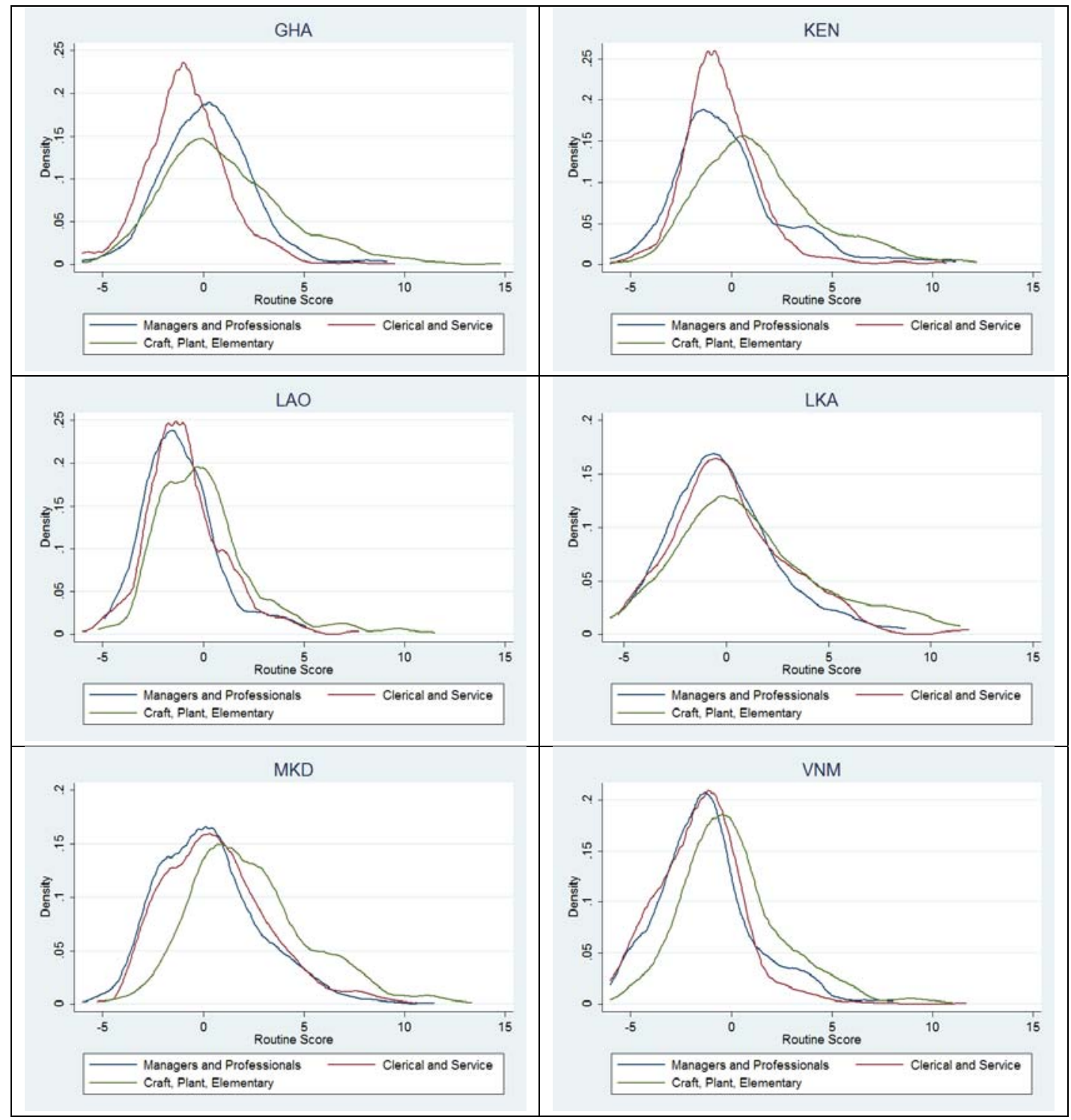


Table C. Pair-wise Spearman Correlations of Skill Intensity Indexes at the 2-Digit level, by Skill Dimension. Countries are sorted by geographic region.

\begin{tabular}{|c|c|c|c|c|c|c|c|c|c|c|}
\hline & BOL & COL & ARM & GEO & $\begin{array}{r}\text { MKD } \\
\text { An }\end{array}$ & $\begin{array}{l}\text { GHA } \\
\text { cal }\end{array}$ & KEN & LAO & LKA & VNM \\
\hline BOL & 1.00 & 0.92 & 0.85 & 0.78 & 0.90 & 0.86 & 0.83 & 0.88 & 0.76 & 0.90 \\
\hline COL & & 1.00 & 0.88 & 0.79 & 0.89 & 0.92 & 0.86 & 0.82 & 0.71 & 0.88 \\
\hline ARM & & & 1.00 & 0.81 & 0.88 & 0.90 & 0.86 & 0.78 & 0.70 & 0.89 \\
\hline GEO & & & & 1.00 & 0.80 & 0.83 & 0.79 & 0.83 & 0.69 & 0.87 \\
\hline MKD & & & & & 1.00 & 0.94 & 0.90 & 0.78 & 0.77 & 0.94 \\
\hline GHA & & & & & & 1.00 & 0.94 & 0.84 & 0.66 & 0.92 \\
\hline KEN & & & & & & & 1.00 & 0.82 & 0.83 & 0.88 \\
\hline LAO & & & & & & & & 1.00 & 0.78 & 0.80 \\
\hline LKA & & & & & & & & & 1.00 & 0.78 \\
\hline VNM & & & & & & & & & & 1.00 \\
\hline & \multicolumn{10}{|c|}{ Interpersonal } \\
\hline BOL & 1.00 & 0.82 & 0.64 & 0.68 & 0.75 & 0.59 & 0.74 & 0.89 & 0.65 & 0.78 \\
\hline COL & & 1.00 & 0.73 & 0.75 & 0.76 & 0.73 & 0.81 & 0.84 & 0.50 & 0.82 \\
\hline ARM & & & 1.00 & 0.77 & 0.81 & 0.68 & 0.71 & 0.81 & 0.70 & 0.84 \\
\hline GEO & & & & 1.00 & 0.81 & 0.69 & 0.84 & 0.83 & 0.78 & 0.89 \\
\hline MKD & & & & & 1.00 & 0.69 & 0.85 & 0.78 & 0.73 & 0.85 \\
\hline GHA & & & & & & 1.00 & 0.76 & 0.82 & 0.52 & 0.78 \\
\hline KEN & & & & & & & 1.00 & 0.85 & 0.80 & 0.87 \\
\hline LAO & & & & & & & & 1.00 & 0.65 & 0.90 \\
\hline LKA & & & & & & & & & 1.00 & 0.78 \\
\hline VNM & & & & & & & & & & 1.00 \\
\hline & \multicolumn{10}{|c|}{ Routine } \\
\hline BOL & 1.00 & 0.68 & 0.48 & 0.57 & 0.51 & 0.65 & 0.66 & 0.37 & 0.66 & 0.59 \\
\hline COL & & 1.00 & 0.47 & 0.71 & 0.68 & 0.72 & 0.60 & 0.63 & 0.51 & 0.80 \\
\hline ARM & & & 1.00 & 0.68 & 0.66 & 0.57 & 0.74 & 0.57 & 0.53 & 0.45 \\
\hline GEO & & & & 1.00 & 0.68 & 0.77 & 0.76 & 0.48 & 0.31 & 0.61 \\
\hline MKD & & & & & 1.00 & 0.47 & 0.56 & 0.51 & 0.56 & 0.49 \\
\hline GHA & & & & & & 1.00 & 0.78 & 0.39 & 0.51 & 0.76 \\
\hline KEN & & & & & & & 1.00 & 0.56 & 0.29 & 0.62 \\
\hline LAO & & & & & & & & 1.00 & 0.49 & 0.57 \\
\hline LKA & & & & & & & & & 1.00 & 0.58 \\
\hline VNM & & & & & & & & & & 1.00 \\
\hline & \multicolumn{10}{|c|}{ Observations } \\
\hline BOL & 34 & 31 & 26 & 26 & 31 & 24 & 30 & 21 & 16 & 34 \\
\hline COL & & 33 & 24 & 26 & 31 & 24 & 29 & 19 & 15 & 33 \\
\hline ARM & & & 27 & 23 & 25 & 21 & 26 & 17 & 14 & 26 \\
\hline GEO & & & & 28 & 27 & 21 & 27 & 18 & 14 & 28 \\
\hline MKD & & & & & 35 & 25 & 30 & 22 & 15 & 35 \\
\hline GHA & & & & & & 27 & 24 & 20 & 13 & 25 \\
\hline KEN & & & & & & & 32 & 20 & 15 & 31 \\
\hline LAO & & & & & & & & 25 & 14 & 23 \\
\hline LKA & & & & & & & & & 18 & 17 \\
\hline VNM & & & & & & & & & & 38 \\
\hline
\end{tabular}


Table D. Pair-wise Spearman Correlations of Skill Intensity Indexes at the 2-Digit level, by Skill Dimension. Countries are sorted by income groups.

\begin{tabular}{|c|c|c|c|c|c|c|c|c|c|c|}
\hline & GHA & KEN & LAO & \multicolumn{5}{|c|}{ Analytical } & ARM & MKD \\
\hline GHA & 1.00 & 0.94 & 0.84 & 0.92 & 0.86 & 0.66 & 0.83 & 0.92 & 0.90 & 0.94 \\
\hline KEN & & 1.00 & 0.82 & 0.88 & 0.83 & 0.83 & 0.79 & 0.86 & 0.86 & 0.90 \\
\hline LAO & & & 1.00 & 0.80 & 0.88 & 0.78 & 0.83 & 0.82 & 0.78 & 0.78 \\
\hline VNM & & & & 1.00 & 0.90 & 0.78 & 0.87 & 0.88 & 0.89 & 0.94 \\
\hline BOL & & & & & 1.00 & 0.76 & 0.78 & 0.92 & 0.85 & 0.90 \\
\hline LKA & & & & & & 1.00 & 0.69 & 0.71 & 0.70 & 0.77 \\
\hline GEO & & & & & & & 1.00 & 0.79 & 0.81 & 0.80 \\
\hline COL & & & & & & & & 1.00 & 0.88 & 0.89 \\
\hline ARM & & & & & & & & & 1.00 & 0.88 \\
\hline MKD & & & & & & & & & & 1.00 \\
\hline & \multicolumn{10}{|c|}{ Interpersonal } \\
\hline GHA & 1.00 & 0.76 & 0.82 & 0.78 & 0.59 & 0.52 & 0.69 & 0.73 & 0.68 & 0.69 \\
\hline KEN & & 1.00 & 0.85 & 0.87 & 0.74 & 0.80 & 0.84 & 0.81 & 0.71 & 0.85 \\
\hline LAO & & & 1.00 & 0.90 & 0.89 & 0.65 & 0.83 & 0.84 & 0.81 & 0.78 \\
\hline VNM & & & & 1.00 & 0.78 & 0.78 & 0.89 & 0.82 & 0.84 & 0.85 \\
\hline BOL & & & & & 1.00 & 0.65 & 0.68 & 0.82 & 0.64 & 0.75 \\
\hline LKA & & & & & & 1.00 & 0.78 & 0.50 & 0.70 & 0.73 \\
\hline GEO & & & & & & & 1.00 & 0.75 & 0.77 & 0.81 \\
\hline COL & & & & & & & & 1.00 & 0.73 & 0.76 \\
\hline ARM & & & & & & & & & 1.00 & 0.81 \\
\hline MKD & & & & & & & & & & 1.00 \\
\hline & \multicolumn{10}{|c|}{ Routine } \\
\hline GHA & 1.00 & 0.78 & 0.39 & 0.76 & 0.65 & 0.51 & 0.77 & 0.72 & 0.57 & 0.47 \\
\hline KEN & & 1.00 & 0.56 & 0.62 & 0.66 & 0.29 & 0.76 & 0.60 & 0.74 & 0.56 \\
\hline LAO & & & 1.00 & 0.57 & 0.37 & 0.49 & 0.48 & 0.63 & 0.57 & 0.51 \\
\hline VNM & & & & 1.00 & 0.59 & 0.58 & 0.61 & 0.80 & 0.45 & 0.49 \\
\hline BOL & & & & & 1.00 & 0.66 & 0.57 & 0.68 & 0.48 & 0.51 \\
\hline LKA & & & & & & 1.00 & 0.31 & 0.51 & 0.53 & 0.56 \\
\hline GEO & & & & & & & 1.00 & 0.71 & 0.68 & 0.68 \\
\hline COL & & & & & & & & 1.00 & 0.47 & 0.68 \\
\hline ARM & & & & & & & & & 1.00 & 0.66 \\
\hline \multirow[t]{2}{*}{ MKD } & & & & & & & & & & 1.00 \\
\hline & \multicolumn{10}{|c|}{ Observations } \\
\hline GHA & 27 & 24 & 20 & 25 & 24 & 13 & 21 & 24 & 21 & 25 \\
\hline KEN & & 32 & 20 & 31 & 30 & 15 & 27 & 29 & 26 & 30 \\
\hline LAO & & & 25 & 23 & 21 & 14 & 18 & 19 & 17 & 22 \\
\hline VNM & & & & 38 & 34 & 17 & 28 & 33 & 26 & 35 \\
\hline BOL & & & & & 34 & 16 & 26 & 31 & 26 & 31 \\
\hline LKA & & & & & & 18 & 14 & 15 & 14 & 15 \\
\hline GEO & & & & & & & 28 & 26 & 23 & 27 \\
\hline COL & & & & & & & & 33 & 24 & 31 \\
\hline ARM & & & & & & & & & 27 & 25 \\
\hline MKD & & & & & & & & & & 35 \\
\hline
\end{tabular}


Table A.X. Pair-wise Spearman Correlations of Skill Intensity Indexes at the 3-Digit level, by Skill Dimension. Countries are sorted by Region groups. Minimum number of observations per occupation=5.

\begin{tabular}{|c|c|c|c|c|c|c|c|c|c|c|}
\hline & BOL & COL & ARM & GEO & $\begin{array}{r}\text { MKD } \\
\text { An }\end{array}$ & $\begin{array}{l}\text { GHA } \\
\text { ical }\end{array}$ & KEN & LAO & LKA & VNM \\
\hline BOL & 1.00 & 0.80 & 0.81 & 0.78 & 0.86 & 0.85 & 0.82 & 0.86 & 0.74 & 0.82 \\
\hline COL & & 1.00 & 0.79 & 0.77 & 0.86 & 0.87 & 0.82 & 0.79 & 0.74 & 0.80 \\
\hline ARM & & & 1.00 & 0.69 & 0.82 & 0.76 & 0.83 & 0.72 & 0.75 & 0.82 \\
\hline GEO & & & & 1.00 & 0.75 & 0.72 & 0.77 & 0.81 & 0.67 & 0.83 \\
\hline MKD & & & & & 1.00 & 0.87 & 0.88 & 0.78 & 0.70 & 0.84 \\
\hline GHA & & & & & & 1.00 & 0.93 & 0.80 & 0.69 & 0.90 \\
\hline KEN & & & & & & & 1.00 & 0.89 & 0.77 & 0.85 \\
\hline LAO & & & & & & & & 1.00 & 0.72 & 0.86 \\
\hline LKA & & & & & & & & & 1.00 & 0.78 \\
\hline VNM & & & & & & & & & & 1.00 \\
\hline & \multicolumn{10}{|c|}{ Interpersonal } \\
\hline BOL & 1.00 & 0.79 & 0.66 & 0.64 & 0.73 & 0.62 & 0.77 & 0.83 & 0.76 & 0.77 \\
\hline COL & & 1.00 & 0.71 & 0.61 & 0.79 & 0.65 & 0.69 & 0.81 & 0.80 & 0.79 \\
\hline ARM & & & 1.00 & 0.49 & 0.71 & 0.45 & 0.60 & 0.74 & 0.59 & 0.66 \\
\hline GEO & & & & 1.00 & 0.57 & 0.66 & 0.65 & 0.68 & 0.78 & 0.77 \\
\hline MKD & & & & & 1.00 & 0.62 & 0.79 & 0.77 & 0.76 & 0.76 \\
\hline GHA & & & & & & 1.00 & 0.62 & 0.76 & 0.76 & 0.74 \\
\hline KEN & & & & & & & 1.00 & 0.82 & 0.67 & 0.79 \\
\hline LAO & & & & & & & & 1.00 & 0.76 & 0.83 \\
\hline LKA & & & & & & & & & 1.00 & 0.83 \\
\hline VNM & & & & & & & & & & 1.00 \\
\hline & \multicolumn{10}{|c|}{ Routine } \\
\hline BOL & 1.00 & 0.59 & 0.59 & 0.41 & 0.57 & 0.66 & 0.57 & 0.63 & 0.70 & 0.51 \\
\hline COL & & 1.00 & 0.41 & 0.38 & 0.54 & 0.64 & 0.58 & 0.53 & 0.37 & 0.65 \\
\hline ARM & & & 1.00 & 0.46 & 0.43 & 0.57 & 0.44 & 0.27 & 0.20 & 0.45 \\
\hline GEO & & & & 1.00 & 0.53 & 0.56 & 0.41 & 0.36 & 0.26 & 0.52 \\
\hline MKD & & & & & 1.00 & 0.46 & 0.59 & 0.42 & 0.54 & 0.49 \\
\hline GHA & & & & & & 1.00 & 0.58 & 0.38 & 0.18 & 0.61 \\
\hline KEN & & & & & & & 1.00 & 0.35 & 0.25 & 0.54 \\
\hline LAO & & & & & & & & 1.00 & 0.58 & 0.40 \\
\hline LKA & & & & & & & & & 1.00 & 0.40 \\
\hline VNM & & & & & & & & & & 1.00 \\
\hline & \multicolumn{10}{|c|}{ Observations } \\
\hline BOL & 75 & 55 & 46 & 47 & 63 & 47 & 53 & 37 & 28 & 64 \\
\hline COL & & 67 & 46 & 44 & 58 & 48 & 47 & 30 & 26 & 55 \\
\hline ARM & & & 62 & 45 & 55 & 40 & 45 & 27 & 26 & 49 \\
\hline GEO & & & & 57 & 53 & 39 & 44 & 28 & 22 & 48 \\
\hline MKD & & & & & 82 & 52 & 56 & 40 & 30 & 65 \\
\hline GHA & & & & & & 60 & 43 & 32 & 30 & 50 \\
\hline KEN & & & & & & & 67 & 32 & 24 & 56 \\
\hline LAO & & & & & & & & 47 & 23 & 34 \\
\hline LKA & & & & & & & & & 36 & 29 \\
\hline VNM & & & & & & & & & & 80 \\
\hline
\end{tabular}


Table E. Pair-wise Spearman Correlations of Skill Intensity Indexes at the 3-Digit level, by Skill Dimension. Countries are sorted by income groups. Minimum number of observations per occupation=5.

\begin{tabular}{|c|c|c|c|c|c|c|c|c|c|c|}
\hline & GHA & KEN & LAO & VNM & $\begin{array}{r}\text { BOL } \\
\text { An }\end{array}$ & $\begin{array}{l}\text { LKA } \\
\text { ical }\end{array}$ & GEO & COL & ARM & MKD \\
\hline GHA & 1.00 & 0.93 & 0.80 & 0.90 & 0.85 & 0.69 & 0.72 & 0.87 & 0.76 & 0.87 \\
\hline KEN & & 1.00 & 0.89 & 0.85 & 0.82 & 0.77 & 0.77 & 0.82 & 0.83 & 0.88 \\
\hline LAO & & & 1.00 & 0.86 & 0.86 & 0.72 & 0.81 & 0.79 & 0.72 & 0.78 \\
\hline VNM & & & & 1.00 & 0.82 & 0.78 & 0.83 & 0.80 & 0.82 & 0.84 \\
\hline BOL & & & & & 1.00 & 0.74 & 0.78 & 0.80 & 0.81 & 0.86 \\
\hline LKA & & & & & & 1.00 & 0.67 & 0.74 & 0.75 & 0.70 \\
\hline GEO & & & & & & & 1.00 & 0.77 & 0.69 & 0.75 \\
\hline COL & & & & & & & & 1.00 & 0.79 & 0.86 \\
\hline ARM & & & & & & & & & 1.00 & 0.82 \\
\hline MKD & & & & & & & & & & 1.00 \\
\hline & \multicolumn{10}{|c|}{ Interpersonal } \\
\hline GHA & 1.00 & 0.62 & 0.76 & 0.74 & 0.62 & 0.76 & 0.66 & 0.65 & 0.45 & 0.62 \\
\hline KEN & & 1.00 & 0.82 & 0.79 & 0.77 & 0.67 & 0.65 & 0.69 & 0.60 & 0.79 \\
\hline LAO & & & 1.00 & 0.83 & 0.83 & 0.76 & 0.68 & 0.81 & 0.74 & 0.77 \\
\hline VNM & & & & 1.00 & 0.77 & 0.83 & 0.77 & 0.79 & 0.66 & 0.76 \\
\hline BOL & & & & & 1.00 & 0.76 & 0.64 & 0.79 & 0.66 & 0.73 \\
\hline LKA & & & & & & 1.00 & 0.78 & 0.80 & 0.59 & 0.76 \\
\hline GEO & & & & & & & 1.00 & 0.61 & 0.49 & 0.57 \\
\hline COL & & & & & & & & 1.00 & 0.71 & 0.79 \\
\hline ARM & & & & & & & & & 1.00 & 0.71 \\
\hline MKD & & & & & & & & & & 1.00 \\
\hline & \multicolumn{10}{|c|}{ Routine } \\
\hline GHA & 1.00 & 0.58 & 0.38 & 0.61 & 0.66 & 0.18 & 0.56 & 0.64 & 0.57 & 0.46 \\
\hline KEN & & 1.00 & 0.35 & 0.54 & 0.57 & 0.25 & 0.41 & 0.58 & 0.44 & 0.59 \\
\hline LAO & & & 1.00 & 0.40 & 0.63 & 0.58 & 0.36 & 0.53 & 0.27 & 0.42 \\
\hline VNM & & & & 1.00 & 0.51 & 0.40 & 0.52 & 0.65 & 0.45 & 0.49 \\
\hline BOL & & & & & 1.00 & 0.70 & 0.41 & 0.59 & 0.59 & 0.57 \\
\hline LKA & & & & & & 1.00 & 0.26 & 0.37 & 0.20 & 0.54 \\
\hline GEO & & & & & & & 1.00 & 0.38 & 0.46 & 0.53 \\
\hline COL & & & & & & & & 1.00 & 0.41 & 0.54 \\
\hline ARM & & & & & & & & & 1.00 & 0.43 \\
\hline \multirow[t]{2}{*}{ MKD } & & & & & & & & & & 1.00 \\
\hline & \multicolumn{10}{|c|}{ Observations } \\
\hline GHA & 60 & 43 & 32 & 50 & 47 & 30 & 39 & 48 & 40 & 52 \\
\hline KEN & & 67 & 32 & 56 & 53 & 24 & 44 & 47 & 45 & 56 \\
\hline LAO & & & 47 & 34 & 37 & 23 & 28 & 30 & 27 & 40 \\
\hline VNM & & & & 80 & 64 & 29 & 48 & 55 & 49 & 65 \\
\hline BOL & & & & & 75 & 28 & 47 & 55 & 46 & 63 \\
\hline LKA & & & & & & 36 & 22 & 26 & 26 & 30 \\
\hline GEO & & & & & & & 57 & 44 & 45 & 53 \\
\hline COL & & & & & & & & 67 & 46 & 58 \\
\hline ARM & & & & & & & & & 62 & 55 \\
\hline MKD & & & & & & & & & & 82 \\
\hline
\end{tabular}


Figure C. Plot of standard deviation of individual skill scores, for a given occupation, vs. log GDP per capita.
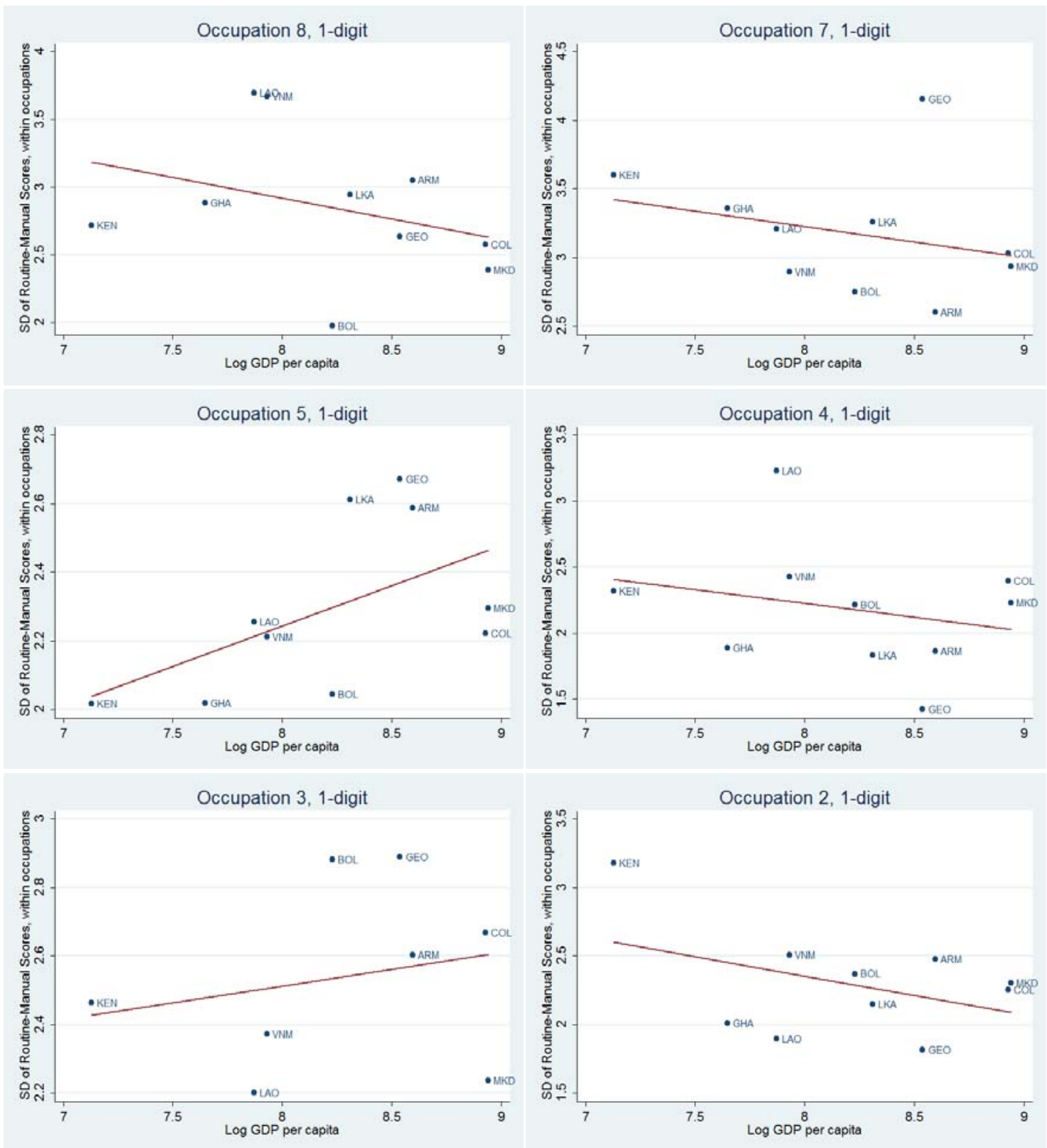

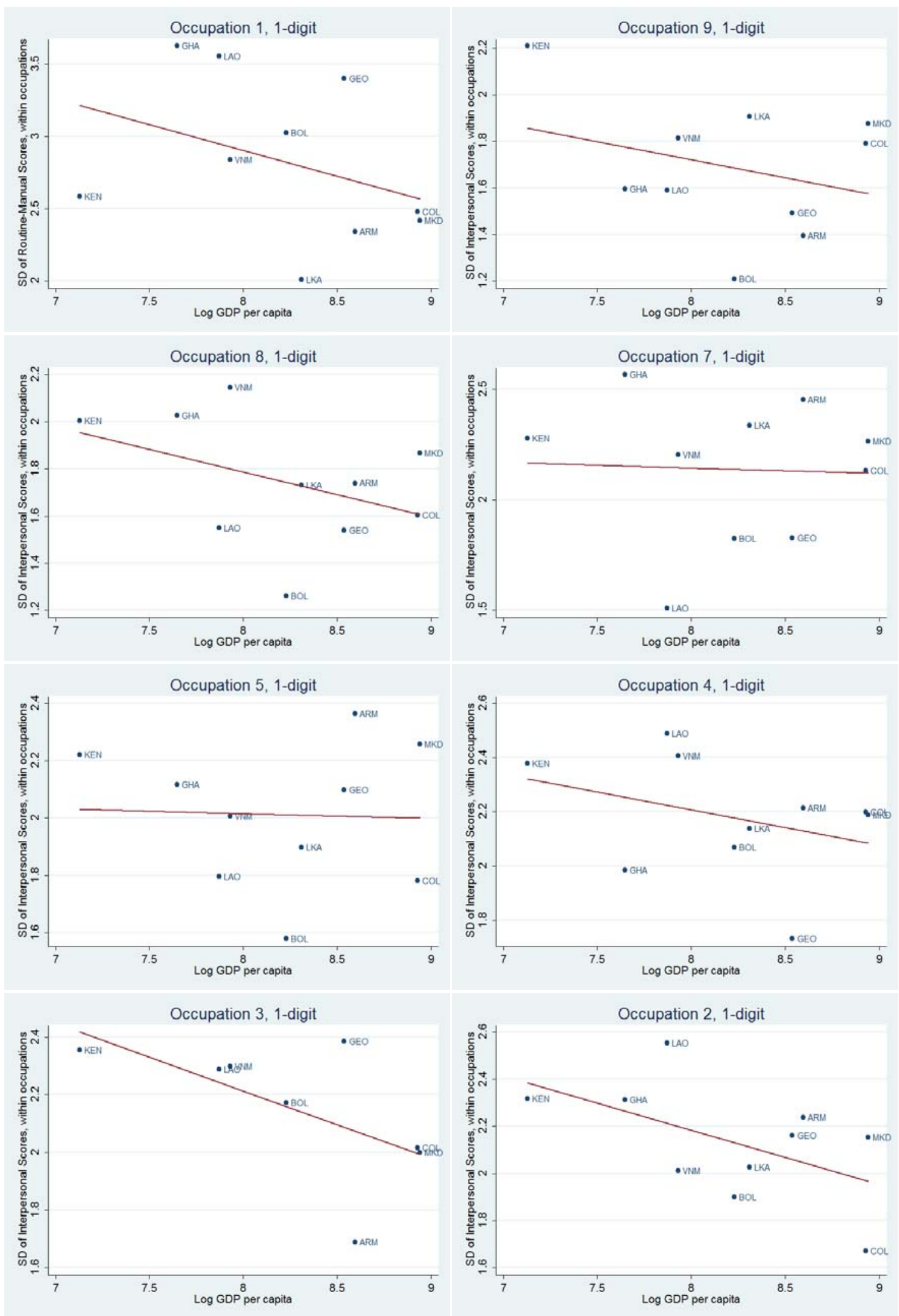

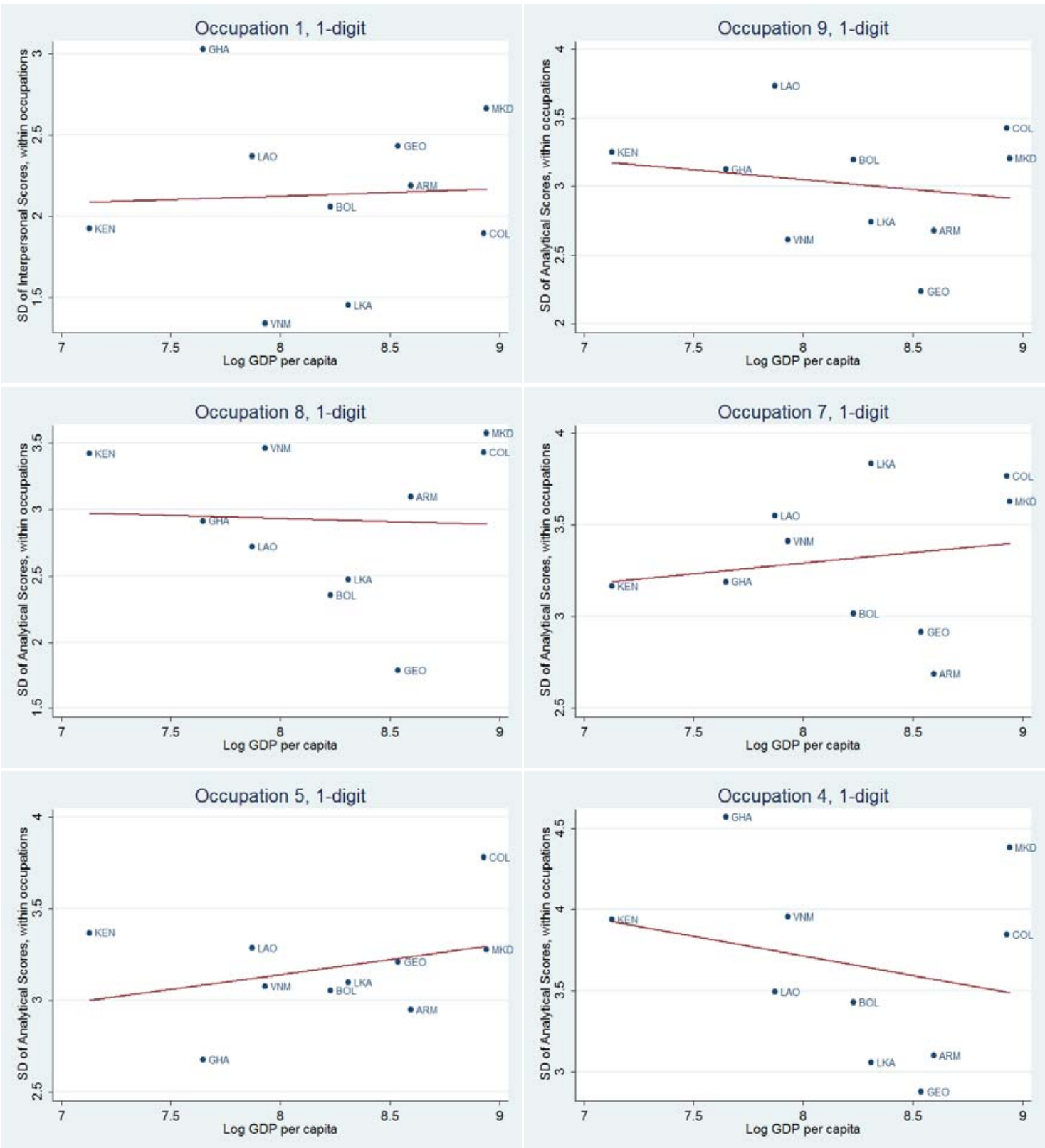

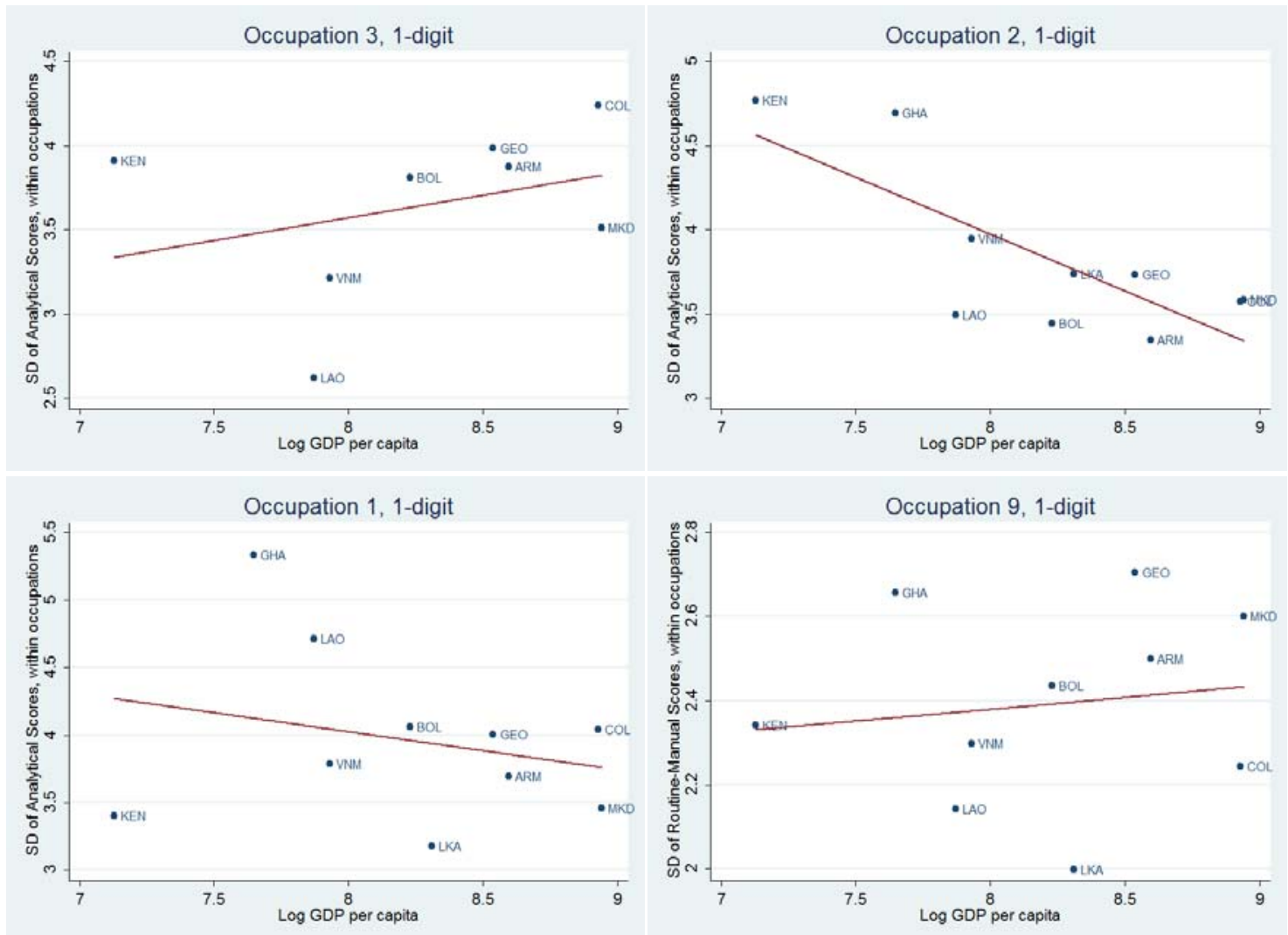


\section{References}

Acemoglu Daron. 2002. “Technical Change, Inequality, and the Labor Market.” Journal of Economic Literature 40: 7-72.

Acemoglu, Daron, and David Autor. 2011. "Skills, Tasks and Technologies: Implications for Employment and Earnings.” Handbook of Labor Economics, vol. 4, chapter 12. Elsevier, 1043-1171.

Acemoglu, Daron, and Fabrizio Zilibotti. 2001. "Productivity Differences.” The Quarterly Journal of Economics, Oxford Universit Press, 116 (2): 563-606.

Aedo, Cristian, Jesko Hentschel, Javier Luque, and Martin Moreno. 2013. "From Occupations to Embedded Skills: A Cross-Country Comparison.” Background Paper for the World Development Report 2013 Jobs, World Bank, Washington, DC.

Arias, O., C. Sanchez-Paramo, M. Davalos, I. Santos, E. Tiongson, C. Gruen, N. de Andrade, G. Saiovici, and C. Cancho. 2014. Back to Work: Growing with Jobs in Europe and Central Asia. World Bank, Washington, DC.

Autor and Handel.2013. "Putting Tasks to the Test: Human Capital, Job Tasks, and Wages." Journal of Labor Economics 31 (2): S59-S96.

Autor, David, David Dorn and Gordon Hanson. 2013a. "The Geography of Trade and Technology Shocks in the United States.” American Economic Review 103: 220-25.

Autor, David, David Dorn and Gordon Hanson. 2015. "Untangling Trade and Technology: Evidence from Local Labour Markets,” The Economic Journal, 125: 621-646.

Autor, David, Frank Levy, and Richard Murnane. 2003. "The Skill Content of Recent Technological Change: An Empirical Exploration." The Quarterly Journal of Economics 118.4, 1279-1333.

Basu, Susanto \& David N. Weil, 1998. "Appropriate Technology and Growth," The Quarterly Journal of Economics, Oxford University Press, 113(4): 1025-1054.

Eli Berman \& John Bound \& Stephen Machin, 1998. "Implications Of Skill-Biased Technological Change: International Evidence," The Quarterly Journal of Economics, MIT Press, vol. 113(4), pages 1245-1279, November.

Gelman, Andrew, and Iain Pardoe, 2007. "Average predictive comparisons for models with nonlinearity, interactions, and variance components." Sociological Methodology, 37(1): 23-51.

Goos, Maarten, Alan Manning, and Anna Salomons. 2014. "Explaining Job Polarization: Routine-Biased Technological Change and Offshoring.” American Economic Review, 104(8): 2509-26.

Handel, Michael, 2008. "What do people do at work: A Profile of US Jobs from the Survey of Workplace Skills, Technology, and Management Practices (STAMP). Mimeo.

Katz, Lawrence F., and Kevin Murphy. 1992. "Changes in Relative Wages, 1963-1987:Supply and Demand Factors,” Quarterly Journal of Economics, 107 (1): 35-78. 
Levy, Frank \& Murnane, Richard J, 1996. "With What Skills Are Computers a Complement?," American Economic Review, American Economic Association, vol. 86(2), pages 258-62, May.

MacCrory, Frank; George Westerman; Alhammadi, Yousef; and Erik Brynjolfsson. 2014. "Racing With and Against the Machine: Changes in Occupational Skill Composition in an Era of Rapid Technological Advance.” Research paper for the Thirty Fifth International Conference on Information Systems, Auckland.

Spitz-Oener, Alexandra, 2006. "Technical change, job tasks, and rising educational demands: looking outside the wage structure." Journal of Labor Economics, 24(2): 235-270.

Tinbergen, Jan. 1974. “Substitution of Graduate by Other Labor,” Kyklos, 27, 217-226. 